Post-metamorphic palaeofluid evolution of the Mecsekalja Zone metamorphic complex

PhD Thesis

\title{
Gergely Dabi
}

Supervisors: Dr. M. Tóth Tivadar, Dr. Schubert Félix

\author{
Doctoral School of Earth Sciences
}

Department of Mineralogy, Geochemistry and Petrology

University of Szeged, Faculty of Science and Informatics

2013

Szeged 


\section{Table of contents}

Introduction

Chapter 1. Carbonate veins of different texture and their role in reconstructing fracture cementation (Ófalu, Goldgrund valley).....

Abstract

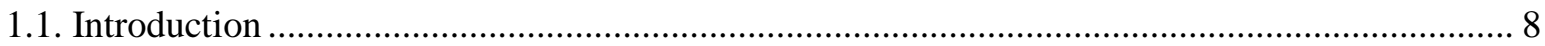

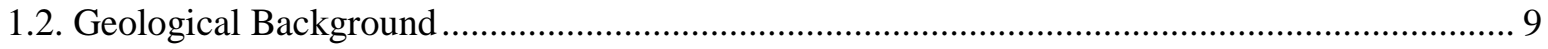

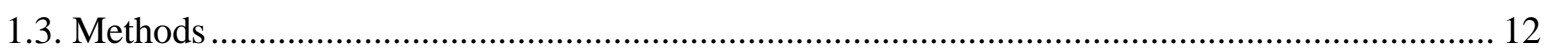

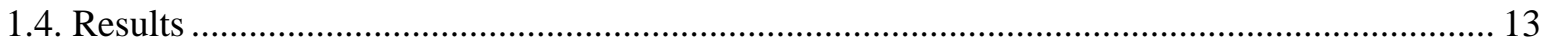

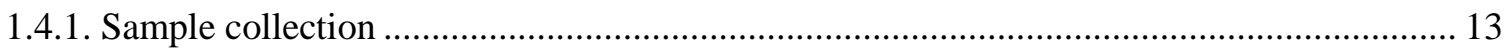

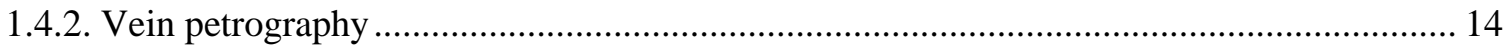

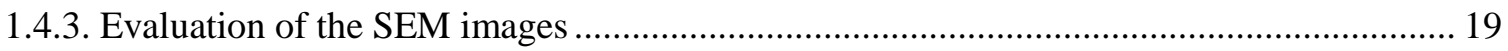

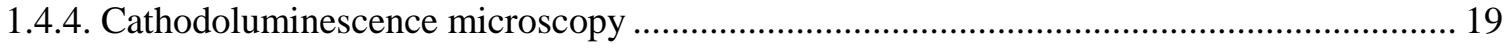

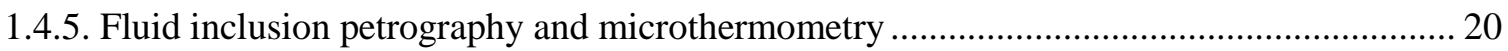

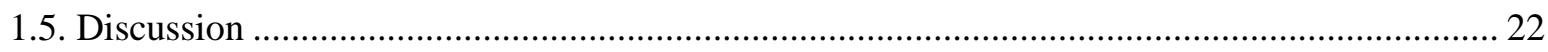

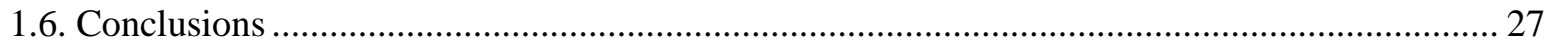

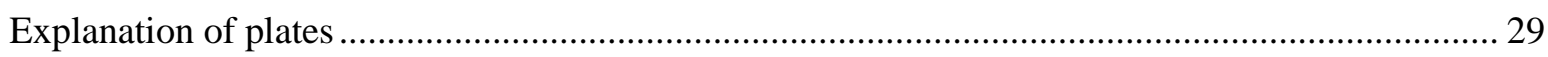

Chapter 2. The relevance of vein texture in understanding the past hydraulic behaviour of a crystalline rock mass: reconstruction of the palaeohydrology of the Mecsekalja Zone, south Hungary ................. 36

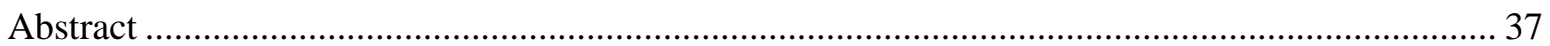

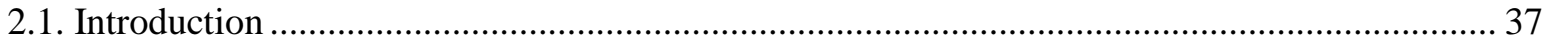

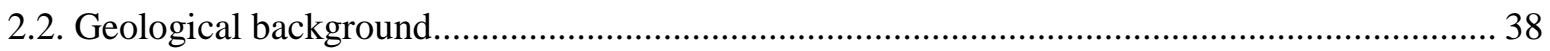

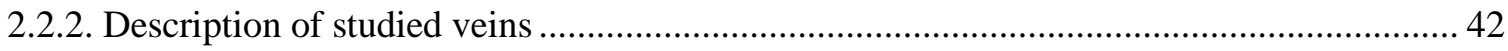

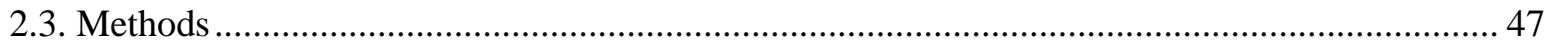

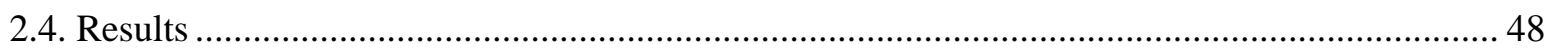

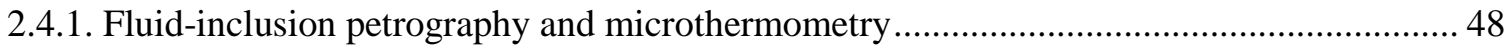

2.4.2. Carbon and oxygen isotope composition of veins .............................................................. 51

Table 2.1. Oxygen and carbon isotope compositions of studied veins ............................................. 53

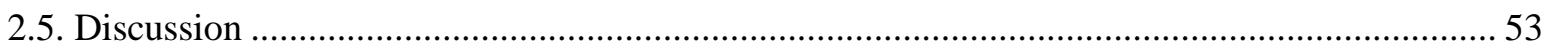

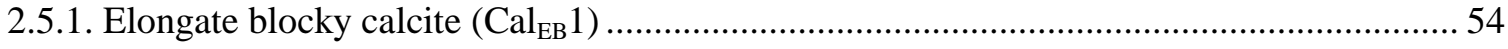




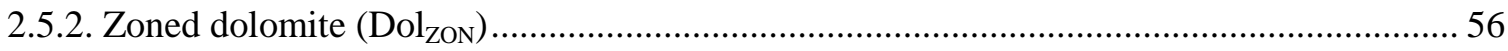

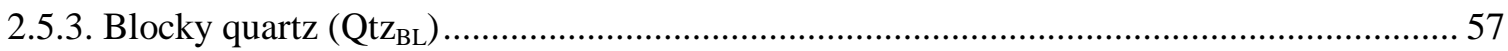

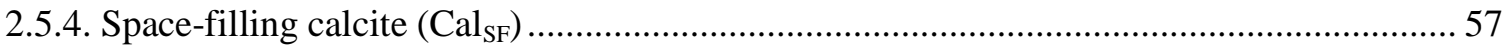

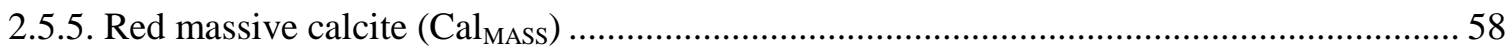

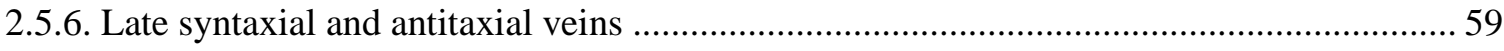

2.5.7. Palaeohydrological evolution and interactions of the Mecsekalja Zone .............................. 60

2.5.8. Implications of vein texture for the hydraulic behaviour of a heterogeneous rock mass .... 63

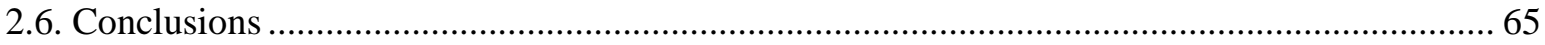

Chapter 3. The hydraulic behavior of a crack-seal vein producing fluid-rock system.......................... 67

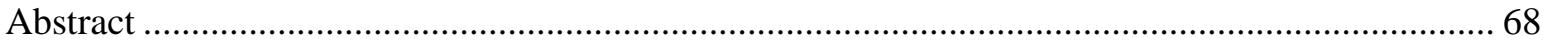

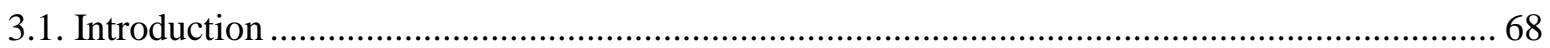

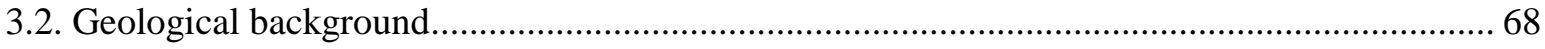

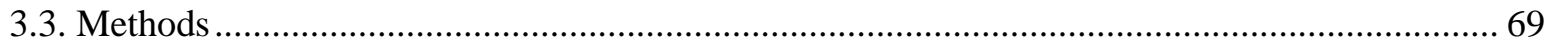

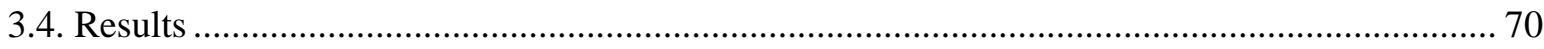

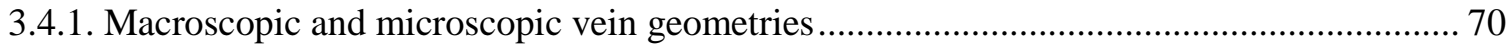

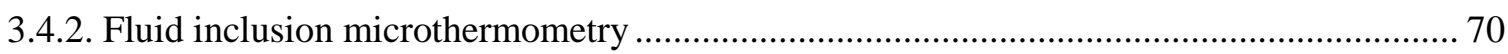

3.4.3. Hydrogen isotope compositions of the studied inclusions ................................................ 70

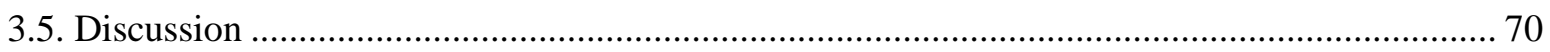

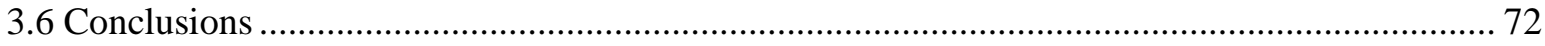

Chapter 4. The origin and role of a calcite-filled microcrack system in a metamorphic crystalline

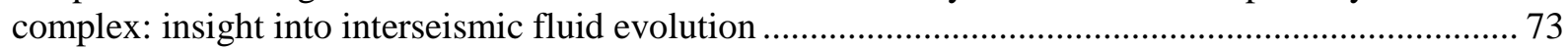

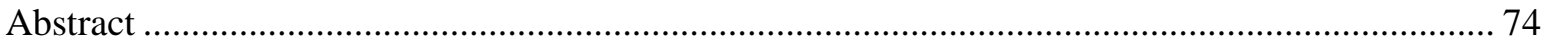

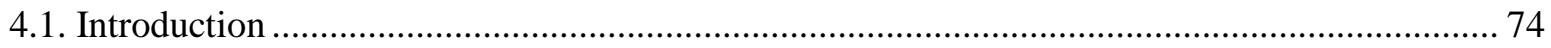

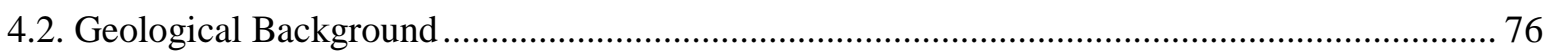

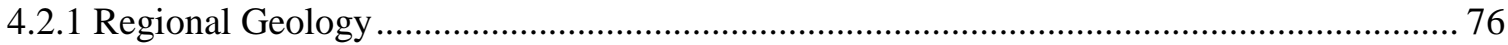

4.2.2 Cretaceous volcanic activity in the Mecsek Mountains and in the Mórágy Granite ............ 76

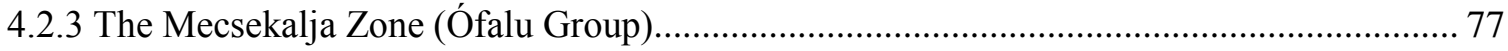

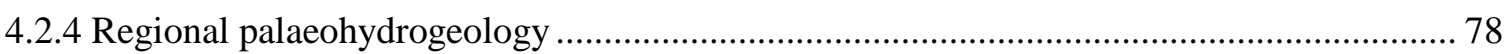

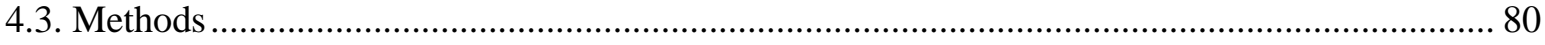

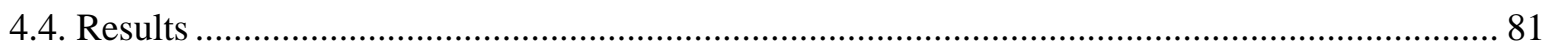

4.4.1. Texture of the studied samples and cathodoluminescent images ........................................ 81 
4.4.2. Fluid inclusion petrography and microthermometry

4.4.3. Stable isotope composition of the microcrack calcite

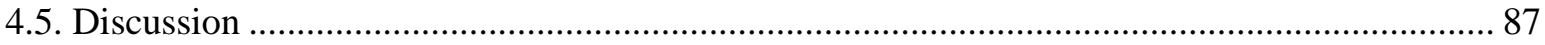

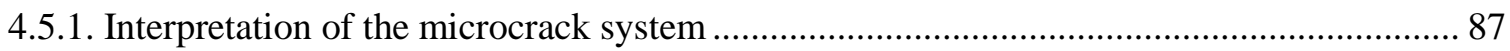

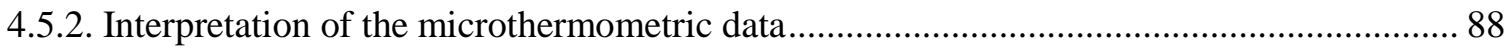

4.5.3. Origin and connections of the microcrack calcite parent fluid........................................... 90

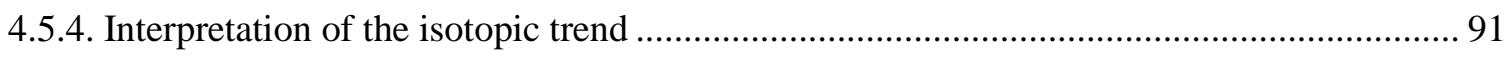

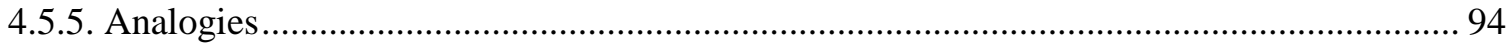

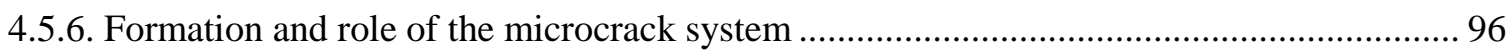

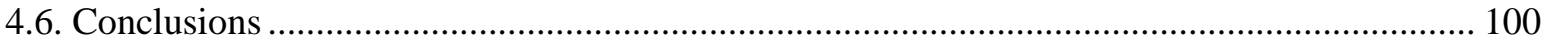

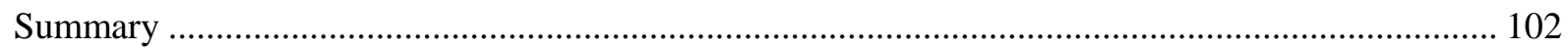

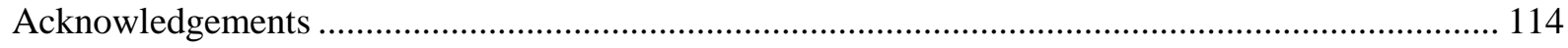

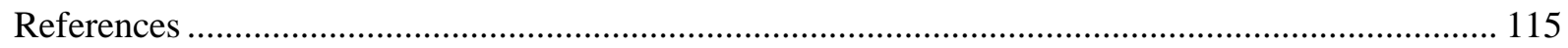




\section{Introduction}

The thesis held in hand discusses the post-metamorphic palaeofluid evolution of the crystalline metamorphic rocks of the Mecsekalja Zone, near Ófalu village, south Hungary. The rocks of the study area now observable at surface outcrops were metamorphosed ca. 300 ma ago (Lelkes-Felvári et al., 2000). During its uplift history a complex stress evolution must have worked upon the rock mass, the most momenta of which can hardly be recognized, and the most phases of which possibly did not leave an inquirable clue. Crystalline rocks can be considered impermeable, and it is the deformation of the rock that enhances the efficiency of fluid flow, both at the micro- and the mesoscale. The stress activated microscale porosity is testified by fluid inclusion planes in granites (Lespinasse, 1999) and also by rock mechanic experiments (e.g. Zoback and Byerlee, 1975a, b; Lajtai, 1998; Gottschalk et al., 1990; Paterson and Wong, 2005). Veins of different configurations are the mesoscale product of deformation and subsequent fluid flow in the newly grown fracture porosity. The above considerations suggest that the uplift history of the Ófalu metamorphic complex is also a complex palaeofluid history, the momenta of which are determined by the obscure stress history of the Mecsekalja Zone. These momenta can be reconstructed by minerals that were precipitated from fluids, i.e. vein minerals or minerals that are obviously not part of the original mineral assemblage and the hydrothermal origin of which can be reasonably assumed, e.g. microcrack calcite in a quartzofeldspathic gneiss.

The present thesis is an attempt to reconstruct the phases of the fluid evolution during the post-metamorphic history of the Mecsekalja Zone metamorphic zone and to extract the nexus of these with the application of the available methods and data, i.e. textural analysis (augmented with cathodoluminescence microscopy), fluid inclusion microthermometry and stable isotope measurements.

The investigation of the palaeofluid evolution of a rock mass has several different purposes. From a practical viewpoint it is the investigation of the physicochemical circumstances or the chemistry of a single fluid flow event, i.e. the investigation of the temperature and pressure and dissolved species. The palaeofluid evolution involves the investigations of subsequent fluid generations at a study area. Data of this kind can help the understanding of the actual status of fluid evolution at a pontential site of petroleum exploitation (e.g. Juhász et al., 2002; Schubert et al., 2007). 
Another important practical application of palaeofluid investigations is when a prognosis is necessary to be given for the future behaviour of a fluid - rock system. This is the case if the investigated rock mass comes into question as a disposal of nuclear waste. Some authors study the variations in the geochemistry of the vein minerals with the aim to examine the possible role recrystallization due to the infiltration of surface waters (Blyth et al., 2000, 2004; Bottomley et al., 1992; Wallin and Peterman, 1999). In this case it is of crucial importance to see what kind of fluid flow events occurred in the geologic past and to understand the geologic nexus of these, i.e. what factors governed the fluid flows and which of these can possibly exist in the hazardous time period. The solution to this latter, i.e. the nexus of the fluid flow events requires a systematic approach and the models developed in the course of the evaluation of the relevant data converge towards a fluid flow model what we call the hydraulic behaviour model of the system. This includes the flow paths activated during the flow events (macroscopic fractures, microfractures or the extant porosity), the operation of the flow path (i.e. continuous or intermittent), the flow type (i.e. advective, fracture channelized or pervasive), the fluids role in the activation of the flow path, the stress field's role in the activation, etc. Some exemplary papers that set a similar target to the above approach are those of Rye and Bradbury (1988), Fisher and Brantley (1992), Hilgers and Sindern (2005), Barker et al., (2006, 2009), Cox (2007).

The above section illustrates the complexity and multitude of information that enables the recognition of a model of this kind, and of course foreshadows the difficulties of gathering the necessary body of information. The forthcoming sections are a compilation of published and submitted papers on the hydrogeologic evolution of the Mecsekalja zone. These papers together serve as a state of the art in the understanding of the palaeohydraulic evolution of a crystalline rock mass and the hydraulic behaviour of the fluid-rock system in cases of certain flow events. The first two of these discuss the sequence of fluid flow events, as can be recognized petrographically, and try to reveal the physicochemical properties of the fluids based on supplementary microthermometric data. Stable isotope data are applied to unravel the source fluid source and the time of distinguished flow events. Superimpositions occur where the interpretation of the newly gathered data required the presentation of those published earlier. The third and the fourth sections concentrate on singular flow events. In these cases the available data made it possible to construct more detailed models of the fluid flow, i.e. these articles should be considered as attempts for the reconstruction of the hydraulic behaviour of individual flow events. 


\section{Chapter 1.}

Carbonate veins of different texture and their role in reconstructing fracture cementation (Ófalu, Goldgrund valley)*

\footnotetext{
* Translated from the original paper, Dabi, G., Schubert, F., M. Tóth, T. Bulletin of the Hungarian Geological
} Society, 2009, 139/1, pp. 3-20. In Hungarian 


\begin{abstract}
The amphibolite member of the Ófalu Formation is exposed by an outcrop in the Goldgrund Valley, near Ófalu (Mecsek Mts., South Hungary) and is cut through by carbonate veins composed of several generations of carbonates and quartz. The main aim of the present study is to confirm the phase-sequence and to reconstruct the precipitation mechanisms of the vein minerals. Optical microscopic observations were carried out alongside cathodoluminescence and scanning electron microscopic studies to enable careful interpretation of internal vein textures. Another goal was to delineate the physico-chemical circumstances of vein material precipitation through fluid inclusion data.

With these it became possible to define six calcite phases, one dolomite phase and one quartz phase from which parent solutions flowed advectively through fracture systems or percolated through former mineral phases of the veins. The investigation also sheds light on the possible role of hydrofracturing at the time of certain fluid flow events. Based on the fluid inclusion studies the parent solutions were low temperature and low salinity fluids.
\end{abstract}

\title{
1.1. Introduction
}

Rocks of the Ófalu Formation are characterized by different degree of metamorphosis and shear and are revealed in greatest detail in the N-S striking Goldgrund valley near Ófalu village (Fig. 1.1). The late brittle deformation of the different rocks of complex metamorphic evolution is shed light on by fractures and fracture systems in the outcrops. These can be open fractures, or can be sealed with multiple generations of mineral precipitates. In the following sections we try to reconstruct the fluid flow events associated with the late brittle phase of the deformational history, based on the textures and chemistry of the mineral precipitates. Our aim is to set forth a precipitation history scheme based on the multiply sealed vein system of the amphibolite body, a typical rock type of the zone, with which the results of similar vein studies of different rock types at the study area can be compared.

A further aim of ours was to apply the viewpoints of the international literature that deals with the interpretation of vein textures, and aid these with different auxiliary methods, to lay down a possible general methodology of the investigation of vein precipitates.

The present paper is also an attempt to discuss the relevance of papers, including cementation experiments, published earlier on the formation of syntectonic textures and minerals precipitated from fluids flow along fractures. Bons (2000) give the following 
definition for veins: "distinct polycrystalline mineral volumes that formed within a rock and that are filled with one or more minerals that precipitated from an aqueous fluid". The textures that characterize syntectonic mineral aggregates in veins can be derived from growth competition and growth anisotropy (Bons, 2000, 2001). According to the above, of the mineral grains that precipitates from an advectively flowing fluid those grow out the others, the growth velocity of which is faster (winner grains), while the slower growing grains cease to grow (looser grains), a process determined by the crystallographic orientation of the nuclei precipitated on the vein wall. The textures of the vein-filling minerals can also be determined by the crack-seal process (Bons, 2000, 2001; Hilgers et al., 2001; Hilgers and Urai, 2005), incase of which the veins form as a result of subsequent opening increments and precipitation. The grains of vein minerals precipitate from the fluids flowed into the newly grown vein volume. This process can result textures of fibrous, elongate blocky or blocky grain morphologies. The opening increment generally can be identified by bands or trails of fluid and solid inclusion, where the inclusion bands define a former plane of vein opening. Besides the morphology of the vein filling mineral grains Bons (2000) also introduce the category of growth morphology, what is defined by the site of mineral growth within the vein. In case of syntaxial growth, precipitation occurs in the veins middle line, from and advectively flowing fluid (Bons 2000). In case of antitaxial growth precipitation occurs between the vein and the host rock, generally on both sides of the vein (Bons, 2000; Hilgers and Urai, 2002a). The resulting texture is generally fibrous and indicates the percolation of the parent fluid through the host rock (Hilgers and Urai, 2002a; Hilgers and Sindern, 2005; Bons and Montenari, 2005). In case of ataxial growth, the site of precipitation varies with every opening increment inside the vein (Bons, 2000; Hilgers and Urai, 2002a). Careful inspection of the vein textures is necessary for the interpretation of the order and mechanisms of growth during vein evolution, and to evaluate the extent of fluid - rock interaction (Oliver and Bons, 2001).

\subsection{Geological Background}

The early mapping studies have called the attention on the existence of the narrow metamorphic belt to the north of the Mórágy Granitoid Complex (Fig.1.1). It is mainly built up of different types of metamorphic rocks of low degree metamorphosis. The high degree of deformation has altered the original textural features what encumber the recognition of the protolith. Early studies interpreted rocks of the zone in conjunction with the granite to the 


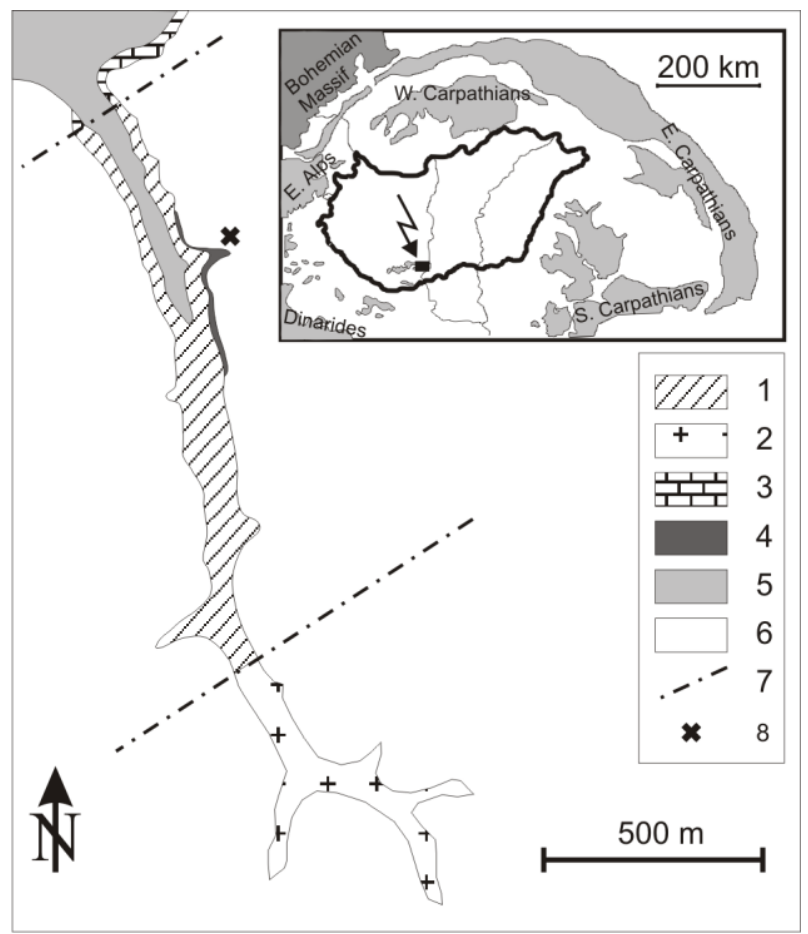

Figure 1.1. Geologic sketch map of the Ófalu Zone in the Goldgrund valley (after Balla, 2003). 1 Ófalu Formation, 2 - Mórágy Granite Formation, 3 - Vasas Marl Formation, 4 - Pannonian sediments, 5 - alluvial deposits, 6 - loess, 7 - borders of the Mecsekalja Shear Zone. Inset: locality of the study area in the Pannonian Basin.

south. The highly sheared main rock type of the zone was defined as „ligamentous” migmatite by Szádeczky-Kardos (1959) and by Jantsky (1979). Szederkényi (1977) recognized the lowmetamorphic character of the zone and argued the role of regional ultrametamorphosis in its formation, while called the attention on features of shear deformation. The rocks resemblance to the ,ligamentous" migmatite he explained with shearing and synchronous K-metasomatism of a metagrauwacke protolith. Ghoneim and Szederkényi (1977) and Szederkényi (1983) studied the the petrological and the geochemical character of the metabasic rocks of the Ófalu Formation, and attempted to settle their palaeotectonic interpretation. The rocks' protolith they defined as a product of oceanic volcanism with tholeitic character.

The recent studies have discussed the formation of the „Ófalu migmatite” in conjunction with mylonitisation. Árkai and Nagy (1994) studied the strongly sheared amphibolites at the tectonic contact of the granite and the mylonite. Based on the zonation in the studied amphiboles and the mineral paragenesis, the temperature and pressure of the mylonitisation they determined to be $580{ }^{\circ} \mathrm{C}$ and $4 \mathrm{kbar}$, respectively, at the more intensively sheared site further from the contact, while $2 \mathrm{kbar}$ and similar temperature at the granite-mylonite boundary. They also mentioned the absence of textural features relevant to partial melting. 
Lelkes-Felvári et al. (2000) studied the ultramylonite from the Mőcsény-1 drillcore. Based on the chemical zonation of the garnets and on the mineral paragenesis, the temperature of the mylonitisation they determined to be around $445{ }^{\circ} \mathrm{C}$, while its pressure was given to be between 5.7 and $6.3 \mathrm{kbar}$. The precursory rock they defined as garnet containing amphibolite facies orthogneiss. The difference in the conditions of the mylonitisation from those determined by Árkai and Nagy (1994) they explained with different intensity of shearing inside the zone. The age of the mylonitic shearing was given to be between 303 and $270 \mathrm{Ma}$, based on ${ }^{40} \mathrm{Ar}-{ }^{39} \mathrm{Ar}$ ages of whole rock and separated biotite samples. Király and Török (2003) have studied the circumstances of the mylonitic shearing based on the chemical analysis of the garnets of the pegmatite dykes crosscutting the granite body. The Ca-rich outer zones of the garnets they found to be contemporaneous with the ductile deformation features of the feldspars and accordingly they assume the flow of a high $\mathrm{Ca}$ content fluid during the mylonitisation. The studies of M. Tóth et al. (2005) on the „migmatite” rocks have revealed that the protolith of the rock was an S-type granitoid gneiss of peraluminous character, or its coarse grain debris. Based on monomineralic quartz grain boundaries they showed, that the crystallization of the protolith occurred at temperatures around $710{ }^{\circ} \mathrm{C}$, what was followed by deformation phases at around 550 and $350{ }^{\circ} \mathrm{C}$, the latter of which is the temperature of the mylonitisation. From here on the rock will be referred to as gneiss mylonite, according to $\mathrm{M}$. Tóth et al. (2005).

The palaeohydraulic evolution of the Ófalu Formation was possibly related to that of the surrounding region, particularly to the Mórágy Granite. Szabó et al. (2003) distinguished four types of hydrothermal phenomenon in the Mórágy Granite, based on the composition of vein minerals, i.e. 1) quartz-calcite; 2) dolomite-calcite; 3) dolomite; and 4) calcite. The formation of the quartz infill they derived from a high temperature, $\sim 250-300{ }^{\circ} \mathrm{C}$ fluid; the dolomite infill from a high temperature, multiply evaporated fluid. The older generation of calcite they interpreted to be precipitated in a reductive, while the younger generation in an oxidative environment, based on dying. The monomineralic calcite infill they considered to be partly the product of a low temperature fluid system (between 100 and $150{ }^{\circ} \mathrm{C}$ ) with salinities varying from sample to sample, between 0.35 and $23.1 \% \mathrm{w} \mathrm{NaCl}$ equiv, and partly from a fluid of high homogenisation temperature (between 108 and $280{ }^{\circ} \mathrm{C}$ ) and of low to medium average salinities. They mention that the data are solely derived from the pink dyed calcite indicating reductive environment. Kovács-Pálffy et al. (2003) discuss the formation of the carbonate vein material with the use of the data of Szabó et al. (2003), discussed above and published 
earlier by the same authors. Furthermore Kovács-Pálffy et al. (2003) discuss that that the main formation period of the carbonate veins is the Mesozoic, based on hydrothermal illite ages of the veins. Gatter and Török (2004) measured homogenisation and final melting temperatures in secondary and pseudosecondary fluid inclusions of pegmatitic quartz grains in the granite and quartz and calcite veins. Based on their measurements, the Th values can be characterized by frequency maxima of between 140 and 150, 200 and 210 and 260 and $270{ }^{\circ} \mathrm{C}$. The composition of the fluid turned out to be of $\mathrm{NaCl}-\mathrm{CaCl} 2$ composition with salinities between 0 and $20 \% w \mathrm{NaCl}$ equiv. They emphasize the importance of brines with high calcium content in the region. Poros (2007) has studied the fluid flow events of the Mórágy Granite based on the investigation of fluid inclusion planes of the rock forming quartz grains of the granite and of primary and secondary fluid inclusions of vein quartz and calcite. She defined six fluid flow events, the third of which produced the vein quartz, and the fourth of which produced vein calcite. The former she derived from fluids with salinities around $7.6 \% \mathrm{wNaCl}$ equiv. ( $T_{\mathrm{m}}\left(\right.$ Ice) between -5 and $-4.8^{\circ} \mathrm{C}$ ), the homogenization temperature of which is between 90 and $200{ }^{\circ} \mathrm{C}$. The latter she derived from fluids with salinities between 4.2 and $0.17 \% \mathrm{wNaCl}$ equiv. ( $T_{\mathrm{m}}$ (Ice) between -2.4 and $-0.2{ }^{\circ} \mathrm{C}$ ), the homogenization temperature of which is between 100 and $290{ }^{\circ} \mathrm{C}$. In both cases she assumed magmatic upheating (related to the late Cretaceous volcanism) and propose their magmatic origin.

\subsection{Methods}

Carbonate veins that cut through the amhibolite body in sharped-face contact with the gneiss mylonite (Fig. 1.2) at the Goldgrund valley near Ófalu were studied. After the field measurements, investigation of the collected thirteen samples started with macroscopic and polarization microscopic description and these were later augmented with cathodoluminescence and scanning electron microscopy. The cathodoluminescence (CL) microphotographs were taken at the Institute for Geochemical Research, Hungarian Academy of Sciences, on a Reliotron type (cold-cathode) cathodoluminescent apparatus that was operated at 7-8 keV current, mounted on a Nikon Eclipse E600 microscope, with a Nikon Coolpix digital camera, in automatic mode. The backscattered electron (BSE) and the scanning electron microscope (SEM) images were made with a Hitachi S-4700 Type II high resolution cold cathode field emission microscope at the University of Szeged. The microthermometric measurements were carried out at the Department of Mineralogy, 
Geochemistry and Petrology, University of Szeged, with a Linkam THMSG 600 heatingfreezing stage, mounted on an Olympus BX41 microscope. Calibration of the heating-freezing stage was carried out using synthetic inclusions entrapped in quartz at $-56.6,0$ and $374{ }^{\circ} \mathrm{C}$. In the course of the measurements first the homogenisation temperatures of the inclusions were

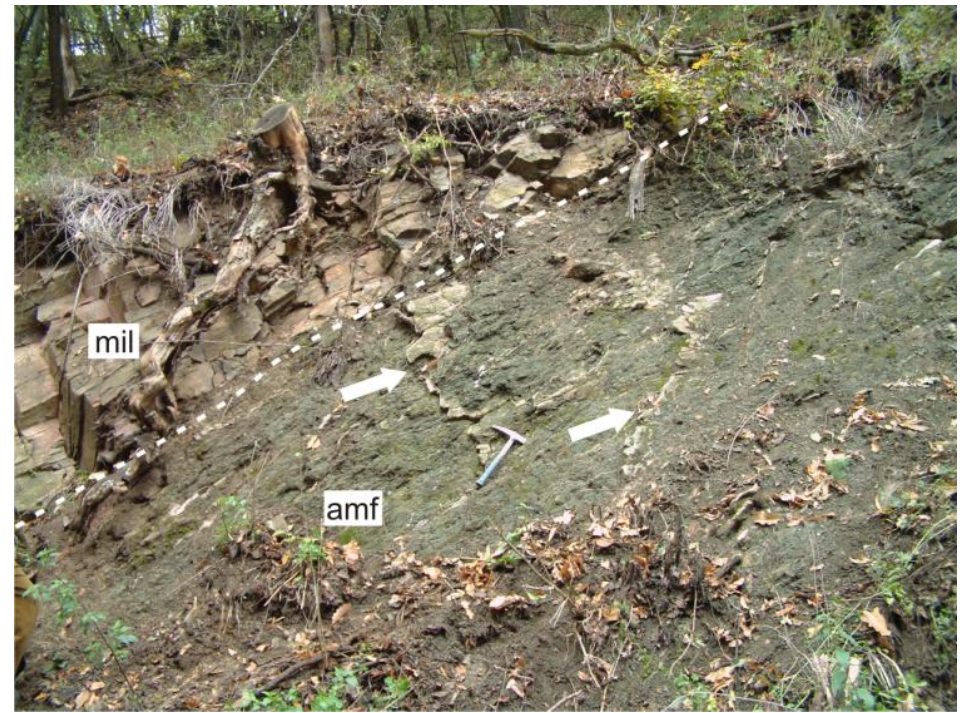

Figure 1.2. The studied amphibolite outcrop and the contact of the amphibolite body and the gneiss mylonite (marked with dashed line). Sampled veins are marked with arrows.

studied to avoid density drop due to stretching of the inclusions during freezing (Goldstein and Reynolds, 1994). The measured final melting temperatures were calculated to values of $\mathrm{NaCl}$ equivalent according to Bodnar (1992). For the description of the microthermometric results the terminology suggested by Schubert et al. (2007) is applied here.

\subsection{Results}

\subsubsection{Sample collection}

The carbonate veins discussed in this study cut through the amphibolite body revealed by the Goldgrund valley near Ófalu village (Fig. 1.1). The amhibolite body in the revealed section is about two meters high, 10 meters long, and has sharp-faced contact with the gneiss mylonite towards the west (Fig. 1.2). Towards east it is buried under weathered debris. About 20 meters towards east the nearest outcrop reveals gneiss mylonite again. The amphibolite is schistose and disintegrated by weathering on the surface. The carbonate veins are steeply dipping, their azimuth varies S-SSE, their surface section are straight (Plate 1.1,A). Vein 
thickness varies between 0.5 and $5 \mathrm{~cm}$. It is not possible to draw conclusions on the relative time of vein formation or on the type of opening in the field, due to the parallel trend and dip of the veins and the outcrop surface and due to the host rock being strongly weathered.

\subsubsection{Vein petrography}

In the following section the texture of the veins and their constituent carbonate minerals are discussed from the vein - host rock interface (vein wall) towards the veins middle line. The discussed veins are symmetrical, thus the so described order is identical from the opposite vein wall towards the middle line (Fig. 1.3,C; Plate 1.2,A). For the description of the vein minerals the terminology put forth in the international literature on the syntectonic veins is applied here (Fig. 1.4). In the following, the physically distinct textural types are discussed as separate phases. The mineral phases discriminated during the microscopic observations are denoted with the abbreviation of the mineral phase, what is supplemented with the capitalized abbreviation of the characteristic texture in subscript, e.g. Dol zon (zoned dolomite).

The host amphibolite is built up of amphibole and plagioclase, with maximum grain size between 500-700 $\mu \mathrm{m}$ (Plate 1.1,G). Biotite is frequent inside and between amphibole grains. Garnet occurs in the amphibole grains. The texture is built up of microlithons (Passchier and Trouw, 2005) with the mineralogy described above, and a net of chlorite that give the foliation of the rock (Plate 1.1,G). The chlorite net between the microlithons is built up of a darker and a lighter coloured chlorite type.

Among the minerals that build up the studied veins, the white calcite is present in the highest quantity and is built up of elongated calcite crystals aligned perpendicular to the vein wall (Plate 1.2,A). At the vein wall a zone built up of small calcite grains, with maximum grain size up to around $500 \mu \mathrm{m}$ can be observed (loser grains, Bons, 2000; Hilgers et al, 2001) (Plate 1.2,A). This is followed by the zone of the most prevalent elongate blocky calcite (winner grains, Plate 1.2,A). The elongate blocky crystals widen from the vein-wall towards the veins middle line (Plate 1.2,A) and are intensely twinned. Where the darker coloured subsequent precipitates occur, the crystals elongated from the vein wall towards the middle line display scalenohedral facets (Plate 1.2,A).

At some places the elongate blocky calcite comprises a complex vein system within a single vein. In this case the elongate blocky crystals are cut through by a thinner vein filled with smaller calcite grains at the outer sides and elongated blocky calcite grains towards the 
middle line (Fig. 1.3,B; Plate 1.2,B). The thin veins cut through the wider veins at low angle, or run parallel with them along short sections. On the macroscopic scale this texture appear as braid-like vein system (Plate 1.1,C). In the following sections the white elongate blocky calcite will be abbreviated as $\mathrm{Cal}_{\mathrm{EB}} 1^{*}$.

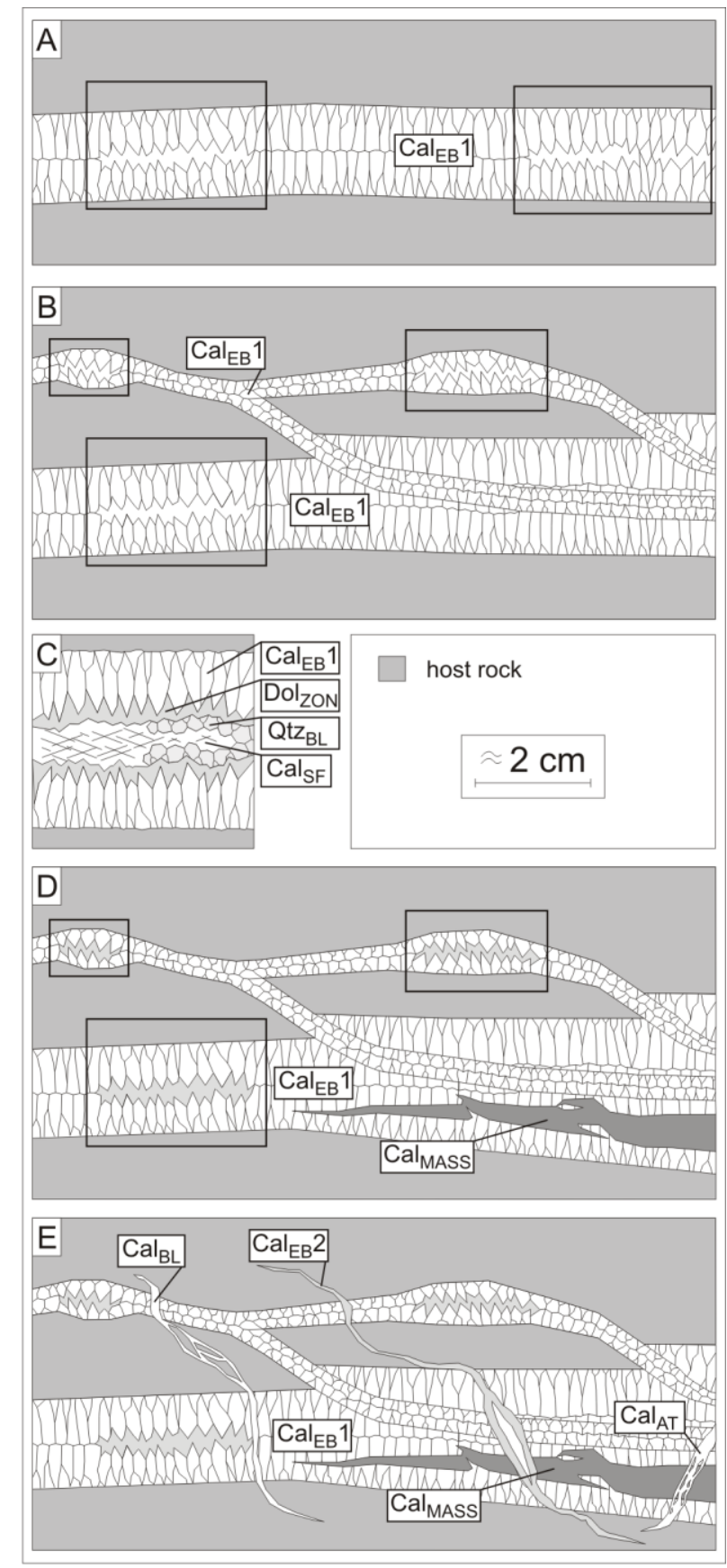

Figure 1.3. (A) Opening of the vein followed by precipitation of the elongate blocky calcite $\left(\mathrm{Cal}_{\mathrm{EB}} 1\right)$. After sealing of the vein, open voids still exist (marked with quadrangles). (B) The chemistry of the solution and that of the calcite precipitated is still the same after the next fracture formation phase, the orientation of the new fractures differs from that of the preexisting veins and the braidy vein system evolves. There are still open voids exist (marked with quadrangles). (C) The Dol ZON , the $\mathrm{Qtz}_{\mathrm{BL}}$ and the $\mathrm{Cal}_{\mathrm{SF}}$ phases deposited in the remnant voids (insets marked with quadrangles in Fig A,B,D. (D) Reopening of existing veins, depositoin of $\mathrm{Cal}_{\text {MASS. }}$ (E) Opening and precipitation of late veins $\left(\mathrm{Cal}_{\mathrm{BL}}, \mathrm{Cal}_{\mathrm{AT}}\right.$ and $\mathrm{Cal}_{\mathrm{EB}} 2$ ).

At some places in the veins filled with $\mathrm{Cal}_{\mathrm{EB}} 1$ a ca. $1 \mathrm{~mm}$ thin stripe of small grains cut

\footnotetext{
${ }^{*}$ In the original paper the calcite phases were denoted with $\mathrm{Cc}\left(\mathrm{e} . \mathrm{g} . \mathrm{Cc}_{\mathrm{EB}} 1\right)$
} 
through the elongated blocky grains asymmetrically, i.e. on one side of the vein (Plate 1.2,C). In transmitted light these small grains are partly reddish and partly transparent carbonates. This small grained stripe contains small quartz grains with radial extinction (Plate 1.2,C).

Towards the vein middle line the $\mathrm{Cal}_{\mathrm{EB}} 1$ elongate blocky grains are in direct contact with zoned greyish-brown rhombohedral dolomite - Dolzon, Fig. 1.4. This mineral phase always occur in the remnant-voids of the veins, in the middle lines of the white carbonate veins, in the continuation of the scalenohedral crystal faces of the $\mathrm{Cal}_{\mathrm{EB}} 1$ grains (Plate 1.2,A).

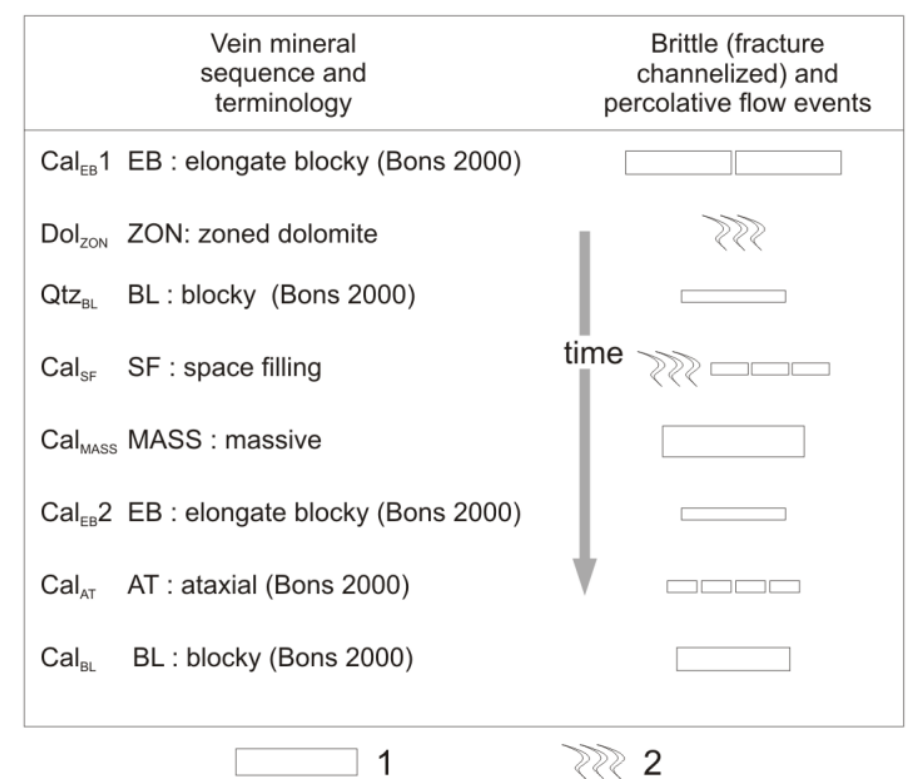

Figure 1.4. Terminology of the vein filling mineral phases with corresponding brittle/percolation events. 1 - brittle event (size and number of quadrangles is proportional to the magnitude and number of brittle vein producing events), 2 - percolating fluid.

The structure of the zoned dolomite is generally complex (Plate 1.2,D, E; Plate 1.5,C), the maximum width is $3,5 \mathrm{~mm}$. Three subzones can be distinguished within the grains of the zone (Fig. 1.5), which extinct parallel with each other and with grains of CalEB1 they are in contact with. As the direct continuation of the $\mathrm{Cal}_{\mathrm{EB}} 1$ grains, a brownish grey dolomite zone occurs (Plate 1.5,C). This is followed by a dark grey subzone, the grey colour of which is given by a cloud of small, $<1 \mu \mathrm{m}$ inclusions (Fig. 1.5; Plate 1.5,C). The youngest subzone of the zoned dolomite does not occur everywhere, and sometimes is in direct contact with the first brownish grey subzone, but always as the last subzone of the phase (Plate 1.2,E). This is a clear, transparent dolomite with thin, 7-50 $\mu \mathrm{m}$ thick greyish brown stripes (Fig. 1.5; Plate $1.2, \mathrm{E})$. 
In the next step of the vein cementation quartz precipitated, Qtz $\mathrm{BL}_{\mathrm{BL}}$ phase (Fig. 1.4; Plate 1.2,D, E). This phase display the typical textural features of growth competition, i.e. very small grains in direct contact with the Dol ${ }_{\mathrm{ZON}}$ crystal facets (loser grains), and overgrown quartz grains of much bigger diameter (winner grains) (Plate 1.2,E). The maximum width is around $1 \mathrm{~mm}$, but the phase has developed in very different degrees from vein to vein, at some places it comprises continuous row of crystals, while at some places it is only present as individual grown-up crystals. In the close proximity of the blocky quartz occasionally thin $(\sim 1$ $\mu \mathrm{m})$ quartz filled veins cut through crystals of the zoned dolomite.

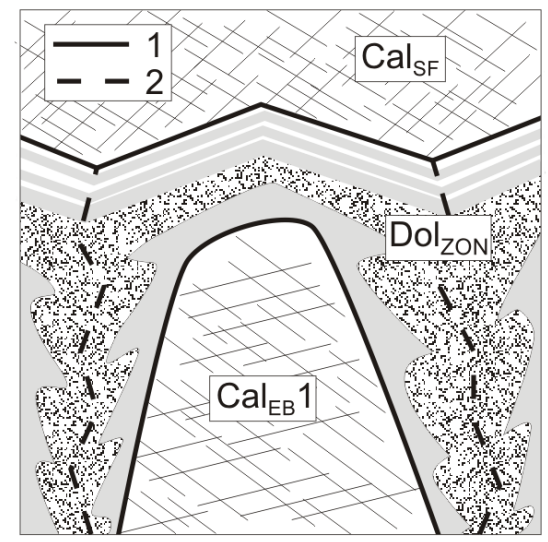

Figure 1.5. Sketch of the three optically distinguishable subzones of $D_{\text {ZON }}$ dolomite, in contact with $\mathrm{Cal}_{\mathrm{EB}} 1$ and $\mathrm{Cal}_{\mathrm{SF}}$. 1 - phase boundaries, 2 - grain boundaries. The second subzone follows grain boundaries.

The youngest phase that fills the remnant voids of the vein system is a massive calcite, surrounded by the earlier precipitated mineral phases $\left(\mathrm{Cal}_{\mathrm{SF}}\right.$, space filling calcite) (Fig. 1.3,C; Plate 1.2,A, D).

At some places the carbonate phases of the veins are partially dissolved and altered, in this case the vein has brownish macroscopic appearance (Plate 1.1,E). However at the microscopic scale both the elongated blocky crystals of the $\mathrm{Cal}_{\mathrm{EB}} 1$ phase and the rhombohedral zones of the Dolzon phase can be recognized (Plate 1.2,G). The brownish pigmentation can also be observed at a thin stripe in the $\mathrm{Cal}_{\mathrm{SF}}$ calcite along the contact with the Dol $\mathrm{ZON}$ facets (Plate $1.2, \mathrm{H})$, i.e. the fluid that caused the pigmentation flowed after the precipitation of the $\mathrm{Cal}_{\mathrm{SF}}$ calcite. In the veins with brown discolouration tabular quartz grains generally occur (Plate $1.2, \mathrm{H})$.

A red massive mineral phase generally occurs in connection to the above described calcite 
veins. The microscopic texture of this phase is sparry, comprised of 60 to $130 \mu \mathrm{m}$ diameter grains (Plate 1.2,F). It is cut through by thin white and orange calcite veins (Plate 1.1,D). The phase is generally in direct contact with grains of the $\mathrm{Cal}_{\mathrm{EB}} 1$ phase and at some places it contains dragged off fragments of the $\mathrm{Cal}_{\mathrm{EB}} 1$ veins (Plate 1.2,F). Hereafter it is referred to as $\mathrm{Cal}_{\text {MASS }}{ }^{*}$ (Fig. 1.4).

The macroscopically distinct white carbonate veins are crosscut by thin, up to $1.5 \mathrm{~mm}$ thick calcite veins. Based on their position inside the white carbonate veins and their crosscutting relation, these thin veins are posterior with respect to the above described veins, and will be referred as late veins.

Amongst the late veins the most conspicuous are the orange-coloured, macroscopically distinguishable $\mathrm{Cal}_{\mathrm{EB}} 2$ phase that is built up of elongate blocky grains, Fig. 1.4. The crystals of the phase are built up of two zones. The one in contact with the vein wall contains orange cloud-like stripes. The subsequent zone of clear calcite (Plate 1.3,A) has not evolved everywhere. Amongst the late veins this is the only type which was found as distinct macroscopic vein (Plate 1.1,F).

Based on its texture, a vein type can be defined and distinguished, which contains solid inclusion bands, the inclusions of which are host rock fragments or fragments of the preexisting calcite vein, that is cross cut by the late vein $\left(\mathrm{Cal}_{\mathrm{AT}}\right)$ (Plate 1.3,E, F). The process that forms solid inclusion bands of solid inclusions dragged off from the vein wall is the multiply repeated opening and sealing of the vein, i.e. the so called crack-seal process (Bons, 2000; Hilgers and Urai, 2005). At the same time the fragments of the host crystals are not unambiguously aligned into vein-parallel bands, based on which the site of the opening changed during the subsequent opening increments, resulting in the so called ataxial growth morphology (Bons, 2000; Hilgers and Urai, 2002a).

White homogeneous calcite veins generally occur amongst the late veins. Their maximum width is $1.5 \mathrm{~mm}$, and they are built up of blocky grains that do not fill completely the vein space $\left(\mathrm{Cal}_{\mathrm{BL}}\right.$ phase) (Fig. 1.4; Plate 1.3,C, D). In the middle line of these veins scalenohedral crystal faces generally surround remnant voids, based on which the growth of the crystals occurred from the vein-wall towards the middle line.

\footnotetext{
${ }^{*}$ In the original paper the phase was named $\mathrm{Cc}_{\mathrm{FG}}$.
} 


\subsubsection{Evaluation of the SEM images}

Backscattered electron images (BSE) and microprobe maps ( $\mathrm{Mg}, \mathrm{Ca}, \mathrm{Fe}, \mathrm{Mn}, \mathrm{Sr}$ ) were made of the minerals at the phase boundaries.

Crystals of the $\mathrm{Cal}_{\mathrm{EB}} 1$ calcite contains only $\mathrm{Ca}$ out of all the studied elements in measurable quantities (Plate 1.4,L,V). Crystals of the Dol distinguished from those of $\mathrm{Cal}_{\mathrm{EB}} 1$ both on the BSE images and based on its $\mathrm{Mg}$ content (Plate 1.4,M,X). Compared to the $\mathrm{Cal}_{\mathrm{EB}} 1$ calcite the Mn content slightly increase (Plate 1.4,N, Y). The second subzone of the zoned dolomite has the appearance of cloudy zones and stripes with indefinite contours (Plate 1.4,K, $\mathrm{U}$, respectively), in which the Ca content increases at the expense of $\mathrm{Mg}$ and $\mathrm{Mn}$ (Plate 1.4,N,Y). In the third subzone of the zoned dolomite the $\mathrm{Mg}$ and $\mathrm{Ca}$ content has homogeneous distribution similar to the first subzone, and the petrographically noticeable striped oscillation cannot be observed on the maps (Plate 1.4,QT). The $\mathrm{Cal}_{\mathrm{SF}}$ calcite is Mn-rich calcite according to the element maps (Plate 1.4,S). There is no noticeable difference in the Fe content of the phases $\mathrm{Cal}_{\mathrm{EB}} 1$, Dol $\mathrm{ZON}$ and $\mathrm{Cal}_{\mathrm{SF}}$ (Plate 1.4,O, $\mathrm{T}, \mathrm{Z})$.

It is not possible to distinguish between $\mathrm{Cal}_{\mathrm{BL}}$ calcite and between the phases in direct contact $\left(\mathrm{Cal}_{\mathrm{EB}} 1\right)$ based on the element maps. The map made of the $\mathrm{Cal}_{\mathrm{AT}}$ phase reveals it in contact with the $\mathrm{Cal}_{\text {MASS }}$ calcite (Plate 1.4,A-E). The images call the attention on the high $\mathrm{Fe}$ content of the $\mathrm{Cal}_{\text {MASS }}$ calcite and on the slightly higher Mn concentration of the $\mathrm{Cal}_{\mathrm{AT}}$ calcite in comparison to that of the $\mathrm{Cal}_{\text {MASS }}$ calcite (Plate 1.4,D). The backscattered electron images made of the $\mathrm{Cal}_{\text {MASS }}$ calcite reveals that its red colour is caused by hematite inclusions (Plate $1.3, \mathrm{G})$ and quartz inclusions are also present. The hematite inclusions are composed of concentric agglomerations of fibrous hematite (Plate 1.3,H).

The BSE images and element maps made of the decomposed elongate blocky crystals with brownish discolouration (Plate 1.4,F-J) indicates that the main constituent of the phase is calcite, and $\mathrm{Fe}$ and $\mathrm{Mn}$ accumulates in disseminated patches. On the BSE image (Plate 1.3,F) a quartz grain and sporadic hematite grains can be observed (Plate 1.4,J).

\subsubsection{Cathodoluminescence microscopy}

The microscopically distinguishable phases can also be recognized on cathodoluminescence images, while the CL technique reveal textural features, that cannot be recognized during observations in transmitted light, e.g. healed microfractures (Milliken and 
Laubach, 2000; Laubach et al., 2000) or cross-cutting microcrack swarms (Plate 1.5,A).

Crystals of the $\mathrm{Cal}_{\mathrm{EB}} 1$ calcite are not luminescent (Plate 1.5,B, D), grains are cross cut by orange luminescent microcrack swarm (Plate 1.5,A). A similar orange luminescent intergrain calcite can generally be identified at the grain boundaries of the $\mathrm{Cal}_{\mathrm{EB}} 1$ crystals (Plate 1.5,E). At some places inside the crystals red CL colour, typical for dolomite can be observed as disseminated patches and in cloud-like zones with indefinite boundaries parallel to scalenohedral boundaries (Plate 1.5,E). The zoned dolomite display red luminescent colour (Plate 1.5,B,D,E). Inside the grains orange luminescent subzones can be observed, that can be identified unequivocally with the second subzone recognizable in transmitted light (Plate 1.5,C, D). The microscopically distinguished third subzone is composed of stripes with different $\mathrm{CL}$ colour and varying thickness (Plate 1.5,B). The $\mathrm{Cal}_{\mathrm{SF}}$ calcite displays homogenous orange luminescent colour (Plate 1.5,B).

Crystals of the $\mathrm{Cal}_{\mathrm{BL}}$ calcite are not luminescent, nevertheless the CL image made of the phase reveal a pre-existing luminescent calcite vein, with the reopening of which the blocky calcite vein formed (Plate 1.5,F), as indicated by the dragged off fragments of the pre-existing

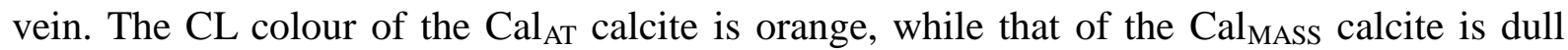
(Plate 1.5,E).

The CL images made of the $\mathrm{Cal}_{\mathrm{EB}} 1$ calcite and the $\mathrm{Dol}_{\mathrm{ZON}}$ dolomite reveal the presence of a cross-cutting microcrack swarm (Plate 1.5,A). The CL colour of the microveins is orange, the average width of the individual cracks is $10 \mu \mathrm{m}$. Based on their presence, less and more intensively damaged zones can be distinguished inside the veins.

\subsubsection{Fluid inclusion petrography and microthermometry}

Microthermometric studies were only conducted on inclusions of $\mathrm{Dol}_{\mathrm{ZON}}, \mathrm{Cal}_{\mathrm{SF}}$ and $\mathrm{Qtz} \mathrm{BL}$ since only these phases contain measurable fluid inclusions.

Only the primary fluid inclusions of petrographically distinguished third zone of the

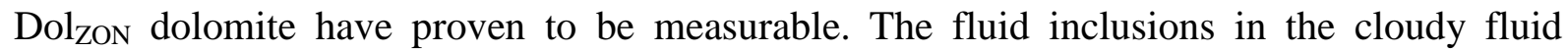
inclusion zone of the second subzone are too small (maximum diameter is $3 \mu \mathrm{m}$ ) for microthermometric measurements. The inclusions of the third subzone are seated along the transparent stripes of the third subzone parallel to the crystal faces, their longest diameter is up to $5 \mu \mathrm{m}$. They are two phase aqueous fluid inclusions with low vapour/liquid ratio $\left(\varphi_{\mathrm{V}}(25\right.$ $\left.{ }^{\circ} \mathrm{C}\right) \sim 0.1$ ). The homogenization temperatures of the inclusions range between 75 and $118{ }^{\circ} \mathrm{C}$, 
with a strong maximum between 95 and $100{ }^{\circ} \mathrm{C}$ (Fig. 1.6). Cooling the inclusions back to room temperature after homogenisation temperature measurements, nucleation of the vapour phase did not occur in any of the inclusions, what renders them to be unsuitable for the measurement of final melting temperatures. The inclusion fluid melted above $0{ }^{\circ} \mathrm{C}$ either in inclusions in which homogenisation temperature measurements were not carried out, what is a typical metastable behaviour.

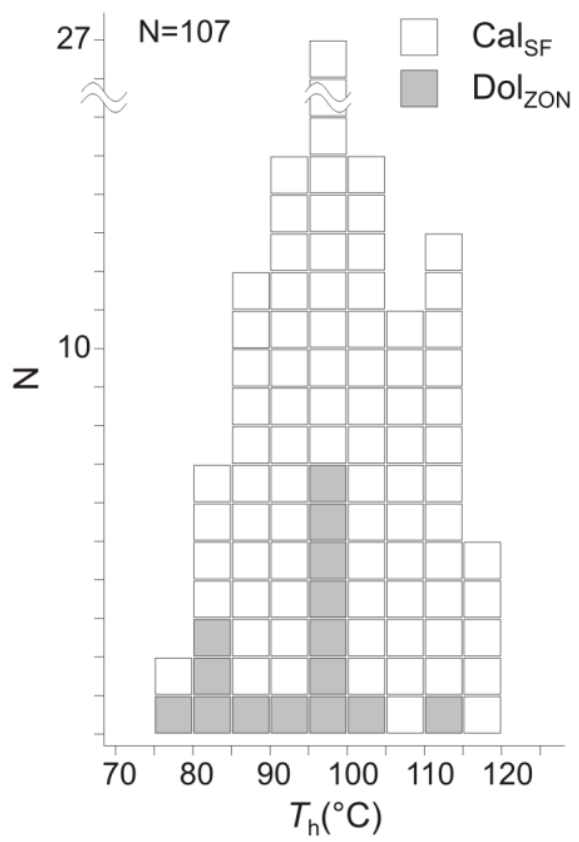

Figure 1.6. Histogram of measured $T_{\mathrm{h}}$ data of fluid inclusions in the zoned dolomite $\left(\mathrm{Dol}_{\mathrm{ZON}}\right)$ and space filling calcite $\left(\mathrm{Cal}_{\mathrm{SF}}\right)$.

Inclusions of the Qtz $\mathrm{BL}_{\mathrm{BL}}$ quartz are various in size, with maximum lengths up to $20 \mu \mathrm{m}$ and are aligned in zones, the boundaries of which are parallel to crystal facets of the euhedral quartz crystals. Furthermore at the contacts of the bigger quartz crystals and the Dol $\mathrm{ZON}$ crystals the smaller (up to $5 \mu \mathrm{m}$ ) inclusions are aligned in lines parallel with each other and the crystal facets. Based on their Raman-spectra (unpublished data) the fluid inclusions are one phase aqueous inclusions.

The petrographic character of the inclusions entrapped in the $\mathrm{Cal}_{\mathrm{SF}}$ calcite cannot be defined unequivocally, since the space filling calcite does not have growth zones, based on what generations of primary inclusions could be defined. Thus the inclusions aligned in linear arrays were interpreted to be secondary in origin, and those which are seated in irregular 
clusters were interpreted to be primary. The final melting temperature measurements were successful in most of the inclusions. The primary inclusions have diverse morphology, their longest diameter varies between 5 and $15 \mu \mathrm{m}$, the typical $\varphi_{\mathrm{V}}\left(25^{\circ} \mathrm{C}\right)$ value is around 0.1 . Homogenisation temperatures of the primary inclusions range between 85 and $119{ }^{\circ} \mathrm{C}$ (Fig. 1.7), while final melting temperatures range between -2.7 and $-0.4^{\circ} \mathrm{C}$ (Fig. 1.7). This means salinities between 0.7 and $4.7 \% w \mathrm{NaCl}$ equiv. Homogenisation temperatures of the secondary inclusions range between 82 and $98{ }^{\circ} \mathrm{C}$ (Fig. 1.7). Based on their final melting temperatures two secondary fluids can be distinguished. One with final melting temperatures in the range of primary inclusions (between -2.1 and $-1.5{ }^{\circ} \mathrm{C}$ - salinities between 2.6 and $3.6 \% w \mathrm{NaCl}$ equiv.), and one with lower final melting temperatures between -4.8 and $-3.1{ }^{\circ} \mathrm{C}$ (salinities between 5.1 and $7.6 \% w \mathrm{NaCl}$ equiv.).

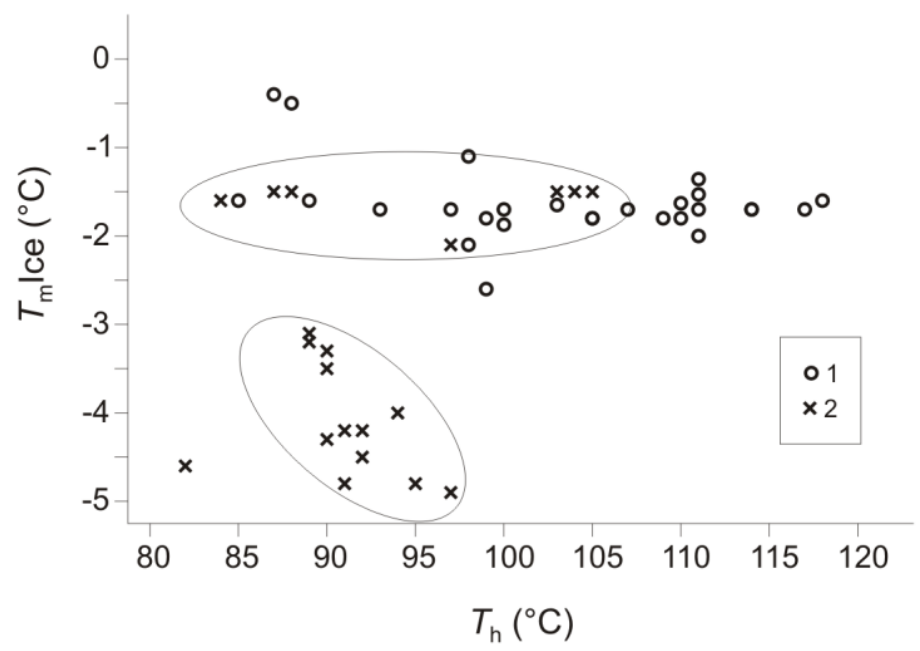

Figure 1.7. Final melting temperature $\left(T_{\mathrm{m}}(\right.$ Ice $\left.)\right)$ vs. homogenisation temperature $\left(T_{\mathrm{h}}\right)$ diagram of fluid inclusions in $\mathrm{Cal}_{\mathrm{SF}}$. $1-$ primary inclusions, 2 - secondary inclusions.

\subsection{Discussion}

The combined microscopic, textural, SEM and cathodoluminescence observations made possible to characterize the different vein minerals in the amphibolite body and to define the relative order of their precipitation. The precipitation order of the last three phases is not clarified, since no samples were found in which their cross-cutting relations can be observed.

The earliest precipitated amongst the studied phases is the elongated blocky calcite $\left(\mathrm{Cal}_{\mathrm{EB}} 1\right.$, Fig. 1.3,A-E; Plate 1.2,A), that represent the highest quantity of all the vein minerals. 
According to the element maps, it is considered to be pure calcite (Plate 1.4, K-O, U-Z). The growth morphology of the mineral phase is syntaxial, i.e. growth of the grains occurred from the vein-wall towards the middle line of the vein (Bons, 2000; Passchier and Trouw, 2005). The grains' microscopic morphology is elongate blocky, what is a texture resulting from the so called growth competition, and indicates advective flow of the parent fluid (Bons, 2000; Passchier and Trouw, 2005; Hilgers et al, 2003). During advective flow, that can occur in fractures of several centimetres width in the studied veins, the degree of fluid-rock interaction is possibly low, since after precipitation occurs on the vein wall further interaction is ceased between the fluid and the host rock (Oliver and Bons, 2001). The veins are evenly filled with the $\mathrm{Cal}_{\mathrm{EB}} 1$ calcite, and are filled completely, with the exception of the remnant voids at some places in the middle line. Lee et al. (1996) studied the terms of the formation of an evenly filled calcite vein with the application of the theoretical thermodynamic model of Morse and McKenzie (1993). According to their results, the degree of supersaturation with respect to calcite in a fluid decrease significantly due to precipitation during fracture channelized flow, as the fluid flow away from the inlet. Thus the flow paths clog in the vicinity of the inlet, and the fracture system cannot be sealed completely. The cementation experiments of Hilgers and Urai (2002b, 2003) confirm the above process. Based on the model of Lee et al. (1996), if the fluid is highly supersaturated, even cementation can occur only in case of high flow velocity. In case of low flow velocities it is the low degree of supersaturation that makes the formation of evenly filled veins possible. At the same time the latter case also demand extremely low (105-106) fluid/mineral ratio. The time necessary for vein formation is between ten thousand and several million years, based on the chemistry of the parent fluid (Lee et al. 1996). Dabi et al. (2006) has detected latent oscillatory zonation based on the mathematical analysis of UV spectra, gathered along lines parallel with the growth direction of the $\mathrm{Cal}_{\mathrm{EB}} 1$ crystals. According to Wang and Merino (1992) oscillatory zonation in calcite implies high degree of supersaturation of the parent fluid. This in turn suggests high flow velocity of the $\mathrm{Cal}_{\mathrm{EB}} 1$ parent fluid and possibly the greater distance of the fluid source, according to the model of Lee et al. (1996).

According to the numerical models of Bons (2001), Hilgers (2001) and Nollet et al. (2005), elongated blocky texture can form if the time intervals between subsequent opening increments are too long for the newly formed volumes to be filled due to the low precipitation rate. In this case growth competition starts due to "growth anisotropy" of the crystals precipitated on the fracture wall, resulting in an elongate blocky texture. In the studied braid- 
like vein systems thinner veins filled with $\mathrm{Cal}_{\mathrm{EB}} 1$ calcite cross-cut pre-existing veins filled with the same calcite phase (Fig. 1.3,B; Plate 1.1,C; Plate 1.2,B). The thin veins merge into the pre-existing veins within several centimetres at some places. The possible explanation of the structure is that the parent fluid got to the site of precipitation during subsequent fracture forming events, while the fracture producing stress field changed. At the same time the scalenohedral facets in contact with the subsequent zoned dolomite indicate that the crystal growth ceased due to the clogging of the vein system. Thus remnant voids existed in the vein system after subsequent fracture formations and precipitation (Fig. 1.3,B).

The $\mathrm{Cal}_{\mathrm{EB}} 1$ calcite is not luminescent, $\mathrm{CL}$ images reveal that the phase is cross-cut by swarms of orange luminescent microcracks (Plate 1.5,A). This swarm cannot be observed in transmitted light, because the newly precipitated calcite phase is in crystallographic continuity with the pre-existing calcite and neither can be identified on the BSE images (Milliken and Laubach, 2000). The orange luminescent calcite along the grain boundaries of the $\mathrm{Cal}_{\mathrm{EB}} 1$ crystals indicates that the grain boundaries were sites of enhanced percolation during later flow events. The intergrain percolation can also be detected at the Dolzon grain boundaries.

The zoned dolomite precipitated in the remnant voids of the pre-existing vein system already filled with the elongated blocky calcite (Fig. 1.3,C). The minimum precipitation temperature of the zoned dolomite is between 95 and $100{ }^{\circ} \mathrm{C}$, according the homogenization temperature data. The cathodoluminescence colour of the phase is red, what is a sum of the characteristic luminescent peaks at 590 and $676 \mathrm{~nm}$, and caused by the $\mathrm{Mn}^{2+}$ that substitutes for $\mathrm{Ca}^{2+}$ and $\mathrm{Mg}^{2+}$ (Machel et al., 1991). The element maps of the phase reinforce the presence of manganese (Plate 1.4,N). Machel and Burton (1991) and Machel (2000) emphasize that the $\mathrm{D}_{\mathrm{Me}}$ value (distribution coefficient between the fluid and the solid phase with respect to the element causing cathodoluminescence) is the resultant of a complex system of geochemical factors, and they also call the attention on the relevance of local processes in these. The cathodoluminescence procedure applied in this study does not make further geochemical conclusions possible to be drawn, but enables the detection of latent fluid flow paths, e.g. healed microfractures (Milliken and Laubach, 2000; Laubach et al., 2004) and percolation paths. Furthermore it enabled the relative order of subsequent phases to be defined in some cases. The red luminescent colour characteristic for the zoned dolomite cannot be discerned in the form of cross-cutting veins or microveins, but can be identified as cloud-like zones inside the $\mathrm{Cal}_{\mathrm{EB}} 1$ phase (Plate 1.5,E). Accordingly the flow paths of the parent fluid were not fractures and at least locally the fluid percolated through the $\mathrm{Cal}_{\mathrm{EB}} 1$ crystals and 
metasomatized it along the percolation paths. Furthermore the remnant voids filled by the zoned dolomite are isolated porosity volumes, what rules out advective flow in case of the Dol $_{\text {Zon }}$ parent fluids. The third subzone is built up of parallel oscillatory luminescent stripes of varying width and luminescence colour (Plate 1.5,B), what is a result of closed system crystallization (Machel and Burton, 1991; Machel, 2000). This textural stigma reinforce the interpretation that the parent fluid did not got to the site of precipitation by fracture channelized flow, instead it pervaded through the pre-existing $\mathrm{Cal}_{\mathrm{EB}} 1$ calcite to the remnant voids, where the dolomite precipitated in closed system. At the same time orange luminescent zones can be identified inside the Dol ${ }_{\text {ZON }}$ crystals with diffuse boundaries along the grain boundaries (Plate 1.5,D) and along stripes parallel with crystal faces (Plate 1.5,B), what was defined as the second subzone. Ca substitution in the second subzone is revealed by the element maps (Plate 1.4,L, V). Furthermore similar orange luminescent seams can be identified along the $\mathrm{Cal}_{\mathrm{EB}} 1$ grain boundaries (Plate 1.5,E). These textural features imply the percolation of a Ca-rich fluid along the grain boundaries of the pre-existing phases and metasomatism along the percolation paths.

Based on the quartz filled microveins cross-cutting the zoned dolomite crystals in the close proximity of the blocky quartz crystals (Plate 1.5,B) the Qtz $\mathrm{BL}_{\mathrm{BL}}$ parent fluid got to the site of precipitation via fracture channelized flow. This is also confirmed by the growth competition of the crystal aggregates, with small grains at the phase boundary between the Dol ${ }_{\text {ZoN }}$ crystals and the $\mathrm{Qtz}_{\mathrm{BL}}$ crystals, and grains with greater diameters towards the middle line (Plate 1.2,E). This texture is indicative of advective flow (Bons, 2000; Passchier and Trouw, 2005; Bons 2001; Hilgers et al., 2003). The Qtz $\mathrm{BL}_{\mathrm{BL}}$ crystals contain one phase aqueous fluid inclusions, what indicates entrapment below $50{ }^{\circ} \mathrm{C}$ (Goldstein and Reynolds, 1994). However such a low fluid temperature is hard to be interpreted if the higher temperatures of the fluids entrapped in the pre-existing Dol $_{\mathrm{ZON}}$ and the subsequent $\mathrm{Cal}_{\mathrm{SF}}$ are taken into consideration. The authors find more feasible that the fluids entrapped in the quartz crystals are metastable, what is also consistent with a low theoretical homogenisation temperature, but does not exclude higher entrapment temperature with the appropriate pressure correction.

According to the microthermometric data the $\mathrm{Cal}_{\mathrm{SF}}$ calcite was precipitated from a low salinity (between 0.7 and $4.3 \% w \mathrm{NaCl}$ equiv.) fluid and at a minimum entrapment temperature between 95 and $100{ }^{\circ} \mathrm{C}$. Based on the presence of secondary inclusions with similar salinity (Fig. 1.7), the same fluid was still present during the entrapment of the secondary inclusions, though the fluid temperature decreased, according to the Th data. The 
$\mathrm{Cal}_{\text {SF }}$ parent fluid can possibly be identified with the fluid that metasomatized the pre-existing carbonates along the grain boundaries or with the fluid that cemented the damaged segments of the $\mathrm{Cal}_{\mathrm{EB}} 1$ crystals (orange luminescent microcrack swarms). The possible identity of the $\mathrm{Cal}_{\mathrm{SF}}$ parent fluid with those percolated along the grain boundaries and with those that were precipitated in locally brecciated zones, raises the role of the parent fluid in the formation of microcrack swarms, i.e. hydrofracturing (Twiss and Moores, 1997; Bons, 2000). That is to say, the $\mathrm{Cal}_{\mathrm{SF}}$ parent fluid percolated through the host rock and the pre-existing vein filling minerals, when the fluid pressure increased for some reason, causing the effective stress to decrease and finally the rock to fail (microcracks formed in the $\mathrm{Cal}_{\mathrm{EB}} 1$ crystals). This was possibly a recurrent process. The microthermometric data is in concordance with the above hypothesis, i.e. the fluids entrapped in the secondary trails with the same salinity as those entrapped in the primary inclusions constrain that the fluid was present during subsequent brittle events. The lower homogenisation temperature in the secondary inclusions (Fig. 1.7) can be interpreted as the decrease of the fluid temperature, but the increase of fluid pressure (and consequently the increase of the fluid density) is also a possible explanation. The latter is also consistent with the precipitation in the remnant voids, i.e. the first crack event made possible a higher pressure drop due to the availability of these volumes. During subsequent hydraulic failures these volumes were filled, and thus the drop of the fluid pressure was lower (resulting in higher average fluid density).

The next phase of the vein evolution was the precipitation of the red massive $\mathrm{Cal}_{\text {MASS }}$ calcite (Fig. 1.3,D). The massive deposit (i), the assimetrically developed micrograin precipitate (on one side of the vein along a trail cross-cutting the $\mathrm{Cal}_{\mathrm{EB}} 1$ crystals) (ii) and the partial decomposition and brown discolouration of the pre-existing vein carbonates (iii) can be different manifestations of this flow event. The connection between (i), (ii) and (iii) is constrained by the presence of micrograin minerals, including quartz and hematite, while the connection between (i) and (iii) is constrained by their relative temporal (cross-cutting) relation to the pre-existing vein minerals.

The temporal relation between $\mathrm{Cal}_{\mathrm{BL}}$ and $\mathrm{Cal}_{\mathrm{MASS}}$ is not clear at this point, due to the lack of observable cross-cutting relations. However the $\mathrm{Cal}_{\mathrm{EB}} 2$ and the $\mathrm{Cal}_{\mathrm{AT}}$ calcites are subsequent to the red massive calcite deposition, what is unequivocally revealed by crosscutting relations (Plate 1.1,D; Plate 1.3,E, F). Thus the relative temporal relations between the late vein calcites are not yet unravelled. It is also possible they are precipitated from the same fluid, though this in discordance with their different $\mathrm{CL}$ colour $\left(\mathrm{Cal}_{\mathrm{AT}}-\mathrm{Cal} \mathrm{BL}_{\mathrm{BL}}\right)$, and the orange 
staining in $\mathrm{Cal}_{\mathrm{EB}} 2$.

The secondary inclusions entrapped in the space filling calcite $\left(\mathrm{Cal}_{\mathrm{SF}}\right)$ reveal a past fluid flow event with a minimum fluid temperature between 82 and $97{ }^{\circ} \mathrm{C}$ and final melting temperatures between -4.8 and $-3.1{ }^{\circ} \mathrm{C}$ (salinities between 5.1 and $7.6 \% \mathrm{wNaCl}$ equiv.). This fluid is of higher salinity than those entrapped in the primary inclusions of $\mathrm{Cal}_{\mathrm{SF}}$, and may be correlated with any of the subsequent phases $\left(\mathrm{Cal}_{\mathrm{MASS}}, \mathrm{Cal}_{\mathrm{AT}}, \mathrm{Cal}_{\mathrm{EB}} 2, \mathrm{Cal}_{\mathrm{BL}}\right)$. It is also possible that the fluid is not related to any of the above mentioned phases, and represents a flow event that hasn't produced any mineral deposit, or one that has not yet been found.

\subsection{Conclusions}

The vein minerals of the first eastern sidevalley of the Goldrgrund valley can be grouped into eight eight groups based on their textures, and these types are produced during at least six fluid flow events.

The first type indicates fracture chanellised fluid flow, which followed a brittle episode of the rock mass. This episode consisted of at least two failure events. In case of the elongate blocky calcite $\left(\mathrm{Cal}_{\mathrm{EB}} 1\right)$ the applicability of the microthermometric methods is questionable due to the subsequent metasomatic events. The texture indicates high degree of saturation and high flow velocity of the parent fluid, what suggest the fluids extraformational origin.

The second flow event was possibly a percolative fluid flow that entered the remnant voids of the pre-existing vein system, and produced the zoned dolomite (Dol $\mathrm{ZON}$ ). The fluid's minimum temperature was between 80 and $100{ }^{\circ} \mathrm{C}$.

The third fluid flowed advectively and produced blocky syntaxial quartz (Qzt $\left.\mathrm{BL}_{\mathrm{BL}}\right)$. The presence of one phase primary inclusions indicates low temperature of the parent fluid, and suggests its meteoric origin.

The fourth flow event was that of the $\mathrm{Cal}_{\mathrm{SF}}$ parent fluid. The occurance of the flow event was possibly triggered by hydrofracturing, i.e. the increase of the parent fluid's pressure caused failure of the host rock and the pre-existing vein system. The minimum temperature of the fluid was between 95 and $100{ }^{\circ} \mathrm{C}$, while the fluid's salinity was between 0.7 and $4.3 \%$ $w \mathrm{NaCl}$ equiv.

The fifth flow event deposited the red massive calcite (Cal $\left.\mathrm{CASS}_{\mathrm{S}}\right)$. Based on the secondary inclusions in the pre-existing $\mathrm{Cal}_{\mathrm{SF}}$ calcite the parent fluid was a low temperature (homogenisation temperatures between 81 and $98{ }^{\circ} \mathrm{C}$ ) and low salinity fluid (salinities 
between 5.1 and $7.6 \% w \mathrm{NaCl}$ equiv.).

Since the time relations between the late cross-cutting veins cannot be defined due to the lack of cross-cutting relations, they define at least one fluid flow event. The texture of the $\mathrm{Cal}_{\mathrm{AT}}$ calcite generation indicates recurrent openings and flow events (crack-seal texure), what suggests different flow mechanism from the flow mechanism of the $\mathrm{Cal}_{\mathrm{EB}} 2$ and $\mathrm{Cal}_{\mathrm{BL}}$ calcites.

In summary it is noteworthy to emphasize that the reconstructed flow events represent local flow mechanisms and the calcite generations described from the amphibolite body may occur with different textures in other rock types of the study area. Thus the examination of outcrops that reveals different rock types of the Ófalu Formation can possibly yield important increments on the knowledge of the hydraulic behaviour of a heterogeneous crystalline complex. 


\section{Explanation of plates}

Plate 1.1.

(A) The studied amphibolite outcrop, with the studied, steeply dipping calcite veins.

(B) White calcite vein $\left(\mathrm{Cal}_{\mathrm{EB}} 1\right)$ with subsequent zoned dolomite ( Dol $\left._{\mathrm{ZON}}\right)$ precipitated in the remnant voids in the middle line with transsecting yellow vein filled with $\mathrm{Cal}_{\mathrm{EB}} 2$.

(C) Braidy vein system filled with white calcite $\left(\mathrm{Cal}_{\mathrm{EB}} 1\right)$. Dashed line marks cross cutting vein filled with the same $\mathrm{Cal}_{\mathrm{EB}} 1$ calcite, arrow marks subsequent dolomite (Dol $\mathrm{ZON}_{\text {) }}$ ) precipitated in the remnant voids in the middle line of the transsecting vein.

(D) Red calcite with dismembered fragments the white calcite veins $\left(\mathrm{Cal}_{\mathrm{EB}} 1\right)$, cross-cut by yellow vein $\left(\mathrm{Cal}_{\mathrm{EB}} 2\right)$.

(E) Brown coloured vein with space filling calcite $\left(\mathrm{Cal}_{\mathrm{SF}}\right)$ precipitated in the remnant voids in the middle line.

(F) Orange calcite vein $\left(\mathrm{Cal}_{\mathrm{EB}} 2\right)$ with open void in its middle line.

(G) Microscopic texture of the host amphibolite, $1 \mathrm{~N}$.

Plate 1.2.

(A) The texture of the white calcite vein in its entire cross section, with elongate blocky crystals $\left(\mathrm{Cal}_{\mathrm{EB}} 1\right)$ widening towards the meddle line, where brown zoned dolomite (Dol $\left.{ }_{\mathrm{ZON}}\right)$, and with space filling calcite $\left(\mathrm{Cal}_{\mathrm{SF}}\right)$ precipitated in the remnant voids, $+\mathrm{N}$.

(B) Two generations of the $\mathrm{Cal}_{\mathrm{EB}} 1$ calcite at the braidy vein system, $+\mathrm{N}$.

(C) Thin stripe of reddish micrograin calcite transsecting the zone of $\mathrm{Cal}_{\mathrm{BB}} 1$ grains, with radially extincting quartz, $+\mathrm{N}$.

(D) $\mathrm{Cal}_{\mathrm{EB}} 1$ caclite and $\mathrm{Dol}_{\mathrm{ZON}}, \mathrm{Qtz}_{\mathrm{BL}}$ and $\mathrm{Cal}_{\mathrm{SF}}$ phases precipitated in a remnant void, $+\mathrm{N}$.

(E) Detail of picture „D”, with brownish grey and striped subzones of Dol $_{\mathrm{ZON}}$, and with blocky crystals of $\mathrm{Qtz}_{\mathrm{BL}}$ phase, $+\mathrm{N}$.

(F) $\mathrm{Cal}_{\mathrm{MASS}}$ phase containing dragged off fragment of $\mathrm{Cal}_{\mathrm{EB}} 1,+\mathrm{N}$.

(G) Texture of the disintegrated brown colured vein with $\mathrm{Cal}_{\mathrm{EB}} 1, \mathrm{Dol}_{\mathrm{ZON}}$ and $\mathrm{Cal}_{\mathrm{SF}},+\mathrm{N}$.

(H) Detail of picture „G”, the $\mathrm{Cal}_{\mathrm{SF}}$ calcite with the brown pigmentation in a narrow zone, $+\mathrm{N}$.

Plate 1.3.

(A) Texture of a vein filled with $\mathrm{Cal}_{\mathrm{EB}} 2,+\mathrm{N}$.

(B) Late vein filled with $\mathrm{Cal}_{\mathrm{EB}} 2$ cross-cutting pre-existing $\mathrm{Cal}_{\mathrm{EB}} 1$ and $\mathrm{Dol}_{\mathrm{ZON}}, 1 \mathrm{~N}$.

(C) Microvein filled with $\mathrm{Cal}_{\mathrm{BL}}$ phase (bounded by dashed lines) cross-cutting $\mathrm{Cal}_{\mathrm{EB}} 1$ crystals, $+\mathrm{N}$.

(D) Detail of picture „C", microvein of phase $\mathrm{Cal}_{\mathrm{BL}}$ containing dragged off fragments of transsected $\mathrm{Cal}_{\mathrm{EB}} 1$ phase, $1 \mathrm{~N}$.

(E) $\mathrm{Cal}_{\mathrm{MAss}}$ phase within the zone of $\mathrm{Cal}_{\mathrm{EB}} 1$, both cross-cut by microvein filled with $\mathrm{Cal}_{\mathrm{AT}},+\mathrm{N}$.

(F) Detail of picture „E”, with dragged off fragments of $\mathrm{Cal}_{\text {MASs }}$ within a microvein filled with $\mathrm{Cal}_{\text {AT }}$ phase, $+\mathrm{N}$.

(G) Backscattered electron (BSE) image of $\mathrm{Cal}_{\mathrm{MAsS}}$ with inclusions of hematite and quartz.

(H) BSE image of a spherical aggregation of fibrous hematite as inclusion in $\mathrm{Cal}_{\text {MASs. }}$.

Plate 1.4.

A - Z) Table composed of BSE images and element maps, with different textures in rows and with BSE images in the first column and with element maps of $\mathrm{Ca}, \mathrm{Mg}, \mathrm{Mn}$ and $\mathrm{Fe}$ in following columns, 
respectively.

Plate 1.5.

Cathodoluminescent images of different vein textures.

(A) Orange cathodoluminescent microcrack swarm cross-cutting the $\mathrm{Cal}_{\mathrm{EB}} 1$ crystals.

(B) Cathodoluminescent image of $\mathrm{Cal}_{\mathrm{EB}} 1, \mathrm{Dol}_{\mathrm{ZON}}$ and $\mathrm{Cal}_{\mathrm{SF}}$. Last subzone of Dol ${ }_{\mathrm{ZON}}$ display striped oscillatory zonation.

(C) Scalenohedral end of a $\mathrm{Cal}_{\mathrm{EB}} 1$ crystal, and Dol $_{\mathrm{ZON}}$ with its first two subzones, $1 \mathrm{~N}$.

(D) Cathodoluminescent counterpart of picture „C”. Yellow luminescent zone with diffuse boundaries correspond to the second subzone of Dol $_{\mathrm{ZON}}$.

(E) Yellow and red luminescent patches in crystals of $\mathrm{Cal}_{\mathrm{EB}} 1$ and yellow luminescent patches in

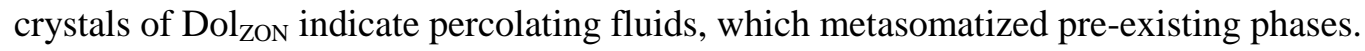

(F) $\mathrm{Cal}_{\mathrm{BL}}$ microvein containing dragged off fragments of cross-cut $\mathrm{Cal}_{\mathrm{EB}} 1$ grains and of a preexisting microvein.

(G) Microvein filled with $\mathrm{Cal}_{\mathrm{AT}}$ containing dragged off fragments of the cross-cut $\mathrm{Cal}_{\mathrm{MASs}}$. 
Plate 1.1.
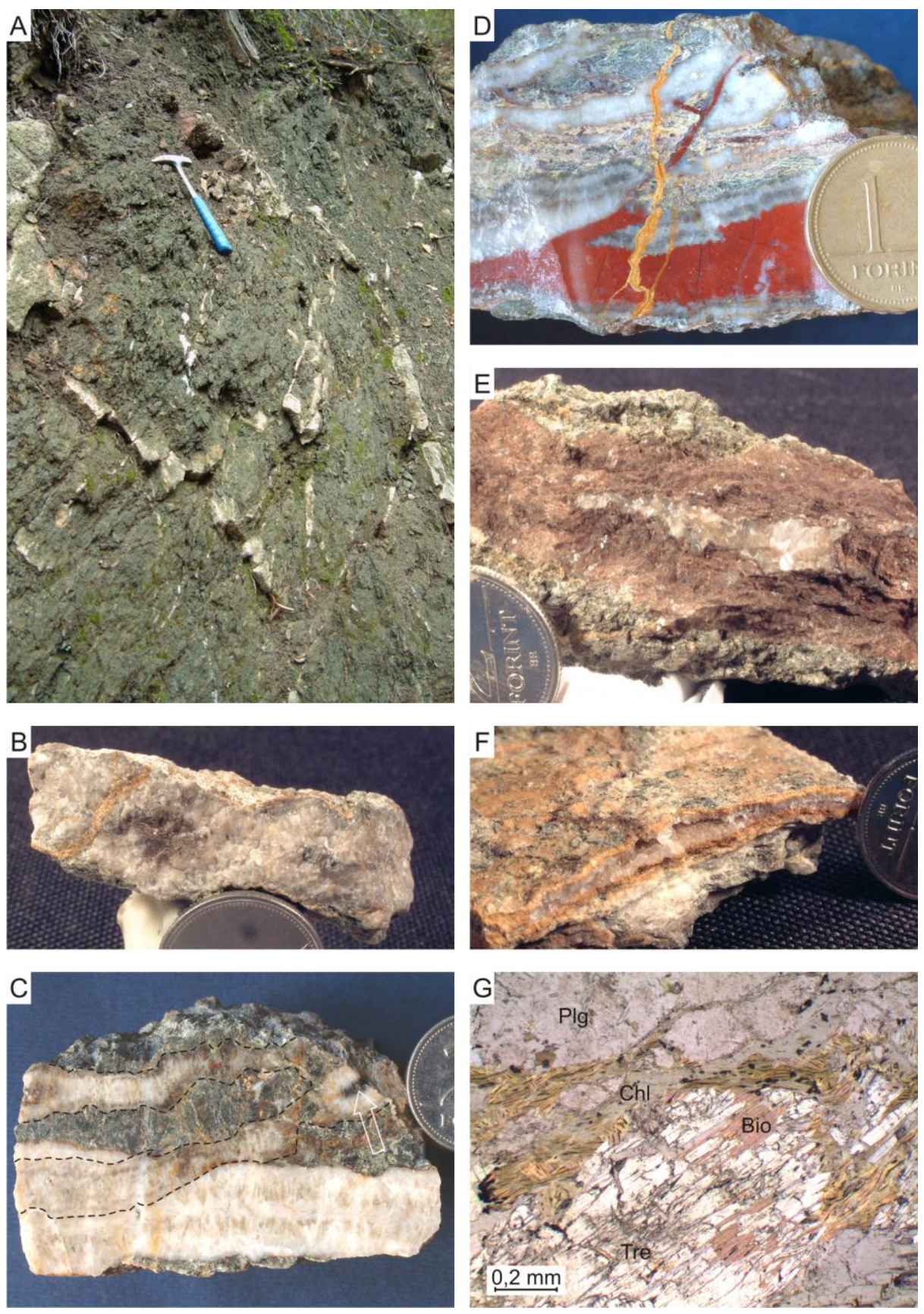
Plate 1.2.
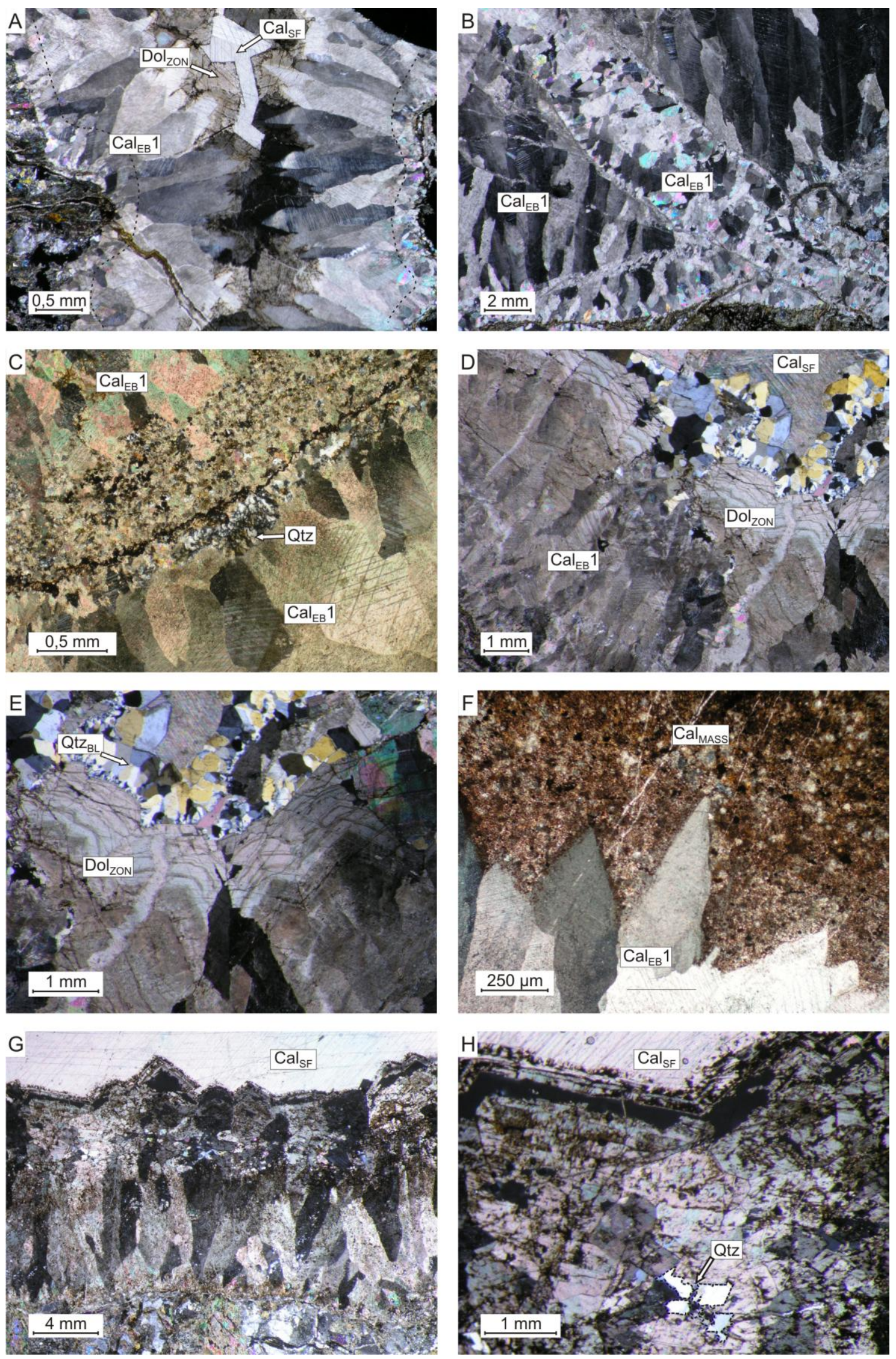
Plate 1.3.
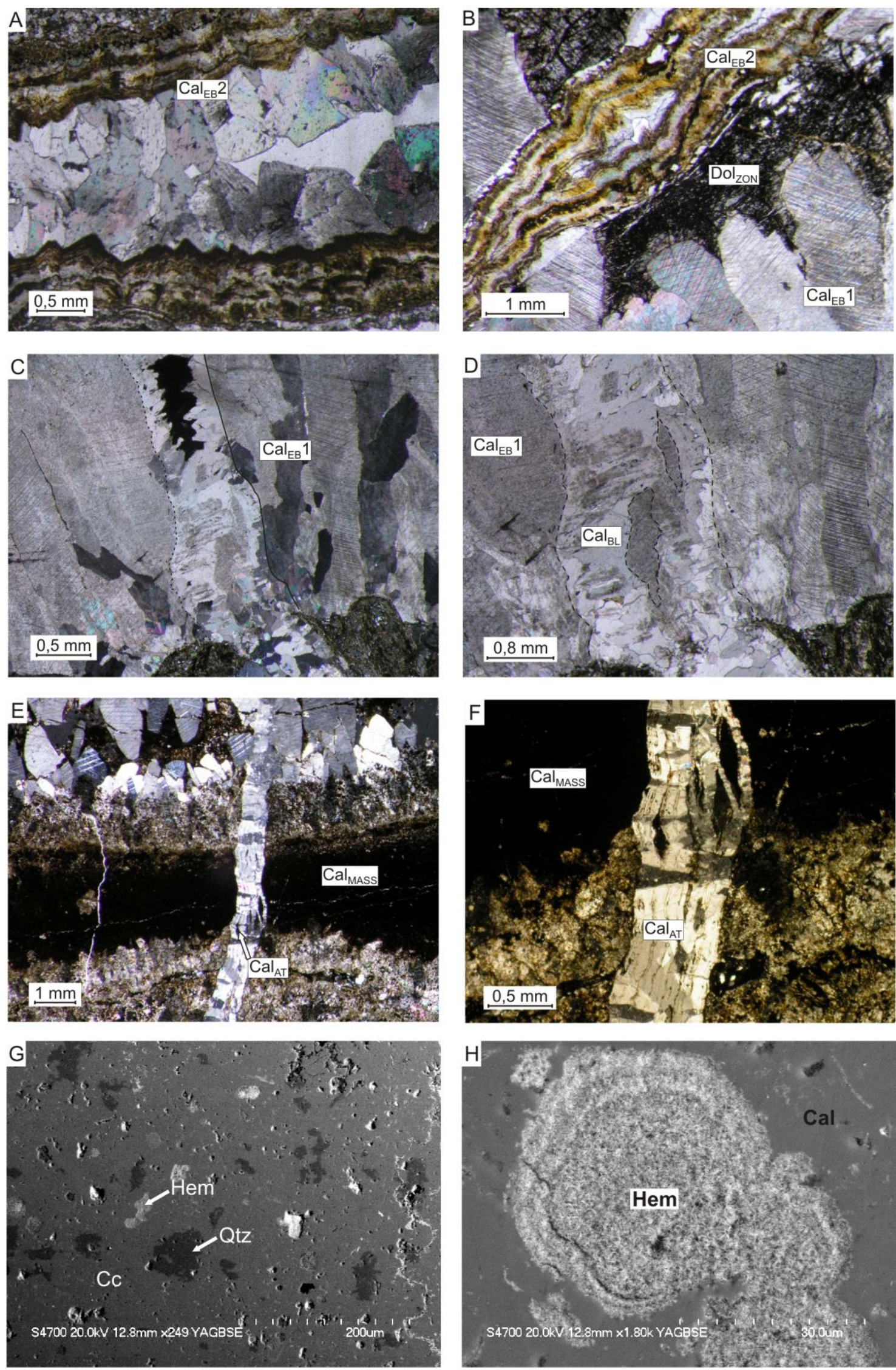
Plate 1.4.
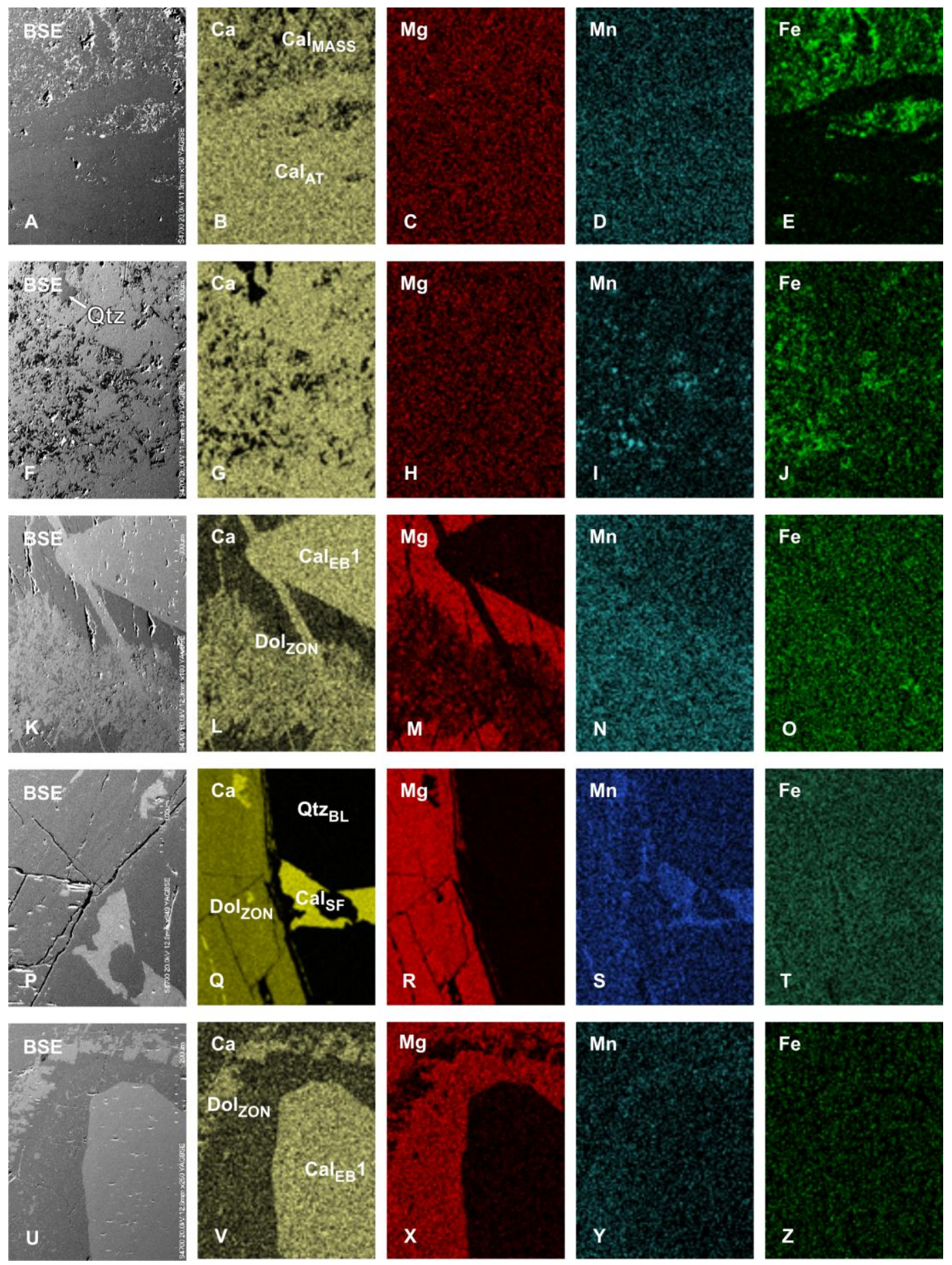
Plate 1.5.
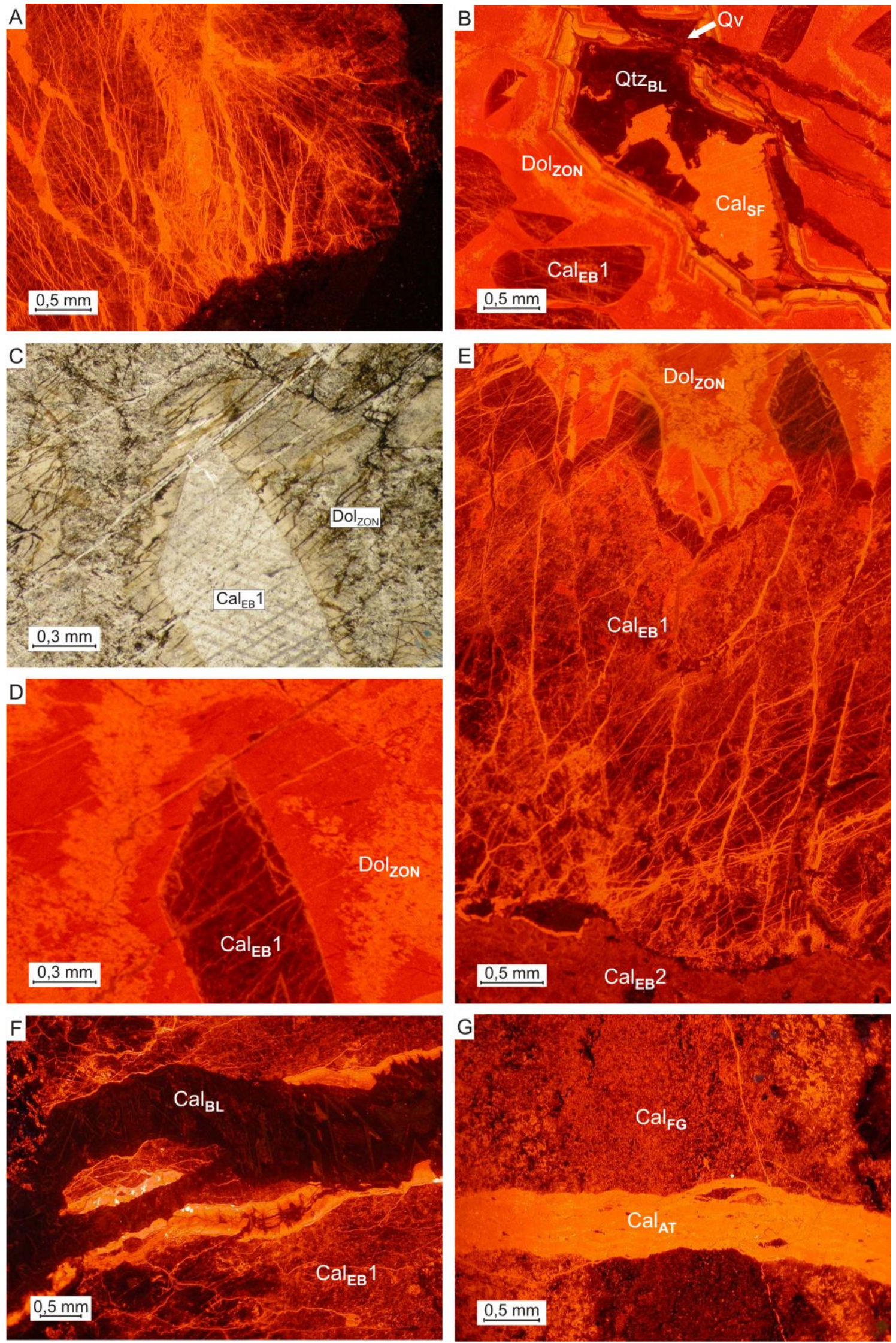


\section{Chapter 2.}

The relevance of vein texture in understanding the past hydraulic behaviour of a crystalline rock mass: reconstruction of the palaeohydrology of the Mecsekalja Zone, south Hungary ${ }^{*}$

\footnotetext{
* Dabi, G., Siklósy, Z., Schubert, F., Bajnóczy, B., M. Tóth, T., 2011. Geofluids, 11, pp. 309-327.
} 


\begin{abstract}
This study reconstructs the palaeohydrogeologic evolution of the shallow-to-moderate Mesozoic subsidence history for the Mecsekalja Zone (MZ), a narrow metamorphic belt in the eastern Mecsek Mountains, Hungary. Brittle deformation of the MZ produced a vein system with a cement history consisting of five sequential carbonate generations and one quartz phase. Vein textures suggest different fluid-flow mechanisms for the parent fluids of subsequent cement generations. Combined microthermometric and stable-isotope measurements permit reconstruction of the character of subsequent fluid generations with different flow types, as defined by vein textures, yielding new information regarding the hydraulic behaviour of a metamorphic crystalline complex. Textural observations and geochemical data suggest that fracture-controlled flow pathways and externally derived fluids were typical of some flow events, while percolation through the rock matrix and the relationship to the Cretaceous volcanism and dyke emplacement were typical of others. The difference in the mode of calcite deposition from pervasive fluids (i.e. pervasive carbonatisation along grain boundaries versus deposition in antitaxial veins) between two calcite generations related to the volcanism inspired a stress-dependent model of antitaxial vein growth. Textural and isotope variations in a vein generation produced by the same parent fluid indicate rock-dependent hydraulic behaviour for different rock types, distinct action of the contemporaneous fracture systems and different extents of fluid-rock interaction. Cathodoluminescence microscopy and fluid-inclusion microthermometry shed light on the possible role of hydraulic fracturing in the formation of massive calcite. The time of formation was estimated from the isotope composition of the oldest calcite generation and its presumptive relationship with the sedimentary sequences to the north, whereas microthermometry permitted conciliation of the reconstructed flow sequence with the Mesozoic subsidence history of the Mórágy Block (including the MZ).
\end{abstract}

\title{
2.1. Introduction
}

Stable-isotope data are widely applied in palaeohydraulic reconstructions of hydrothermal vein systems in different geological settings. Applications include assessment of fluid-rock interaction (Hilgers and Sindern, 2005) and the evolution of mineralising fluids during fluidrock interaction (Cox, 2007). Bottomley and Veizer (1992) and Rye and Bradbury (1988) 
assessed recrystallisation of a pre-existing vein system and fluid-rock interaction during nappe stacking, respectively. Templeton et al. (1998) investigated the mixing of mineralising fluids during compressionrelated fluid expulsion. Juhász et al. (2002) and Fourcade et al. (2002) used stable-isotope data, together with fluid-inclusion microthermometry, to resolve flow interactions between crystalline rocks and overlying sediments. Numerous studies have proven the ability of stable isotopes to resolve the origins of fluids in crystalline rocks (e.g. Bottomley and Veizer, 1992; Blyth et al., 2000).

In the recent decades, the formation of different vein textures and their implications for the flow regime (i.e. advective, fracture-channelised-flow versus percolation through the host rock) have been brought into focus (Bons, 2000; Hilgers and Urai, 2002a). Hilgers and Sindern (2005) and Barker et al. (2006) combined stable-isotope data with radiogenic isotopes $\left(\mathrm{Sr}^{87} / \mathrm{Sr}^{86}\right)$ and trace and rare earth elements to resolve the fluid source and flow path of antitaxial vein parent fluids. Rye and Bradbury (1988) found that vein calcites with the same fluid source but different textures display different isotope compositions.

Deformation during the Mesozoic evolution of the Tisza Mega-unit (TMU) produced a post-metamorphic vein sequence in the Mecsekalja Zone (Dabi et al., 2009a), the only exposed representative of the TMU crystalline complexes. This study reports stable-isotope data in concert with a detailed textural description and fluid-inclusion microthermometry of veins from the Mecsekalja Zone (Mecsek Mountains, SW Hungary), to unravel the hydraulic behaviour of a metamorphic complex. The textural, isotope and microthermometric data are interpreted in with the context of the subsidence history of the Mecsekalja Zone and the wellknown Mesozoic evolution of the Tisza Mega-unit, its wider environment. The palaeofluid evolution reconstructed from the vein sequence is synchronised with the post-metamorphic Alpine evolutionary stages of the Tisza Mega-unit and the Mesozoic subsidence history of the Mecsekalja Zone to yield new information about the tectonic conditions associated with different vein systems and textures.

\subsection{Geological background}

The study area is representative of the metamorphic complexes of the Tisza Mega-unit (TMU), a large composite lithospheric block with complex internal structure made up of nappe systems (Fig. 2.1A, Kovács et al., 2000; Haas and Péró, 2004). The TMU is the basement of the Pannonian Basin and is overlaid by thick Cenozoic sequences. Units of the 
TMU are built up of Variscan crystalline complexes beneath Upper Carboniferous to Triassic overstep sequences. Variscan granitoids and crystalline complexes of the TMU may be correlated with the Moldanubian (-Helvetic) Zone, which means that during the Variscan Orogeny the TMU was an integral part of the Variscan Mountain Range (Haas and Péró, 2004) and thus, in its present position, the TMU is an exotic terrane of European Plate origin.

Its Alpine evolutionary stages include Bathonian separation from the European Plate (because of the opening of the Penninic-Vahic ocean branch), Cretaceous continental rift-type alkali basalt volcanism and Late Cretaceous nappe stacking (Haas and Péró, 2004). The main nappestacking stage was in the Turonian-Coniacian (pre-Gosau phase).
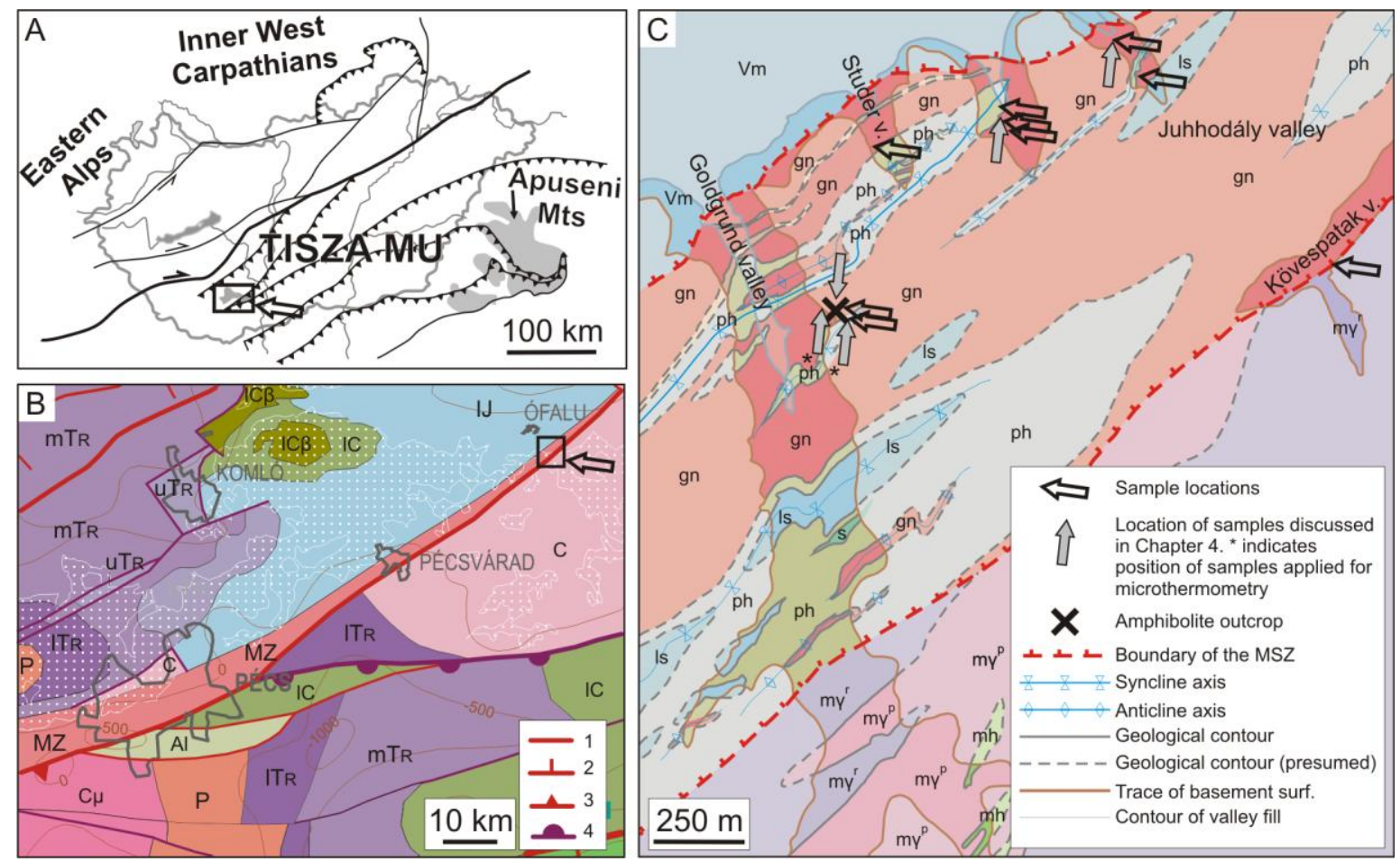

Figure 2.1. (A) Position of the Tisza Mega-unit in the basement of the Pannonian Basin. Inset shows the position of B. (B) Regional geological map of the study area. The MZ is a narrow metamorphic zone between Mesozoic sequences in the Eastern Mecsek Mountains and the Variscan Mórágy Granite, Mórágy Hills. The contact of the $\mathrm{MZ}$ is tectonic both to the north and to the south. Dotted area marks surface outcrops of the pre-Cenozoic formations. 1. Cenozoic tectonic line, 2. Cenozoic fault, 3. Cenozoic overthrust, 4. Mesozoic nappe. Inset shows the position of C. After Haas et al., 2010. (C) Outcrops of the MZ are exposed in the north-south valleys southeast of Ófalu village. The studied amphibolite body is marked with an X. Cl, Variscan metamorphic complex; MZ, Mecsekalja Zone; C, Variscan granitoid rocks; P, Permian; ITR, Lower Triassic; mTR, Middle Triassic; uTR, Upper Triassic to Lower Jurassic; 1J, Lower to Middle Jurassic; 1C, Upper Jurassic to Lower Cretaceous; 1C $\beta$, Lower Cretaceous basaltic rocks; Al, Albian; gn, gneiss; ph, phyllite; s, serpentinite; ls, limestone; $\gamma^{r}$, rarely porphyritic monzogranite; $\mathrm{m} \gamma^{\mathrm{p}}$, porphyritic monzogranite; mh, monzonite; Vm, Vasas Marl Formation. After Balla et al., 2009. 
The Mecsekalja Zone (MZ) is a 1.5-km-wide, NE-SW trending tectonic zone located in the Eastern Mecsek Mountains, Hungary (Fig. 2.1B), which can be traced in boreholes to the north-east under a thick cover of overlying Cenozoic to Quaternary sediments (Fülöp, 1994). At the study area, the zone is composed of enclaves of amphibolites (originally not marked on the cited map), serpentinite and crystalline limestone bodies in host mylonitic gneiss and quartz phyllite (Balla et al., 2009; Fig 2.1C). The amphibolite was metamorphosed at $580{ }^{\circ} \mathrm{C}$ and a pressure between 2 and 4 kbar (Árkai and Nagy, 1994), whereas the peak metamorphism of the host mylonitic gneiss is around $450{ }^{\circ} \mathrm{C}$ and 6.7 to $7.3 \mathrm{kbar}$ (LelkesFelvári et al., 2000). The age of mylonitic shearing has been dated to between 270 and 303 Ma (Lelkes-Felvári et al., 2000) by the ${ }^{40} \mathrm{Ar}-{ }^{39} \mathrm{Ar}$ method. Based on zircon morphology, the protolith of the mylonite has been defined as granitic orthogneiss, the protolith of which crystallised at $710{ }^{\circ} \mathrm{C}$ followed by metamorphic recrystallisation at $550^{\circ} \mathrm{C}$ (M. Tóth et al., 2005). The crystalline limestone bodies contain lower Devonian conodonts (S. Kovács, Eötvös University, oral communication, 2010). These rock types are referred collectively as the Ófalu Formation. Their common foliation suggests that they were metamorphosed and deformed together. Rocks of the Ófalu Formation are strongly foliated. The trend of their foliation is NE - SW, with a steep dip. The common foliation and lack of brittle deformation along their boundaries suggest a common history during the Late Carboniferous to Early Permian mylonitic shearing of the gneiss, along its retrograde path. Dabi et al. (2009a) described a six-phase vein evolution from the Goldgrund valley amphibolite body, and Dabi et al. (2009b) presented fluid-inclusion microthermometry from antitaxial veins crosscutting the gneissic rocks.

The MZ is bordered by tectonic contacts both north and south; the neighbouring rocks are Liassic marls (Vasas Marl Formation, Császár et al. 2007) and Variscan granites (Mórágy Granite Formation, Király and Koroknai, 2003; Balla et al., 2009), respectively (Fig. 2.1B,C). The north-west boundary is a long-recognised structural line, although its character is not yet defined, with a dip angle between 35 and $50^{\circ}$ to the north-west, according to coal exploration wells (Balla et al., 2009). The continuity of the sedimentary sequences to the north and their age (Carboniferous to Late Cretaceous) suggest that the resent-day structure was formed later than Late Cretaceous. The geometry of the south-east boundary is less known; though, its tectonic character is presumptive based on brittle features at the contact zone and the lack of contact metamorphic features in the Ófalu Formation (Balla et al., 2009).

The Liassic marl to the north (Vasas Marl Formation) is a member of a continuous 
sedimentary sequence between the Upper Carboniferous and Upper Cretaceous (Fig. 2.1B). Marine sedimentation commenced in the Middle Triassic (Anisian Lapisi Limestone Formation) and continued until the Late Cretaceous, with pelagic marls and limestones between the Sinemurian and the Kimeridgian (Némedi Varga, 1998). In the Eastern Mecsek Mountains, basaltic volcanism occurred in the Early Cretaceous between 135 and $110 \mathrm{Ma}$ (Harangi, 1994); though, volcanic bombs in the Late Berriasian and Hauterivian strata of the Márévár Limestone indicate an earlier initiation (ca. $140 \mathrm{Ma}$ ). Basaltic dykes are frequent in the study area and crosscut the rocks of the Mórágy Granite Formation, the Ófalu Formation and rocks of the Jurassic formations to the north. These rocks are referred to collectively as the Rozsdásserpenyő Alkaline Basalt Formation and are of alkali basaltic, alkali trachytic, to alkali rhyolitic composition (Balla et al., 2009). The dykes are possibly related to the basaltic volcanism in the eastern Mecsek Mountains, but their geochemical character suggests that they are more closely related to the subvolcanic rock types of the eastern Mecsek (Balla et al., 2009), which crosscut the folded structures of Cretaceous strata, implying an Upper Cretaceous age (Balla et al., 2009). Intrusive breccias frequently crosscut the rocks of the Mórágy Granite Formation and are regarded as the product of the enhanced volatile pressure during dyke emplacement (Balla et al., 2009). Pervasive carbonatisation and carbonate infiltration were described from rocks of the Mórágy Granite in the course of systematic petrographic investigations (Balla et al., 2009). The fine-grained carbonate usually forms thin 'films' around the single grains in the granite. It is regarded as being 'triggered by the explosion- like escape of the volatile components' during dyke emplacement.

The Mórágy Granite to the south has been subject to a series of site investigations over the past decade as a potential location for a deep repository for low-level radioactive waste (for a summary see Balla et al., 2009). As part of these investigations, numerous studies of the palaeohydrogeology of the site were carried out, including analysis of the fluid-inclusion planes (FIPs) of rock-forming minerals and veins (Poros et al., 2008; Szabó et al., 2008). Szabó et al. (2008) identified four fluid-flow events. The fluids of a single regional event have homogenisation temperatures between 130 and $238{ }^{\circ} \mathrm{C}$, and salinities between $1.9 \%$ and $4.5 \%$ $w \mathrm{NaCl}$ equivalent. The remaining events were local. Two were of higher temperature and salinity $\left(227{ }^{\circ} \mathrm{C}<T_{\mathrm{h}}<293{ }^{\circ} \mathrm{C}\right.$, and $9.98-10.85 \% w \mathrm{NaCl}$ equivalent respectively), and one was of lower temperature and salinity $\left(137{ }^{\circ} \mathrm{C}<T_{\mathrm{h}}<209{ }^{\circ} \mathrm{C}, 0.9-2.2 \% w \mathrm{NaCl}\right.$ equivalent, respectively). These fluid-flow events were defined based on the FIPs of rock-forming minerals, showing that the fluids of the regional event produced veining. Poros et al. (2008) 
defined six fluid-flow events, the fourth of which produced calcite veins and which they assigned to the regional flow event described by Szabó et al. (2008), based on its correspondingly low temperature and salinity $\left(T_{\mathrm{h}}\right.$ between 100 and $250{ }^{\circ} \mathrm{C}$, salinities between 0.2 and $5 \% w \mathrm{NaCl}$ equivalent). Both Szabó et al. (2008) and Poros et al. (2008) observed regionally defined fluid flow in both the FIPs of rock-forming quartz and the primary inclusions of vein calcites. Poros et al. (2008) dated this regional flow event to the Late Cretaceous. Kovács-Pálffy and Földvári (2003) had previously published K/Ar age data of authigenic illites of veins which showed that the main period of veining was during the Mesozoic.

Császár (2003) constructed the Mesozoic subsidence curve of the Mórágy Block (including near-surface occurrences of the Mórágy Granite Formation and rocks of the Ófalu Formation) and the Jurassic Zsibrik Block to the north, where Jurassic sequences are exposed on and near the surface. These calculations suggest that Early to Late Cretaceous uplift of both blocks occurred because of the pre-Gosau tectonic movements. The study area is partially covered by Lower Miocene to Holocene sediments and loess.
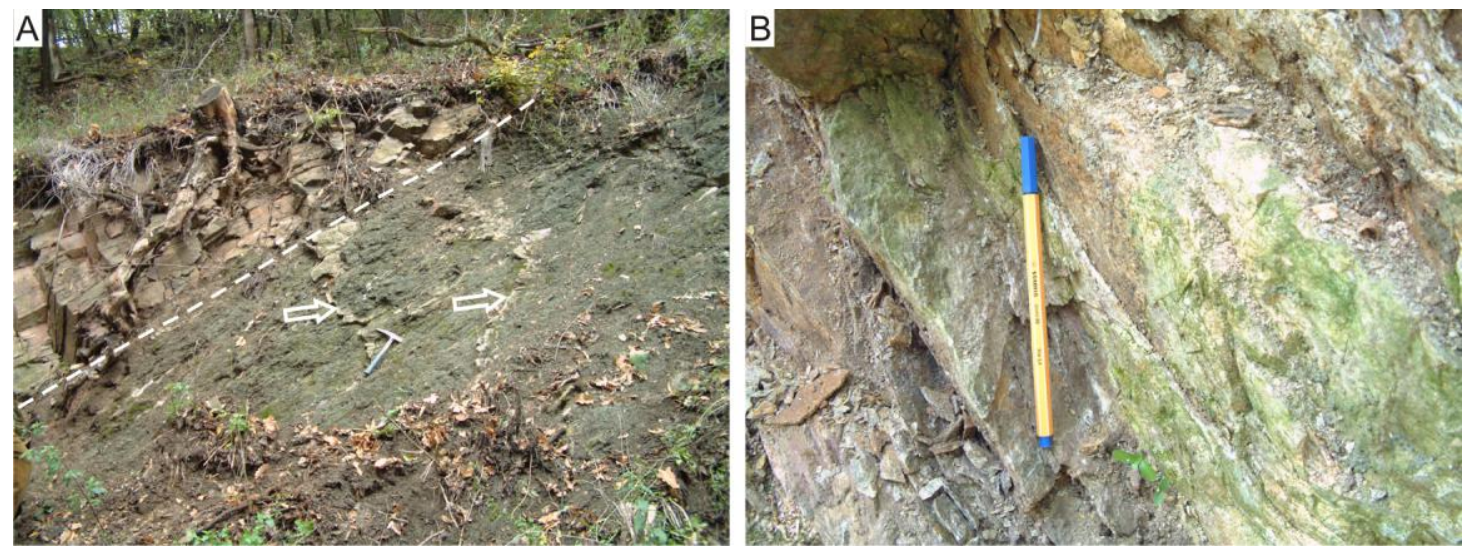

Figure 2.2. Outcrop photographs. (A) Goldgrund valley amphibolite outcrop. The studied amphibolite body is marked with an X on Fig. 2.1C. The contact between the studied amphibolites and the host mylonitic gneiss is revealed by the outcrop. Veins are marked with arrows. (B) Juhhodály valley gneiss outcrop, with thin antitaxial vein at the pen-cap.

\subsubsection{Description of studied veins}

\subsubsection{Vein textures in amphibolite}

The Goldgrund Valley outcrop (Figs $2.1 \mathrm{C}$ and 2.2A) provides an exceptionally good exposure of the amphibolite and permits study of a well-developed vein system. Dabi et al. (2009a) described a succession of five distinct carbonate and one quartz vein-filling phase 
which, based on their textures, define at least six fluid-circulation events (Fig. 2.3). The following section is a brief characterisation and interpretation of these vein textures.
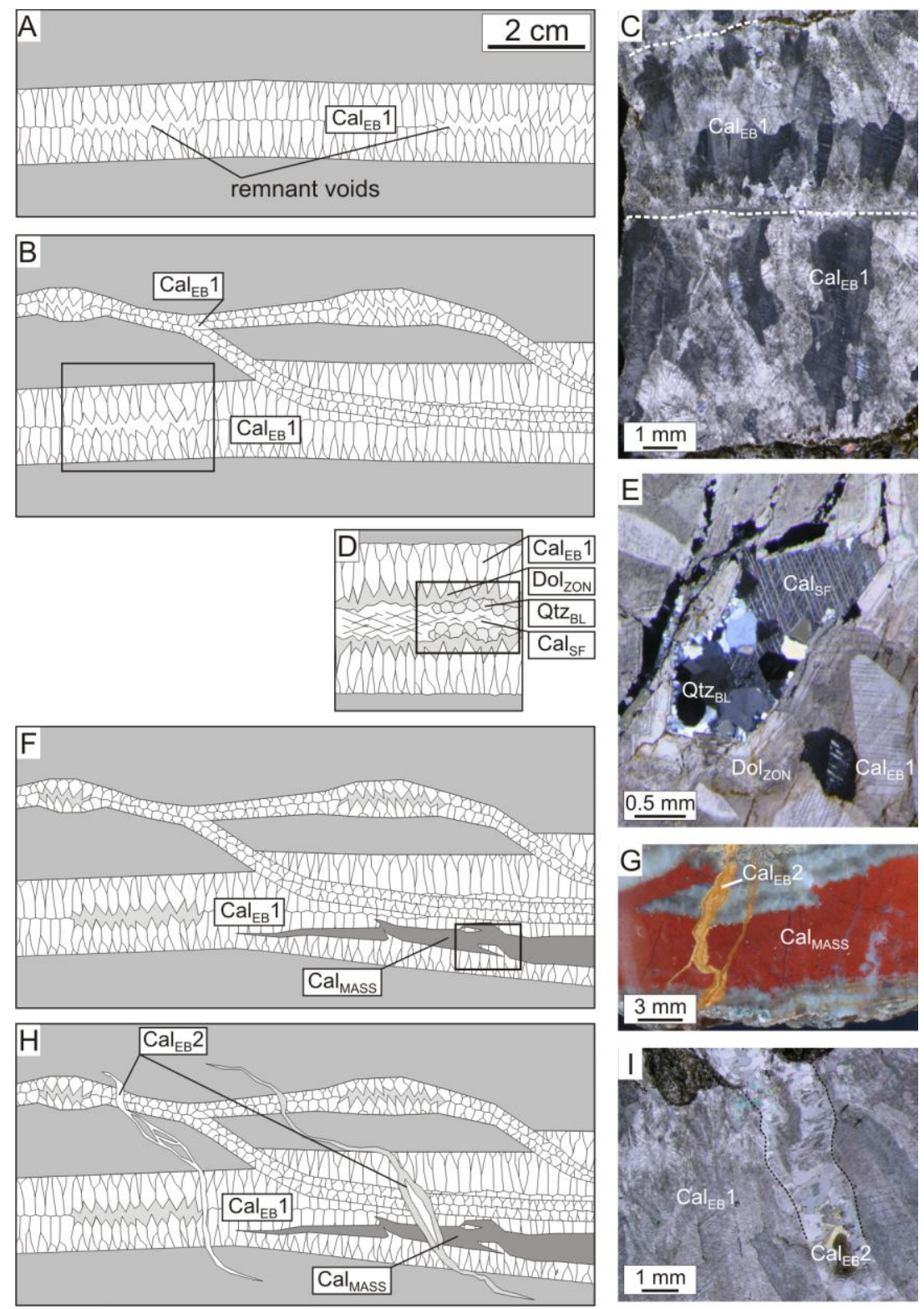

Figure 2.3. The vein system in the studied amphibolite body (Dabi et al. 2009a). (A, B) Precipitation of $\mathrm{Cal}_{\mathrm{EB}} 1$ occurred in at least two phases, based on the braid-like vein configurations. Remnant voids were present after occlusion of the vein system. (C) Vein filled with younger generation of $\mathrm{Cal}_{\mathrm{EB}} 1$ (framed with dashed lines) cutting through an older vein of $\mathrm{Cal}_{\mathrm{EB}} 1$. (D, E) Remnant voids are filled with zoned dolomite $\left(\mathrm{Dol}_{\mathrm{ZON}}\right)$, blocky quartz $(\mathrm{Qtz}, \mathrm{BL})$ and massive space-filling calcite $\left(\mathrm{Cal}_{\mathrm{SF}}\right)$. $(\mathrm{F}, \mathrm{G})$ Precipitation of the red massive calcite $\left(\mathrm{Cal}_{\mathrm{MASS}}\right)$ owing to reopening of the vein system. Limonite-stained calcite $\left(\mathrm{Cal}_{\mathrm{EB}} 2\right)$ cuts through red massive calcite. $(\mathrm{H}, \mathrm{I})$ Late synaxial calcite $\left(\mathrm{Cal} \mathrm{EB}^{2}\right)$ cuts earlier phases.

The first vein-filling generation is syntaxial calcite consisting of white, intensely twinned elongate blocky crystals $\left(\mathrm{Cal}_{\mathrm{EB}} 1\right.$, Fig. 2.3A-C, Dabi et al., 2009a). $\mathrm{Cal}_{\mathrm{EB}} 1$ makes up the 
majority of vein-filling minerals within the samples studied and evolved in at least two steps based on the braid-like configuration of the veins (Fig. 2.3B,C). Circulation of parent fluids ceased before the precipitated mineral completely filled the fractures, leaving closed voids in the centre (referred to as remnant voids, Fig. 2.3A,B). Vein occlusion in conjunction with a syntaxial texture is characteristic of advective transport and channelised flow (Lee et al., 1996; Hilgers and Urai, 2002b; Hilgers et al., 2003). Cathodoluminescence image analysis reveals swarms of orange luminescent microveins (Fig. 2.4A) and red luminescent patches within adjacent crystals of elongate blocky calcite (Fig. 2.4B). $\mathrm{Cal}_{\mathrm{EB}} 1$ calcite displays intense twinning. (G. Dabi, T. M. Tóth and F. Schubert, unpublished conference abstract, 2006) described latent oscillatory patterns subparallel with the crystal growth directions in the $\mathrm{Cal}_{\mathrm{EB}} 1$ crystals, using UV-fluorescent microscopy.
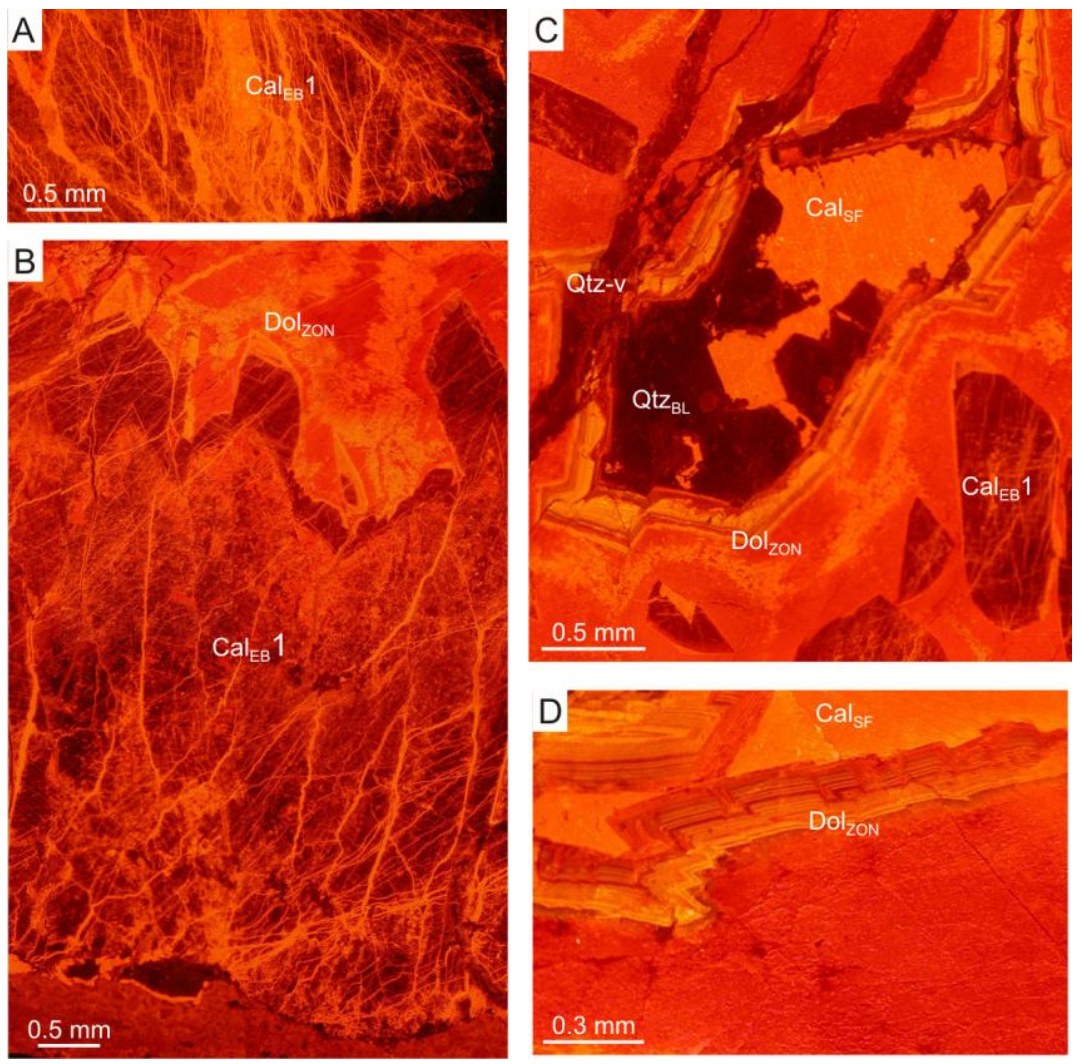

Figure 2.4. Cathodoluminescence microscope images of the different textural types in the amphibolites crosscutting veins. (A) Orange luminescent microvein swarm cutting through syntaxial calcite $\left(\mathrm{Cal}_{\mathrm{EB}} 1\right)$, displaying brecciation of the vein system. (B) Nonluminescent syntaxial calcite $\left(\mathrm{Cal}_{\mathrm{EB}} 1\right)$ and red luminescent zoned dolomite (Dol ${ }_{\mathrm{ZON}}$ ). Neighbouring crystals of $\mathrm{Cal}_{\mathrm{EB}} 1$ are transected by red luminescent patches, suggesting percolation of a dolomitising fluid along the preceding vein system. Orange luminescent alteration of $\mathrm{Cal}_{\mathrm{EB}} 1$ crystals along grain boundaries and in dolomite suggests pervasion of fluid from the vein-wall interface towards remnant voids. (C) Cathodoluminescence image of a remnant void segment with zoned dolomite (Dol $\mathrm{ZON}_{\mathrm{ZN}}$ ), nonluminescent blocky quartz $\left(\mathrm{Qtz}_{\mathrm{BL}}\right)$, veins filled with quartz $(\mathrm{Qtz}-\mathrm{v})$ and massive space-filling calcite $\left(\mathrm{Cal} \mathrm{SF}_{\mathrm{SF}}\right)$. (D) Oscillatory zonation in zoned dolomite $\left(\mathrm{Dol}_{\mathrm{ZON}}\right)$. 
Zoned dolomite (Dol ${ }_{\mathrm{ZON}}$ ) was precipitated in the closed remnant voids and grew syntaxially on pre-existing calcite scalenohedrons (Fig. 2.3D,E). Growth in these voids supposes percolation of parent fluids along a pre-existing vein system filled with $\mathrm{Cal}_{\mathrm{EB}} 1$. Red luminescent patches, typical of dolomite, within the earlier vein calcite (Fig. 2.4B) further hint at percolation through the pre-existing vein system. These patches are interpreted to be indicative of metasomatic alteration of the pre-existing $\mathrm{Cal}_{\mathrm{EB}} 1$ calcite along the percolation paths of the Dolzon parent fluid. Cathodoluminescence image analysis reveals oscillatory subzones of the dolomite (Fig. 2.4C,D).

In the next phase of remnant void-filling, syntaxial blocky quartz was precipitated (Qtz $\mathrm{BL}$, Fig. 2.3D,E), the texture of which is characteristic of advective flow (Bons, 2000; Hilgers and Urai, 2002b; Hilgers et al., 2003). The presence of thin $(\sim 30 \mu \mathrm{m})$ microveins filled with quartz also suggests advective flow of the parent fluid, with quick occlusion of the flow pathways suggested by the sporadic occurrence of the blocky quartz.

Filling of remnant voids was completed with precipitation of a massive calcite (referred to as space-filling calcite, $\mathrm{Cal}_{\mathrm{SF}}$, Fig. 2.3D,E). Based on its orange luminescent colour (Fig. 2.4C,D) and the presence of swarms of orange cathodoluminescent microveins (Fig. 2.4A) transecting crystals of earlier elongate blocky calcite and zoned dolomite, its parent solution was associated with brecciation of the preexisting vein system. This space-filling calcite displays less intense twinning than the preceding elongate blocky calcite.

In the next phase, reopening of the veins occurred and red, massive calcite was precipitated, containing solid inclusions of spherulitic haematite and quartz (referred to as massive calcite, $\mathrm{Cal}_{\text {MASS }}$, Fig. 2.3F,G).

The above-described veins in the amphibolite body are transected by 2 - to 3 -mm-thick veins filled with elongate blocky calcite $\left(\mathrm{Cal}_{\mathrm{EB}} 2\right.$, Fig. 2.3H,I). These later veins display syntaxial growth and are either partly or entirely limonite stained (Fig. 2.3G) or white. In some places, bands of limonite- stained calcite and clear white calcite occur together in the same vein. In this case, yellow limonite-stained bands occur at the vein-wall interface, suggesting precipitation prior to the precipitation of the clear calcite (syntaxial growth). Both of these calcites are untwinned and lack any signs of subsequent alteration.

\subsubsection{Vein textures in mylonitic gneiss}

Veins are prevalent in the mylonitic gneiss, although poor outcropping hinders exposure of 
mesoscale vein configurations. The outcrops from which samples were collected are represented in Fig. 2.1C.

Cathodoluminescence image analysis of the mylonitic gneiss revealed disseminated orange luminescent calcite in the rock matrix (Fig. 2.5A). Fourcade et al. (2002) ascribed disseminated carbonates as being precipitated from fluids that once pervaded the rock matrix. In the Mórágy Granite to the south, pervasive carbonatisation was ascribed to explosion- like escape of volatile components (Balla et al., 2009).

The mylonitic gneiss is generally cut by syntaxial elongate blocky calcite veins. These veins display intense twinning (Fig. 2.5B) and in some places display faulted segments. Where present, remnant voids in the middle of veins contain dolomite. Cathodoluminescence images reveal intense alteration of these veins (Fig. 2.5C), with a high degree of twinning and alteration suggesting early precipitation of the calcite and a common origin with $\mathrm{Cal}_{\mathrm{EB}} 1$.
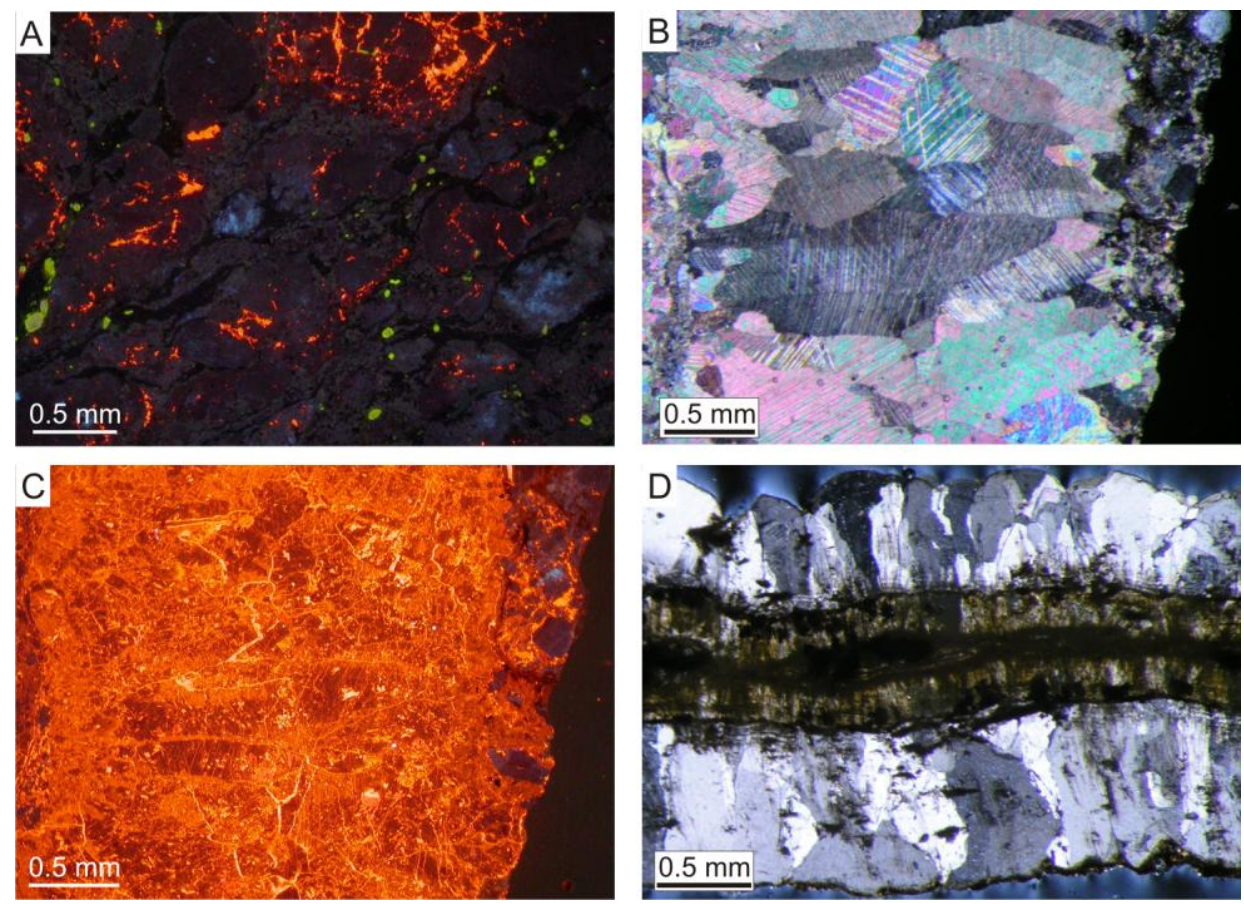

Figure 2.5. Cathodoluminescence and optical microscope images of different calcite phases in the gneissic rocks. (A) Orange luminescent calcite seams in mylonitic gneiss (feldspars display bluish, apatites green luminescence colour). (B) Syntaxial elongate blocky calcite vein in mylonitic gneiss $\left(\mathrm{Cal}_{\mathrm{EB}} 1\right)$ displaying intense twinning. (C) Cathodoluminescence microscope image revealing intense alteration of the nonluminescent $\mathrm{Cal}_{\mathrm{EB}} 1$. (D) Antitaxial vein in mylonitic gneiss. Band of limonite-stained calcite in the middle indicates that precipitation of limonite-stained calcite preceded that of the white clear calcite. Crystals widen towards the vein-wall interface and contain solid inclusion bands and trails dragged from the wall rock, indicating antitaxial growth.

Untwinned white antitaxial calcite veins $\left(\mathrm{Cal}_{\mathrm{ANT}}\right)$ with a maximum width of $\sim 5 \mathrm{~mm}$ are 
prevalent in the mylonitic gneiss (Fig. 2.2B). Dabi et al. (2009b) measured the homogenisation temperatures of primary fluid inclusions in the antitaxial veins. They found an extremely wide range of homogenisation temperatures (between 50 and $240{ }^{\circ} \mathrm{C}$ ), whichthey interpreted as caused by fluid-pressure fluctuation during vein development, and possibly stretching of the inclusions. The uniform salinities of the same inclusions, between 0.18 and $0.53 \% w \mathrm{NaCl}$ equivalent, suggest a common origin. In some places, antitaxial veins constitute well-developed vein systems, but generally they are parallel with the foliation, implying that mechanic anisotropy of the rock (Twiss and Moores, 1992) governed their formation. Calcite crystals in these veins display parallel (sometimes curved) grain boundaries or widen towards the vein-wall interface; that is, crystal boundaries diverge, suggesting growth competition (Bons, 2000; Fig. 2.5D). The zones of divergent grain boundaries contain bands and trails of solid inclusions (Ramsay, 1980; Hilgers and Urai, 2005). All display characteristic signs of antitaxial growth (Hilgers et al., 2001). In some places, these veins contain a medial, yellow limonite-stained band (Fig. 2.5D), indicating that precipitation of limonite-stained calcite preceded precipitation of clear white calcite (antitaxial growth). This order of precipitation is consistent with that of the $\mathrm{Cal}_{\mathrm{EB}} 2$ calcites and suggests their common origin. The parent fluids of veins displaying an antitaxial texture percolated through the host rock, according to Bons (2000), Hilgers and Urai (2002a) and Hilgers and Sindern (2005).

\subsection{Methods}

Fluid-inclusion studies were carried out at the Department of Mineralogy, Geochemistry and Petrology, University of Szeged, on a Linkam THMSG 600 heatingfreezing stage mounted on an Olympus BX41 microscope. Doubly polished 60- to $70-\mu \mathrm{m}$-thick chips were first mapped for fluid inclusions. Initial heating of samples was carried out to avoid the stretching of inclusions resulting from freezing the aqueous liquid phase. Metastable equilibrium (lack of a vapour phase at temperatures of liquid and vapour coexistence) during cooling after homogenisation is common in studied inclusions. This inhibits $T_{\mathrm{h}}$ measurements, especially at lower homogenisation temperatures (if homogenisation temperatures of inclusions are measured separately). Stepwise $1{ }^{\circ} \mathrm{C}$ heating was applied, checking all studied inclusions between steps both to avoid the loss of the vapour phase before homogenisation temperature measurement and to avoid stretching of inclusions at lower homogenisation temperatures. Final melting temperature measurements were undertaken via the cycling 
technique (Goldstein and Reynolds, 1994). Salinities are given according to Bodnar (1992). Calibration of the heating-freezing stage was carried out using synthetic inclusions of pure $\mathrm{H}_{2} \mathrm{O}\left[T_{\mathrm{m}}(\mathrm{Ice})=0{ }^{\circ} \mathrm{C}, T_{\mathrm{h}}=374{ }^{\circ} \mathrm{C}\right]$ and $\mathrm{H}_{2} \mathrm{O}-\mathrm{CO}_{2}$ inclusions $\left[T_{\mathrm{m}}\left(\mathrm{CO}_{2}\right)=-56.6{ }^{\circ} \mathrm{C}\right]$ entrapped in quartz.

Drilled calcite powder was used for stable-isotope measurements. Stable-isotope compositions of the evolved $\mathrm{CO}_{2}$ gas were measured by a ThermoFinnigan delta plus XP continuous-flow mass spectrometer, using a GASBENCH II preparation device as an inlet port, at the Institute for Geochemical Research. Results are expressed using standard d notation relative to $\mathrm{V}-\mathrm{PDB}$ for $\mathrm{C}$ and $\mathrm{V}-\mathrm{SMOW}$ for $\mathrm{O}$ in \%o. The reproducibility for both $\mathrm{C}$ and $\mathrm{O}$ isotope analyses is better than $0.15 \%$, based on replicate measurements of standards and samples.

Calculation of the oxygen isotope composition of parent fluids from the appropriate fractionation equation and the oxygen isotope composition of the mineral requires formation temperature to be very well constrained. The use of microthermometry and resulting homogenisation temperature data gives only a minimum crystallisation temperature. Increasing the temperature of a fluid with a given isotope composition would decrease the isotope composition of the precipitating calcite. And vice versa, by assuming a higher crystallisation temperature, the calculated fluid isotope composition is pushed towards lessdepleted compositions. Thus, fluid isotope compositions calculated using measured homogenisation temperatures are considered here as being a minimum value of the fluids original composition.

\subsection{Results}

\subsubsection{Fluid-inclusion petrography and microthermometry}

Fluid-inclusion measurements were performed on crystals of the $\mathrm{Cal}_{\mathrm{EB}} 1, \mathrm{Dol}_{\mathrm{ZON}}$ and $\mathrm{Cal}_{\mathrm{SF}}$ phases. Final melting temperature data were successfully gained only in a subset of the homogenisation temperature measurements as a result of the frequent disappearance of vapour bubbles after homogenisation or freezing.

Fluid inclusions of $\mathrm{Cal}_{\mathrm{EB}} 1$ form cloudy inclusion bands aligned along parallel growth zones in line with the scalenohedral facets of the host calcite crystals (Fig. 2.6A). Based on this textural feature, assemblages of these fluid inclusions are regarded as primary in origin (Goldstein and Reynolds, 1994). Fluid inclusions of these primary assemblages are irregular 
in shape, with their longest dimension varying between 5 and $10 \mu \mathrm{m}$. Two-phase liquidvapour aqueous inclusions occur sparsely amongst the one-phase inclusions. Fluid inclusions of differing $\varphi \mathrm{V}\left(25^{\circ} \mathrm{C}\right)$ value (the ratio of inclusion volume to the volume of the vapour phase in the fluid inclusion at room temperature) do not show any spatial clustering within the cloudy inclusion zones. Homogenisation temperatures of two-phase inclusions in the zone of primary inclusions are between 50 and $105^{\circ} \mathrm{C}(\mathrm{n}=39)$, with a maximum frequency between 75 and $90{ }^{\circ} \mathrm{C}$ (Fig. 2.7A). Final melting temperatures are between -2.5 and $-1.6^{\circ} \mathrm{C}(\mathrm{n}=4)$, indicating a salinity range between 2.74 and $4.2 \% \mathrm{w} \mathrm{NaCl}$ equivalent.
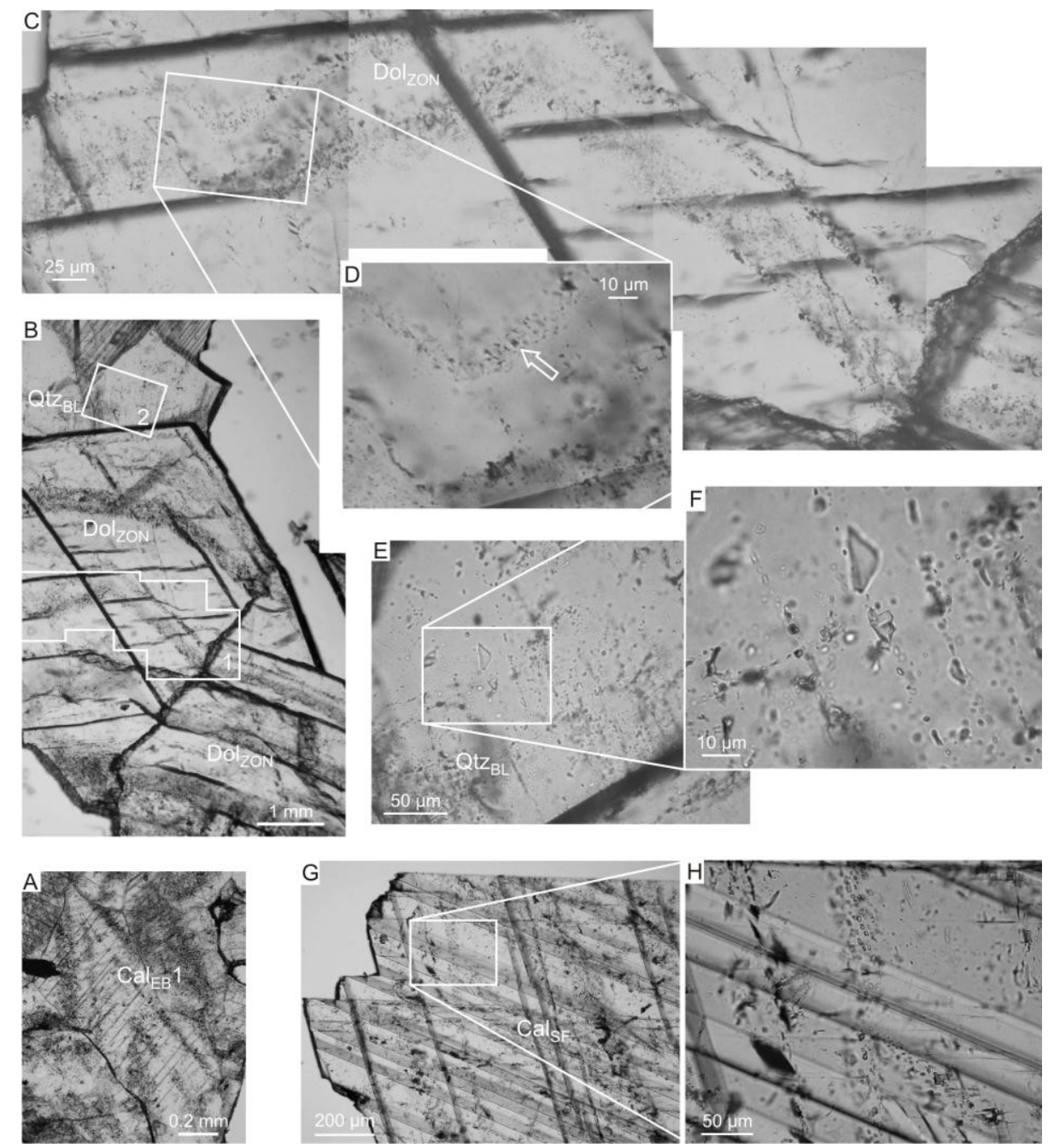

Figure 2.6. Fluid-inclusion petrography of the vein-filling phases. (A) Primary fluid-inclusion assemblages parallel to scalenohedral facets of a $\mathrm{Cal}_{\mathrm{EB}} 1$ crystal. (B-D) Primary fluid-inclusion assemblages parallel to rhombohedral facets of a Dol zoN crystal. Inset 1 in B indicates position of $\mathrm{C}$, inset 2 indicates position of $6 \mathrm{E}$. (E, F) Primary one-phase aqueous fluid-inclusion assemblage in a blocky quartz crystal. (G, H) Secondary inclusion trails in massive calcite $\left(\mathrm{Cal}_{\mathrm{SF}}\right)$.

Zoned dolomite contains two-phase aqueous inclusions in parallel bands aligned with 
rhombohedral crystal facets (Fig. 2.6B,C). Inclusions generally display negative crystal shapes with a longest dimension of up to $\sim 5 \mu \mathrm{m}$ (Fig. 2.6D). Homogenisation temperatures range between 75 and $120^{\circ} \mathrm{C}(\mathrm{n}=15)$, with a maximum frequency between 95 and $100{ }^{\circ} \mathrm{C}$ (Fig. 2.7B). Final ice-melting temperature measurements were hindered by both the lack of vapour phase nucleation after $T_{\mathrm{h}}$ measurements and the loss of the vapour phase after freezing.
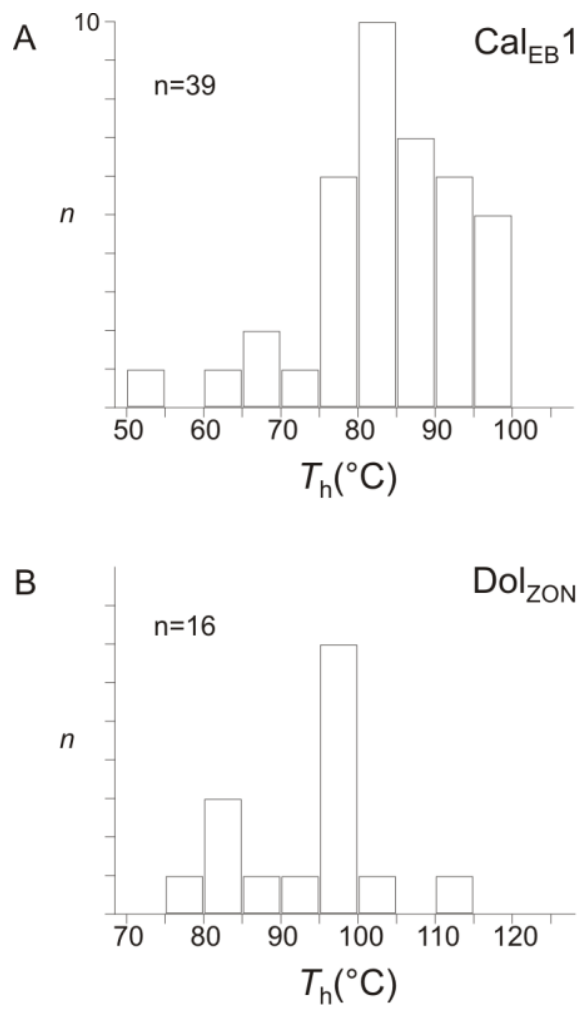

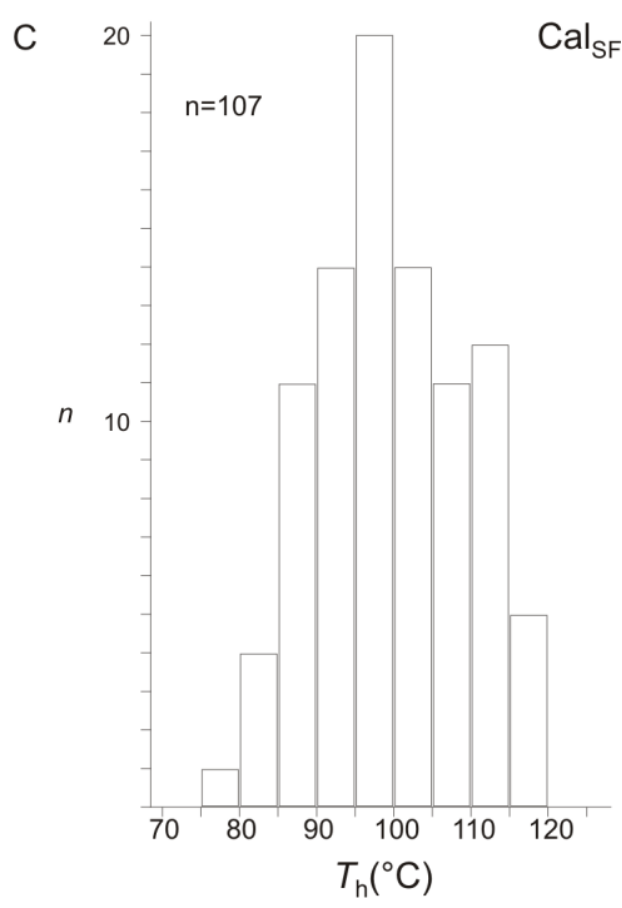

Figure 2.7. Histograms of measured $T_{\mathrm{h}}$ data in syntaxial calcite $\left(\mathrm{Cal}_{\mathrm{EB}} 1, \mathrm{~A}\right)$, zoned dolomite $\left(\right.$ Dol $\left._{\mathrm{ZON}}, \mathrm{B}\right)$ and massive calcite $\left(\mathrm{Cal}_{\mathrm{SF}}, \mathrm{C}\right)$.

The blocky quartz phase $\left(\mathrm{Qtz}_{\mathrm{BL}}\right)$ contains all-liquid aqueous inclusions (as inferred from unpublished Raman spectroscopy data) which are seated in irregular groups (Fig. 2.6E,F) and can be interpreted as primary in origin. Inclusions lengths are between 3 and $20 \mu \mathrm{m}$.

The massive space-filling calcite $\left(\mathrm{Cal}_{\mathrm{SF}}\right)$ contains two phase liquid-vapour aqueous inclusions. Sparsely occurring isolated inclusions are interpreted as primary in origin, with lengths ranging from 2 to $20 \mu \mathrm{m}$ and generally irregular shapes. These inclusions homogenise to liquid phase between 85 and $120{ }^{\circ} \mathrm{C}(\mathrm{n}=92$, Fig. 2.7C), while their final ice-melting temperatures range between -2.6 and $-0.5{ }^{\circ} \mathrm{C}(\mathrm{n}=25$, Fig. 2.8). Inclusions occur along trails 
crosscutting the massive calcite, generally having a negative crystal shape (Fig. 2.6G,H), and can be interpreted as secondary in origin. Secondary fluid inclusions belong to two distinct groups based on their final melting temperatures (Fig. 2.8). The first group has final melting temperatures between -2.1 and $-1.5{ }^{\circ} \mathrm{C}(\mathrm{n}=7)$, in the range of primary inclusions, and homogenisation temperatures between 84 and $105{ }^{\circ} \mathrm{C}$, while the second group have final melting temperatures between -4.9 and $-3.1{ }^{\circ} \mathrm{C}(\mathrm{n}=13)$, with similar homogenisation temperatures between 82 and $97^{\circ} \mathrm{C}$.

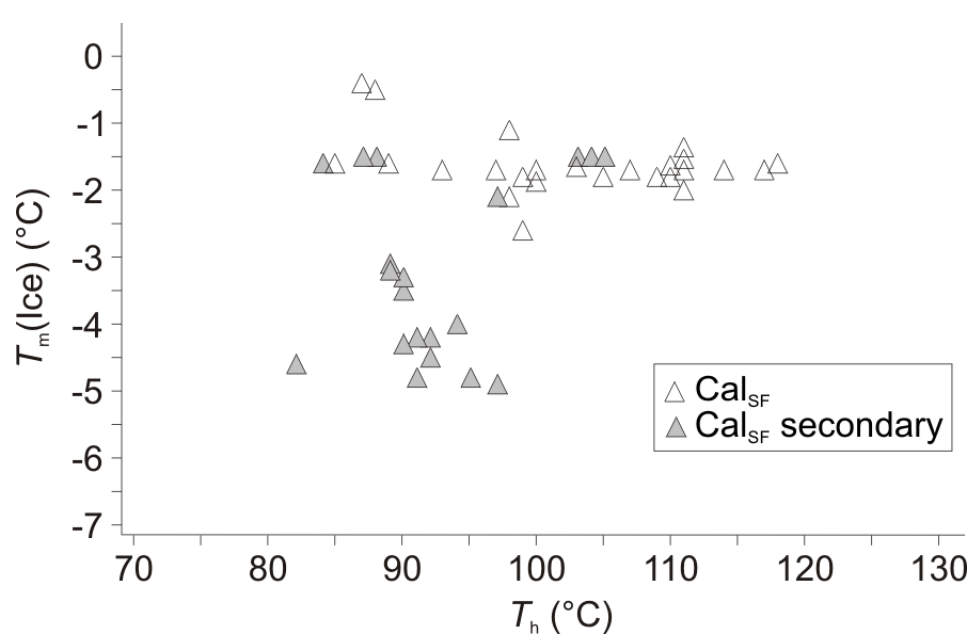

Figure 2.8. $T_{\mathrm{h}}-T_{\mathrm{m}}$ (Ice) diagram of $\mathrm{Cal}_{\mathrm{SF}}$ inclusions.

\subsubsection{Carbon and oxygen isotope composition of veins}

The carbon and oxygen isotope compositions of the studied veins are presented in Table 2.1. Graphical presentation of these results (Fig. 2.9A) demonstrates that samples of different texture display different isotope compositions.

Elongate blocky calcite ( $\mathrm{Cal}_{\mathrm{EB}} 1$, including data from one gneiss vein sample) displays the least depleted isotope ratios and a wide range of $\delta^{18} \mathrm{O}$ values between 23.2 and $30.3 \%$ and $\delta^{13} \mathrm{C}$ values between $0.3 \%$ and $3.3 \%$ (Fig. 2.9A). The samples analysed show a trend towards more depleted isotope values. Within-vein variations are up to $3.8 \% \delta^{18} \mathrm{O}$ and up to $1.4 \%$ o $\delta^{13} \mathrm{C}$, and the data do not show any consistent relationship to distance from the vein walls. Zoned dolomite (Dol ZoN) displays $\delta^{18} \mathrm{O}$ values between $21.9 \%$ and $25.1 \%$ and $\delta^{13} \mathrm{C}$ values between $-2.9 \%$ and $-1.0 \%$ (Fig. $2.9 \mathrm{~A}$ ). The $\delta^{18} \mathrm{O}$ values of spacefilling calcite $\left(\mathrm{Cal}_{\mathrm{SF}}\right)$ range from $18.2 \%$ to $19.3 \%$, and $\delta^{13} \mathrm{C}$ values from $-2.3 \%$ o to $-1.9 \%$. Late syntaxial veins $\left(\mathrm{Cal}_{\mathrm{EB}} 2\right)$ display $\delta^{18} \mathrm{O}$ values ranging from $20.0 \%$ to $21.3 \%$ and $\delta^{13} \mathrm{C}$ values ranging from $-10.6 \%$ o to - 
9.4\%, with more depleted values in limonite-stained samples. Antitaxial veins $\left(\mathrm{Cal}_{\mathrm{ANT}}\right)$ in gneiss display $\delta^{18} \mathrm{O}$ values ranging from $20.6 \%$ to $22.7 \%$ and $\delta^{13} \mathrm{C}$ values between $-9.8 \%$ and $-6.5 \%$, with a trend towards the more depleted values of late syntaxial veins $\left(\mathrm{Cal}_{\mathrm{EB}} 2\right)$ in amphibolite (Fig. 2.9A).
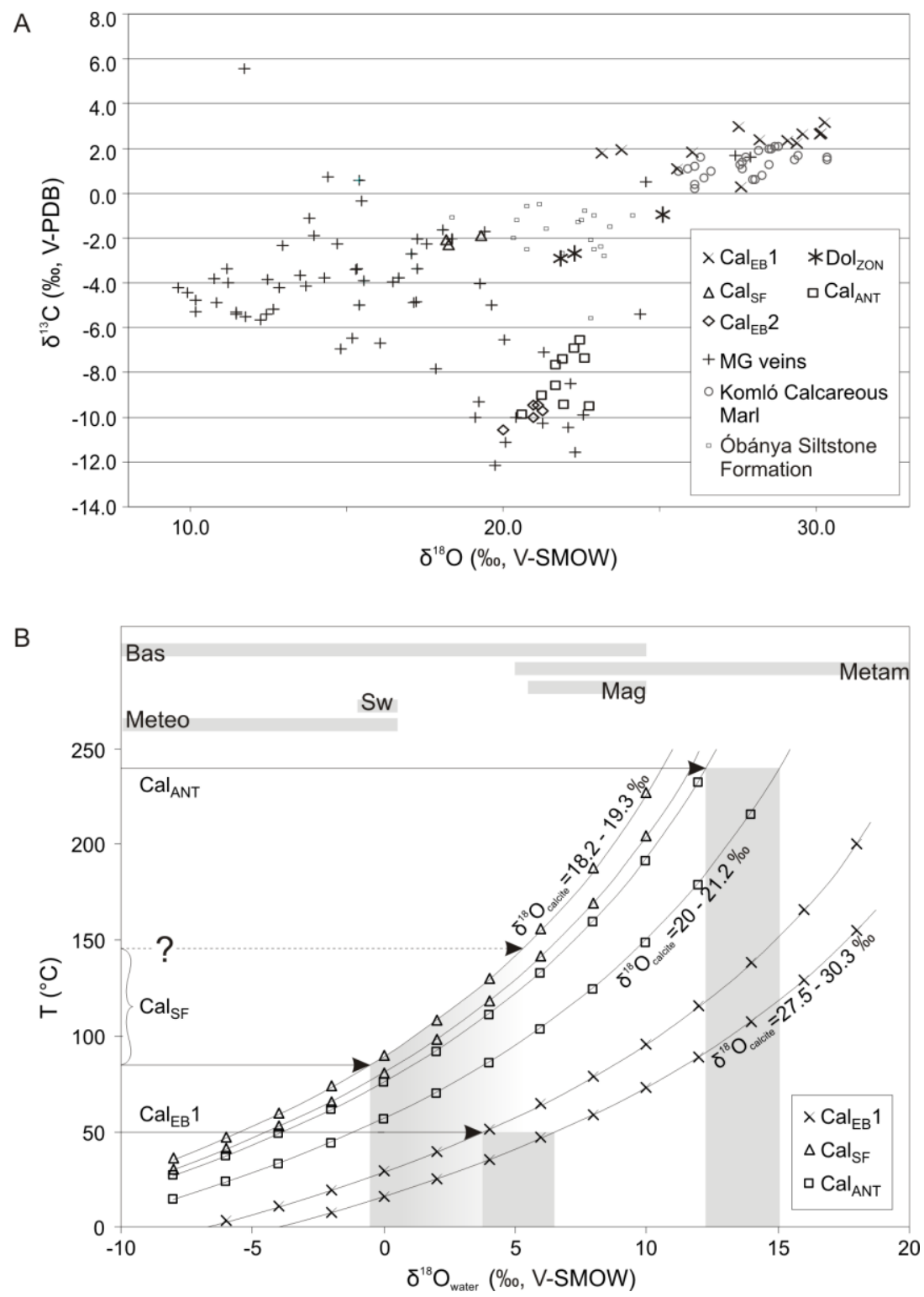

Figure 2.9. (A) Stable-isotope compositions of vein calcites. Vein isotope compositions of the Mórágy Granite Formation to the south (MG veins, Kovács-Pálffy \& Földvári, 2003), the Komló Calcareous Marl Formation (Raucsik, 1997) and the Óbánya Siltstone Formation (Varga et al. 2007) are also indicated. (B) Temperature$\delta^{18} \mathrm{O}_{\text {water }}$ plot of vein calcites. The curved lines represent $\delta^{18} \mathrm{O}$ values of samples of different textural types. Knowledge of the formation temperature permits the calculation of the oxygen isotope composition of the parent fluid (horizontal axis) using the relevant fractionation equations. The isotopic range of fluids of different origin is also indicated (Taylor, 1987): Meteo., meteoric water; Bas., basinal brine; Sw., seawater; Mag., magmatic; Metam., metamorphic. 


\begin{tabular}{|c|c|c|}
\hline Sample (type) & $\delta^{13} \mathrm{C}(\% \circ \mathrm{V}-\mathrm{PDB})$ & $\delta^{18} \mathrm{O}(\% \circ \mathrm{V}-\mathrm{SMOW})$ \\
\hline Amf01 (Cal $\left.{ }_{E B} 2\right)$ & -9.4 & 21.0 \\
\hline Amf01 (Cal $\left.\mathrm{EB}_{2} 2, \mathrm{lim}.\right)$ & -9.7 & 21.3 \\
\hline $\mathrm{Amf02}\left(\mathrm{Cal}_{\mathrm{EB}} 1\right)$ & 2.4 & 28.2 \\
\hline Amf02 (Cal $\left.\left.\right|_{E B} 1\right)$ & 1.8 & 26.1 \\
\hline Amf03 (Cal $\left.{ }_{\mathrm{EB}} 1\right)$ & 3.0 & 27.6 \\
\hline Amf03 $\left(\mathrm{Cal}_{\mathrm{EB}} 1\right)$ & 2.0 & 23.8 \\
\hline Amf03 (Cal $\left.{ }_{\mathrm{SF}}\right)$ & -1.9 & 19.3 \\
\hline Amf03 (Dol $\left.{ }_{\text {ZoN }}\right)$ & -2.9 & 21.9 \\
\hline Amf03 (Cal $\left.\left.\right|_{\mathrm{EB}} 2, \lim .\right)$ & -10.6 & 20.0 \\
\hline Amf08 $\left(\mathrm{Cal}_{\mathrm{SF}}\right)$ & -2.3 & 18.2 \\
\hline Amf08 $\left(\mathrm{Cal}_{\mathrm{SF}}\right)$ & -2.1 & 18.2 \\
\hline Amf09 (Cal $\left.{ }_{\mathrm{EB}} 1\right)$ & 0.3 & 27.6 \\
\hline Amf09 (Cal $\left.\left.\right|_{E B} 1\right)$ & 2.7 & 29.6 \\
\hline $\operatorname{Amf10}\left(\mathrm{Cal}_{\mathrm{EB}} 1\right)$ & 1.8 & 23.2 \\
\hline $\operatorname{Amf10}\left(\mathrm{Cal}_{\mathrm{EB}} 1\right)$ & 1.1 & 25.6 \\
\hline $\operatorname{Amf11}\left(\mathrm{Cal}_{\mathrm{EB}} 1\right)$ & 2.4 & 29.1 \\
\hline $\operatorname{Amf11}\left(\mathrm{Cal}_{\mathrm{EB}} 1\right)$ & 2.7 & 30.1 \\
\hline Amf11 (Cal $\left.\left.\right|_{\mathrm{EB}} 1\right)$ & 2.3 & 29.4 \\
\hline $\operatorname{Amf11}\left(\mathrm{Cal}_{\mathrm{EB}} 1\right)$ & -9.5 & 21.1 \\
\hline $\operatorname{Amf10}\left(\mathrm{Cal}_{\mathrm{EB}} 2\right)$ & 3.2 & 30.3 \\
\hline AmfUNK (Cal $\left.{ }_{E B} 2\right)$ & -10.0 & 21.0 \\
\hline VOL01vF (Cal $\left.{ }_{\mathrm{ANT}}\right)$ & -9.9 & 20.6 \\
\hline VOL01vF (Cal $\left.{ }_{\mathrm{ANT}}\right)$ & -9.4 & 21.9 \\
\hline Amf03 (Dol $\left.{ }_{\text {ZoN }}\right)$ & -2.7 & 22.3 \\
\hline Amf03 (Dol & -1.0 & 25.1 \\
\hline VOL02vE (Cal $\left.{ }_{E B} 1\right)$ & 2.7 & 30.2 \\
\hline $\operatorname{KOV01vN}\left(\mathrm{Cal}_{\mathrm{ANT}}\right)$ & -7.7 & 21.7 \\
\hline KOV01vH (Cal $\left.{ }_{\mathrm{ANT}}\right)$ & -6.9 & 22.3 \\
\hline JUH01v1 (Cal $\left.{ }_{\text {ANT }}\right)$ & -7.4 & 21.9 \\
\hline JUH01v1 (Cal ANT $\left._{1}\right)$ & -7.4 & 22.6 \\
\hline JUH01v2 (Cal $\left.{ }_{\mathrm{ANT}}\right)$ & -6.5 & 22.5 \\
\hline VOL02vB (Cal $\left.{ }_{A N T}\right)$ & -9.5 & 22.7 \\
\hline GGR01v1 (Cal $\left.{ }_{\text {ANT }}\right)$ & -9.0 & 21.2 \\
\hline GGR01vX (Cal $\left.{ }_{\text {ANT }}\right)$ & -8.6 & 21.7 \\
\hline
\end{tabular}

Table 2.1. Oxygen and carbon isotope compositions of studied veins

\subsection{Discussion}

A six-stage palaeohydrological evolution model reconstructed on the basis of vein textures alone (Dabi et al., 2009a) is further confirmed by microthermometric and stable-isotope data. This interpretation is presented in conjunction with textural observations. Textural features, 
isotope compositions and minimum crystallisation temperatures of the studied vein-filling phases are summarised in Table 2.2.

\begin{tabular}{|c|c|c|c|c|c|c|}
\hline & \multicolumn{2}{|c|}{ Host rock/texture } & \multirow[b]{2}{*}{ Cathodoluminescence } & \multicolumn{2}{|c|}{ Isotope composition } & \multirow{2}{*}{$\begin{array}{c}\text { Crystallization } \\
\text { temperature }\end{array}$} \\
\hline & Amphibolite & Gneiss & & \%о (SMOW) & \%o (PDB) & \\
\hline $\mathrm{CaI}_{\mathrm{EB}} 1$ & Syntaxial & Syntaxial & $\begin{array}{l}\text { Brecciated, } \\
\text { metasomatized }\end{array}$ & 23.2 to 30.3 & 0.3 to 3.3 & Max. $50^{\circ} \mathrm{C}$ \\
\hline Dol $_{\text {ZON }}$ & Syntaxial & & Red, oscillatory & 21.9 to 25.1 & -2.9 to -1.0 & Min. $75^{\circ} \mathrm{C}$ \\
\hline $\mathrm{Qtz}_{\mathrm{BL}}$ & Syntaxial & & & & & Max. $50^{\circ} \mathrm{C}$ \\
\hline $\mathrm{Cal}_{\mathrm{SF}}$ & Massive & & Orange & 18.2 to 19.3 & -2.3 to -1.9 & Min. $85^{\circ} \mathrm{C}$ \\
\hline $\mathrm{Cal}_{\text {MASS }}$ & Massive & & Dull & & & $\operatorname{Min} .82^{\circ} \mathrm{C}$ \\
\hline $\mathrm{Cal}_{\mathrm{EB}} 2$ & Syntaxial & & Dull (limonite stained) & 20.0 to 21.3 & -10.6 to -9.4 & $240(?)^{\circ} \mathrm{C}$ \\
\hline $\mathrm{Cal}_{\mathrm{ANT}}$ & & Antitaxial & & 20.6 to 22.7 & -9.9 to -6.5 & \\
\hline
\end{tabular}

Table 2.2. Features of the successive vein-filling phases. crystallization temperatures are minima, as suggested by the lowest measured homogenisation temperature of the fluid inclusion.

\subsubsection{Elongate blocky calcite $\left(\mathrm{Cal}_{E B} \mathrm{I}\right)$}

Syntaxial elongate blocky calcite veins $\left(\mathrm{Cal}_{\mathrm{EB}} 1\right)$ are prevalent in both the amphibolite body and the outcrops of mylonitic gneiss, with distinct stable-isotope compositions suggesting similar origins. The interpretation of early occurrence in the reconstructed sequence is based on their textural relationship with subsequent carbonates: crosscutting in the amphibolite and intense twinning of syntaxial vein calcite both in the amphibolite and in the mylonitic gneiss.

Cross-cutting relations of the $\mathrm{Cal}_{\mathrm{EB}} 1$ veins in the studied outcrop indicate at least two fluid-flow events, whereas vein textures indicate quasi continuous growth and uninterrupted fluid flow. The $\mathrm{Cal}_{\mathrm{EB}} 1$ calcites display a range of stable-isotope compositions too wide to be interpreted as inherited from and determined by a homogenous source with which the fluid reached equilibrium. Oxygen and carbon isotope data of Cox (2007) indicate that externally derived fluids introduced into a developing fracture system may lead to variable isotopic compositions of fluids because of variable buffering by host rock, as also described by Lassey and Blattner (1988). This process can lead to significantly different isotopic compositions within spatially and temporally related veins. These deviations can be caused by variations of the reactive path length, an increase or decrease in the effective reactive surface, or variations in flow rate (Cox, 2007; Barker et al., 2009). Thus, the wide range of oxygen and carbon isotope compositions and within-vein variations suggest that the parent fluids of the texturally uniform veins reached the site of precipitation through dynamically changing pathways. This 
can result from partial occlusion of the vein system because of mineral precipitation (Lee and Morse, 1999; Hilgers and Urai, 2002b) that diverts the fluid to pathways with different reactive lengths and thus different degrees of fluid-rock interaction (Barker et al., 2009). The measured differences in the isotope composition along mm-scale distances imply different fluid-flow pathways in the vein system. The wide range of measured isotopic compositions indicates that the reactive path lengths were too short for the fluids to attain isotopic equilibrium with the host rock (Barker et al., 2009). Isotope data from transecting veins may be more representative of the unbuffered parent fluid because, according to the model of Lassey and Blattner (1988), the fluid-rock system becomes more fluid-buffered during its evolution, so the late veins of a vein generation are less rock-buffered. The $\delta^{18} \mathrm{O}$ and $\delta^{13} \mathrm{C}$ values of late $\mathrm{Cal}_{\mathrm{EB}} 1$ veins are the highest amongst the samples, suggesting that the heaviest isotope compositions reflect equilibrium with the least rock-buffered fluids.

The presence of one-phase fluid inclusions in primary assemblages of $\mathrm{Cal}_{\mathrm{EB}} 1$ suggests low-temperature precipitation $\left(<50{ }^{\circ} \mathrm{C}\right.$, Goldstein and Reynolds, 1994). The measured twophase inclusions are interpreted to be primary inclusions stretched during subsequent thermal evolution of the MZ, because they do not show any spatial clustering within the cloudy inclusion zones. Thus, the measured homogenisation temperatures of these inclusions do not apply to the temperature of crystallisation, but their final melting temperatures are valid for the salinity of the parent fluid (between 2.74 and $4.2 \% w \mathrm{NaCl}$ equivalent). Applying a crystallisation temperature of $50{ }^{\circ} \mathrm{C}$ and using the fractionation equation of O'Neil et al. (1969), the calculated oxygen isotope composition of the parent fluid is between 3.8\%o and 6.6\% (Fig. 2.9B). This value suggests a fluid of basinal, metamorphic or magmatic origin (Taylor, 1987; Blyth et al., 2000), or a fluid exchanged with rock. Liquid aqueous inclusions imply crystallisation temperatures near or below $50{ }^{\circ} \mathrm{C}$ (Goldstein and Reynolds, 1994), which casts doubt upon a magmatic or metamorphic origin. If the fluid is of metamorphic or magmatic origin, a temperature drop is implied, which is inconsistent with calcite precipitation, because the decrease in fluid temperature at constant salinity increases calcite solubility, and vice versa (Parry, 1998). Isothermal precipitation is possible during decompression of fluid that is saturated with dissolved carbon dioxide (Parry, 1998). Such a process might occur if a rock-fracturing event were to open new porosity, lower fluid pressure and cause effervescence of dissolved $\mathrm{CO}_{2}$. The similarity of the isotopic composition of $\mathrm{Cal}_{\mathrm{EB}} 1$ calcite to Mesozoic carbonaceous formations to the north, and to marine carbonates in general (Prokoph et al., 2008), may provide a possible clue as to the fluid source. According 
to the best knowledge of the authors, stable-isotope data have been published only from the Toarcian Óbánya Siltstone Formation (Varga et al., 2007) and the Toarcian - Bajocian Komló Calcareous Marl Formation (Raucsik, 1997; Fig. 2.9A). The similarity between the vein isotopic compositions and the latter data suggests that the parent fluid is related to Mesozoic carbonaceous sediments. If so, because deposition of carbonaceous sediments began during the Middle Triassic (Anisian Lapisi Limestone Formation), the $\mathrm{Cal}_{\mathrm{EB}} 1$ fluid-flow event could not have occurred before the Anisian.

A syntaxial elongate blocky texture is indicative of advective fluid transport through a fracture system that tends to clogg, as demonstrated by the experimental studies of Hilgers and Urai (2002b) and Hilgers et al. (2003). This process produces partially filled fracture systems, with decreasing filling with distance from the obstruction, because of a shift in saturation state along the flow pathway. Lee et al. (1996) and Lee and Morse (1999) pointed out that fairly uniform deposition of calcite can occur only if the flow is quite rapid (tens to thousands of $\mathrm{cm} \mathrm{h-1),} \mathrm{because} \mathrm{of} \mathrm{the} \mathrm{risk} \mathrm{of} \mathrm{high} \mathrm{supersaturation.} \mathrm{(G.} \mathrm{Dabi,} \mathrm{T.} \mathrm{M.} \mathrm{Tóth} \mathrm{and} \mathrm{F.}$ Schubert, unpublished conference abstract, 2006) described oscillatory zoning in grains of $\mathrm{Cal}_{\mathrm{EB}} 1$. The presence of latent oscillation along lines subparallel to the growth directions indicates surface enrichment during mineral growth and that the growth rate of the crystal was greater than the diffusion rate of the trace element in the surface layer at the temperature of crystallisation (Watson, 1996, 2004). (G. Dabi, T. M. Tóth and F. Schubert, unpublished conference abstract, 2006) detected the oscillatory zoning with UV luminescent microscopy, so the trace element responsible for the oscillation is not known. The lack of data on the diffusion rate of the oscillatory trace element hampers conclusions on crystal growth rates and saturation.

\subsubsection{Zoned dolomite (Dol $\left.{ }_{\text {ZON }}\right)$}

Red luminescent patches on the $\mathrm{Cal}_{\mathrm{EB}} 1$ cathodoluminescence images suggest that the parent fluid of Dolzon percolated through grains of $\mathrm{Cal}_{\mathrm{EB}} 1$, at least locally within the amphibolite body. Dolomite veins were not found by the authors, although it is possible that they exist, according to unpublished field reports (S. Józsa, Eötvös University, oral communication, 2007). Crystallisation of the zoned dolomite occurred in closed remnant voids, as suggested by the lack of dolomite veins cutting through crystals of $\mathrm{Cal}_{\mathrm{EB}} 1$. Applying a crystallisation temperature of $95{ }^{\circ} \mathrm{C}$ (the minimum crystallisation temperature according to 
the distribution of the measured $T_{\mathrm{h}}$ data, Fig. 2.7A) and using Northrop and Clayton's (1966) fractionation equation for dolomite (in Friedman and O'Neil, 1977), the minimum oxygen isotope composition of the parent fluid is between $-0.2 \%$ and $3.0 \%$, indicative of a basinal brine, seawater or meteoric water (Taylor, 1987).

\subsubsection{Blocky quartz $\left(Q t z_{B L}\right)$}

Primary, all-liquid fluid inclusions in the blocky quartz Qtz $\mathrm{BL}_{\mathrm{BL}}$ suggest low-temperature entrapment of fluids and crystallisation. All-liquid fluid inclusions are indicative of lowtemperature fluids (below $50{ }^{\circ} \mathrm{C}$, Goldstein and Reynolds, 1994) and possible meteoric origin. The syntaxial texture and the presence of thin veins transecting preceding phases suggest fracture-channelised flow of the parent fluid.

\subsubsection{Space-filling calcite $\left(\mathrm{Cal}_{S F}\right)$}

Massive space-filling calcite was found only in the remnant voids of veins crosscutting the amphibolite body. The orange luminescent colour of both the $\mathrm{Cal}_{\mathrm{SF}}$ calcite and the swarms of microveins cutting through earlier $\mathrm{Cal}_{\mathrm{EB}} 1$ and Dol $_{\mathrm{ZON}}$ suggest that the fluid-flow event that produced $\mathrm{Cal}_{\mathrm{SF}}$ included brecciation of the pre-existing vein system. Homogenisation temperatures of the primary, twophase fluid inclusions range from 85 to $119{ }^{\circ} \mathrm{C}$, with last melting temperatures between -2.6 and $-0.4{ }^{\circ} \mathrm{C}$ (salinities between 0.7 and $4.7 \% \mathrm{wNaCl}$ equivalent-. The presence of secondary fluid inclusions with the same range of last melting temperatures $\left[T_{\mathrm{m}}\right.$ (Ice) between -2.1 and $-1.5^{\circ} \mathrm{C}$ and salinities between 2.57 and $3.55 \% \mathrm{wNaCl}$ equivalent] but lower homogenisation temperatures $\left(T_{\mathrm{h}}\right.$ between 85 and $\left.105^{\circ} \mathrm{C}\right)$ implies that the $\mathrm{Cal}_{\mathrm{SF}}$ parent fluid was present during failure of the vein system (as revealed by the brecciated vein segments) and experienced intermittent flow. Dabi et al. (2009a) found veins of similar orange CL colour displaying ataxial crack-seal texture. The identification of these veins as space-filling calcite further confirms the intermittent flow of the $\mathrm{Cal}_{\mathrm{SF}}$ parent fluid. Differences in the $T_{\mathrm{h}}$ data can be interpreted as representing differences in fluid density, with higher homogenisation temperatures equivalent to lower fluid density and vice versa. Assuming that the space-filling calcite was precipitated from the same fluid as that in the secondary inclusions, the first failure event permitted a greater pressure drop and thus greater density drop of the fluid because of the availability of remnant voids. Subsequent failure events permitted only smaller pressure drops and thus higher densities, reflected by the 
distinctly lower $T_{\mathrm{h}}$ range of the secondary inclusions.

Szabó et al. (2008) and Poros et al. (2008) detected a regional fluid-flow event with fluid salinity in the same range as the primary fluids in $\mathrm{Cal}_{\mathrm{SF}}$. This fluid was also detected in FIPs of rock-forming quartz in the Mórágy Granite Formation to the south. Fourcade et al. (2002) interpreted disseminated carbonates in whole rock samples as being precipitated from fluids that once pervaded the rock matrix. The possible match between the orange luminescent calcite seams of rock-forming minerals in mylonitic gneiss (Fig. 2.5A) and space-filling calcite potentially confirms percolation of the $\mathrm{Cal}_{\mathrm{SF}}$ parent fluid and its volatile origin related to the Early Cretaceous dyke emplacement.

Stable-isotope composition of $\mathrm{Cal}_{\mathrm{SF}}$ calcite is between $18.2 \%$ and $19.3 \%$ or oxygen and between $-2.3 \%$ and $-1.9 \%$ o for carbon. Assuming a crystallisation temperature of $85{ }^{\circ} \mathrm{C}-$ consistent with the lowest homogenisation temperature of the primary inclusions - the $\delta^{18} \mathrm{O}_{\text {fluid }}$ value is between $-0.6 \%$ and $0.5 \%$, indicative of meteoric water, basinal brine or seawater (Fig. 2.9B). However, failure caused by fluid is more likely at higher fluid pressures. A higher fluid and crystallisation temperature is possible and a certain amount of pressure correction can be applied. For example, applying a higher crystallisation temperature of 140 ${ }^{\circ} \mathrm{C}$ - consistent with a fluid pressure of ca. $80 \mathrm{MPa}$ - would result in a $\delta^{18} \mathrm{O}_{\text {fluid }}$ value of between $4.8 \%$ and $5.9 \%$, indicative of basinal brine or magmatic and metamorphic water (Taylor, 1987).

\subsubsection{Red massive calcite (Cal MASS $_{\text {) }}$}

The red calcite contained solid inclusions of quartz and spherulitic haematite and lacked fluid inclusions. Because the preceding $\mathrm{Cal}_{\mathrm{SF}}$ calcite contained two secondary fluid generations (one of which represents the $\mathrm{Cal}_{\mathrm{SF}}$ parent fluid), and $\mathrm{Cal}_{\mathrm{EB}} 2$ was subsequently precipitated from a fluid of different salinity (Dabi et al., 2009b), it is plausible that the secondary inclusions of $\mathrm{Cal}_{\mathrm{SF}}$, with their lower final melting temperatures (Fig. 2.8), could have trapped the parent fluid of $\mathrm{Cal}_{\text {MASs. }}$ The fluid entrapped in the higher salinity secondary inclusions of $\mathrm{Cal}_{\mathrm{SF}}\left[T_{\mathrm{h}}\right.$ between 82 and $97{ }^{\circ} \mathrm{C}$ and $T_{\mathrm{m}}$ (Ice) between -4.8 and $-3.1{ }^{\circ} \mathrm{C}$, corresponding to salinities between 5.1 and $7.6 \% \mathrm{wNaCl}$ equivalent] may be the parent fluid of Cal MASs.

A number of experimental investigations regarding the formation of spherulitic haematites have been carried out (Kandori et al., 2000, 2002), but few if any have modelled fluids that 
are analogues of real crustal fluids. The crosscutting relationship of the veins demonstrates that the red massive calcite-producing flow event preceded $\mathrm{Cal}_{\mathrm{EB}} 2$ and $\mathrm{Cal}_{\mathrm{ANT}}$, and thus also the pre-Gosau tectonic movements of the Early to Late Cretaceous (see below). The preGosau tectonic movements were preceded by basanitic to phonolitic volcanism between 135 and $110 \mathrm{Ma}$ (Harangi, 1994). Analogies with the Mauna Kea hydrothermal spherulitic haematites (Morris et al., 2005) and the presence of both alkaline basalt and alkaline trachyte dykes related to the Early Cretaceous Eastern Mecsek basaltic volcanism (Balla et al., 2009) suggest the potential role of volcanic activity in producing the red massive calcite.

\subsubsection{Late syntaxial and antitaxial veins}

In the Mórágy granite to the south, Koroknai (in Balla et al., 2009) noted that 'thinner dykes locally continue upwards in fractures filled with carbonate and limonitic material, from which the rock material of the dyke has partly or completely vanished'. Thus, it can reasonably be assumed that the limonite-stained calcites are related to Cretaceous dyke emplacement and volatile escape. This assumption is further constrained by the similarity of the $\mathrm{Cal}_{\mathrm{ANT}}$ parent fluids (Dabi et al., 2009b) to the fluids of the regional fluid-flow events defined by Szabó et al. (2008) and Poros et al. (2008).

Late syntaxial calcite $\left(\mathrm{Cal}_{\mathrm{EB}} 2\right)$ within the amphibolite body contains no fluid inclusions. The orange limonitestained zone at the vein-wall interface of these veins suggests that precipitation of orange calcite preceded white calcite. The presence of limonite-stained calcite in antitaxial veins indicates a possible common parent fluid for $\mathrm{Cal}_{\mathrm{EB}} 2$ and $\mathrm{Cal}_{\mathrm{ANT}}$. This suggestion is reinforced by their shared order of precipitation, as inferred from texture and the lack of calcite twins in both late syntaxial and antitaxial veins. Trails and bands of solid inclusions record a crack-seal process during vein growth (Ramsay, 1980; Hilgers and Urai, 2005), which in turn is interpreted as the result of fluid pressure fluctuations by Etheridge et al. (1984) and Bons (2000). Although interpretation of homogenisation temperature measurements in calcite is difficult, especially if trapping of fluids occurs during fluidpressure fluctuation, previous microthermometric studies of Dabi et al. (2009b) on primary inclusions of the antitaxial veins imply supralithostatic fluid pressures during vein growth. Curvature of grain boundaries suggests that sequential growth of the antitaxial veins proceeded through a sequence of extensional shear mode openings (Bons, 2001; Hilgers et al., 2001). According to the model of Sibson (1998), supralithostatic fluid pressures can lead to 
extensional shear only in a compressional tectonic regime (see Fig. 2 in Sibson, 1998).

Salinity of antitaxial calcite parent fluids is between 0.18 and $0.53 \mathrm{wNaCl}$ equivalent (Dabi et al., 2009b). The range of salinities of the regional flow event defined by Szabó et al. (2008) and Poros et al. (2008) in the Mórágy Granite to the south overlaps with the salinities measured in primary inclusions of space-filling calcite $\left(\mathrm{Cal}_{\mathrm{SF}}\right)$ and antitaxial calcite $\left(\mathrm{Cal}_{\mathrm{ANT}}\right)$. Both authors detected the flow event in healed microcracks within rock-forming quartz so, assuming that these fluids are the same as the parent fluids of massive space-filling $\left(\mathrm{Cal}_{\mathrm{SF}}\right)$ and antitaxial $\left(\mathrm{Cal}_{\mathrm{ANT}}\right)$ calcite, it is plausible that the parent fluids of both $\mathrm{Cal}_{\mathrm{SF}}$ and $\mathrm{Cal}_{\mathrm{ANT}}$ pervaded the rock matrix. An antitaxial texture is in itself indicative of percolation of parent fluids through host rock, according to Bons (2000), Hilgers and Urai (2002a) and Hilgers and Sindern (2005). Furthermore, the stable-isotope data from antitaxial veins display a trend towards the more depleted compositions of their syntaxial counterparts (Fig. 2.9A). Such a trend is similar to the distribution of stable-isotope data from antitaxial and syntaxial veins produced by the same fluid in limestone, as described by Rye and Bradbury (1988), who interpreted the data from antitaxial veins as reflecting different degrees of buffering by the host rock during flow along the developing stylolite system. The narrower range of syntaxial veins was considered to be in isotope equilibrium with the parent fluid. Based on all the aforementioned considerations, herewith we regard the fluid flow of $\mathrm{Cal}_{\mathrm{ANT}}$ parent fluids as being pervasive through the host rock. Furthermore, based on textural observations, late syntaxial calcite veins evolved in the amphibolite bodies contemporaneously with antitaxial veins in the gneissic host. Thus, the presence of syntaxial veins in the amphibolite bodies suggests that the fracture system in the amphibolite bodies acted as rapid fluid conduits connected to the fluid source. At the same time antitaxial counterparts in the gneissic host, and the trend of their isotope compositions towards more rock-buffered values, indicate pervasive flow of the same parent fluid.

\subsubsection{Palaeohydrological evolution and interactions of the Mecsekalja Zone}

The combination of stable-isotope and microthermometric data suggests a two-stage evolution of the sheared crystalline rocks of the Ófalu Formation, consistent with the Mesozoic subsidence history of the study area as reconstructed by Császár (2003, Fig. 2.10).

The first stage is characterised by fluids of carbonaceous, possibly Mesozoic affinity, and low-temperature fluids presumably derived from carbonaceous sediments $\left(\mathrm{Cal}_{\mathrm{EB}} 1\right)$, basinal 
brines $\left(\mathrm{Dol}_{\mathrm{ZON}}\right)$ and meteoric fluids $\left(\mathrm{Qtz} \mathrm{BL}_{\mathrm{BL}}\right)$. This sequence is consistent with a shallow crustal position of the $\mathrm{MZ}$ (trapping temperatures below $50{ }^{\circ} \mathrm{C}$ ), although $\mathrm{Dol}_{\mathrm{ZON}}$ represents a deeper parent fluid (minimum trapping temperature of $75-100{ }^{\circ} \mathrm{C}$ ) and perhaps a short subsidence period. The $\mathrm{Cal}_{\mathrm{EB}} 1$ parent fluid equilibrated with Mesozoic carbonaceous rocks, and the deposition of carbonaceous sediments in the region began in the Anisian (Török, 1998), so the earliest time for potential $\mathrm{Cal}_{\mathrm{EB}} 1$ precipitation is Middle Triassic (Fig. 2.10). A shallow crustal

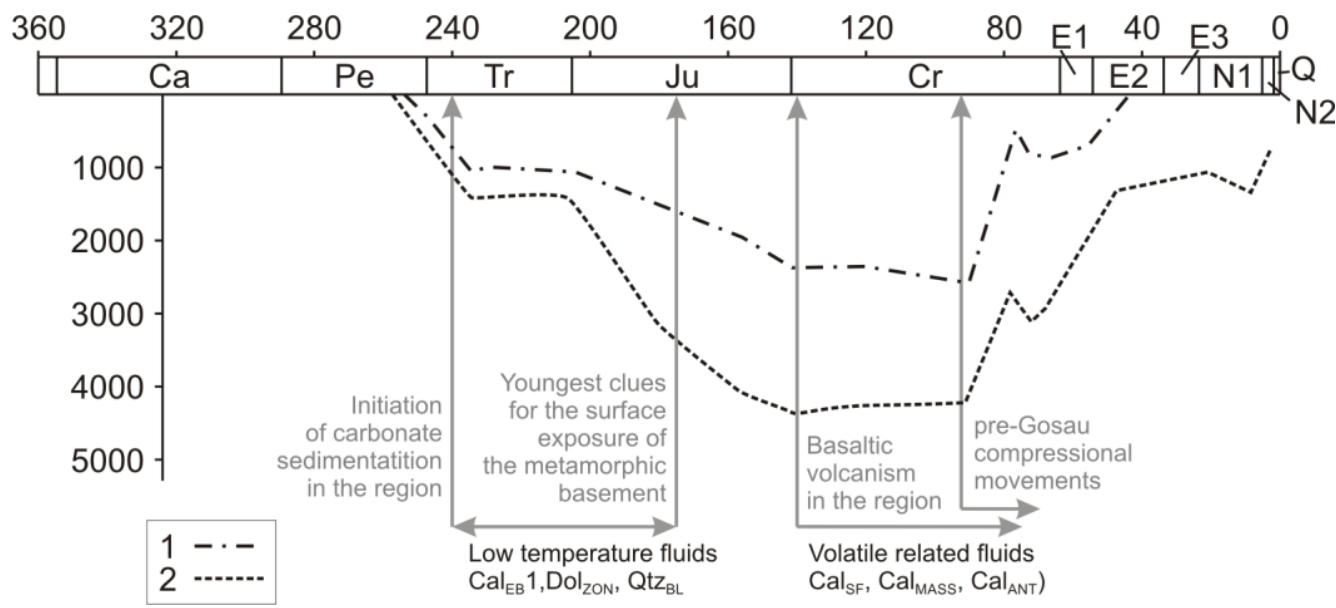

Figure 2.10. Subsidence curves of the Mórágy Block, including the MZ (1) and the Zsibrik Block to the north (2) in the Mesozoic, after Császár (2003). Horizontal arrows mark the time intervals of formations of the vein-filling phases, vertical arrows mark different geologic events that delineate the time of vein formation. See text for details.

position of the southern foreland is suggested during the Pliensbachian (Némedi Varga, 1998), whereas heavy-mineral studies of Toarcian black shale (Varga et al., 2009) in the Mecsek Mountains suggest denudation of metamorphic rocks. Thus, geological evidence is also suggestive of a shallow crustal position for the low-temperature meteoric fluid-flow event that produced the blocky quartz (Fig. 2.10). Assuming a possible basinal origin of the fluids and their higher temperature in comparison with the $\mathrm{Cal}_{\mathrm{EB}} 1$ fluids, precipitation of $\mathrm{Dol}_{\mathrm{ZON}}$ most likely occurred between the early Upper Triassic and the Middle Liassic, when the sedimentary sequences were thickest. Comparison of isotope data from these early carbonate phases with stable-isotope data from the Mórágy Granite (Fig. 2.9A) suggests that the fluid evolution of the two complexes was not linked during the Triassic to Late Jurassic.

The second stage $\left(\mathrm{Cal}_{\mathrm{SF}}, \mathrm{Cal}_{\mathrm{MASS}}, \mathrm{Cal}_{\mathrm{EB}} 2\right.$ and $\left.\mathrm{Cal}_{\mathrm{ANT}}\right)$ is characterised by low-salinity fluids possibly pervaded through the rock matrix. The similarity of these fluids to those defined by Poros et al. (2008) and Szabó et al. (2008) suggests that the MZ and the Mórágy 
Granite complex became part of the same hydraulic system. The second stage is also consistent with subsidence of the rocks to a maximum burial depth between 4000 and $5000 \mathrm{~m}$ (Császár, 2003). A relation between these fluids and the Cretaceous volcanic activity and dyke emplacement is suggested by the pervasive carbonatisation $\left(\mathrm{Cal}_{\mathrm{SF}}\right)$, coprecipitation with spherulitic haematite $\left(\mathrm{Cal}_{\mathrm{MASS}}\right)$ and the limonite-stained calcites $\left(\mathrm{Cal}_{\mathrm{EB}} 2, \mathrm{Cal}_{\mathrm{ANT}}\right)$, especially if we consider their direct association with the dykes, as described by Koroknai (in Balla et al., 2009). Initiation of the volcanism in the Late Berriasian-Early Valanginian constrains the earliest time of $\mathrm{Cal}_{\mathrm{SF}}$ deposition (Fig. 2.10).

The temperature history defined by the succession of vein minerals corresponds to the Triassic to Late Cretaceous evolution of the region. Based on the sedimentary sequences of the Mecsek Mountains, transgression began in the Anisian and lasted until the Carnian. Based on the relationship of $\mathrm{Cal}_{\mathrm{EB}} 1$ calcite to Triassic and Jurassic carbonaceous formations, the Anisian is also the earliest starting date for the fluid-flow event/precipitation. From the end of the early Middle Triassic until the Middle Liassic, thick successions of fluvial and lagoon sediments were deposited. In the Middle Liassic, subsidence of the region began and deposition of shallow marine to pelagic marls occurred. A shallow crustal position of the southern foreland is suggestedduring the Pliensbachian (Némedi Varga, 1998), and heavymineral studies of Toarcian black shale (Varga et al., 2009) in the Mecsek Mountains suggest denudation of the underlying metamorphic rocks. This geological evidence suggests a shallow crustal position for the low-temperature meteoric fluid-flow event that produced the blocky quartz $\left(\mathrm{Qtz} \mathrm{Z}_{\mathrm{BL}}\right)$. Based on a possible basinal origin of the fluids and their higher temperature relative to the $\mathrm{Cal}_{\mathrm{EB}} 1$ fluids, precipitation of $\mathrm{Dol}_{\mathrm{ZON}}$ most likely occurred between early Upper Triassic and the Middle Liassic, when the sedimentary sequences were thickest. According to the subsidence curve of Császár (2003), a similarly shallow Triassic burial depth can be inferred for the crystalline-cover interface of both the Mórágy Block (including the MSZ) and the Zsibrik Block to the north. For the Jurassic and Cretaceous, faster and deeper subsidence of the Zsibrik Block was calculated, with a maximum burial depth of ca. $4400 \mathrm{~m}$ between the Late Jurassic and the Late Cretaceous. For the Mórágy Block, a maximum burial depth of ca. $2400 \mathrm{~m}$ was assumed for the same time interval. Uplift of both blocks began during the pre-Gosau orogenic phase in the Turonian. The denudation of the crystalline rocks of the Mórágy Block commenced during the Middle Eocene, and the crystalline basement of the carbonaceous rocks has not reached the surface (Császár, 2003). 


\subsubsection{Implications of vein texture for the hydraulic behaviour of a heterogeneous rock mass}

In the second stage of the palaeohydraulic evolution of the $\mathrm{MZ}$, volatiles related to the Early Cretaceous dyke emplacement governed the hydrogeology of the MZ metamorphic complex. The parent fluids of both $\mathrm{Cal}_{\mathrm{SF}}$ and $\mathrm{Cal}_{\mathrm{ANT}}$ percolated through the host rock. The differences between these phases - the possible relation between pervasive carbonatisation and $\mathrm{Cal}_{\mathrm{SF}}$, and the development of antitaxial veins related to the flow of the $\mathrm{Cal}_{\mathrm{ANT}}$ parent fluid - motivate a two-stage, stress-dependent hydraulic model.

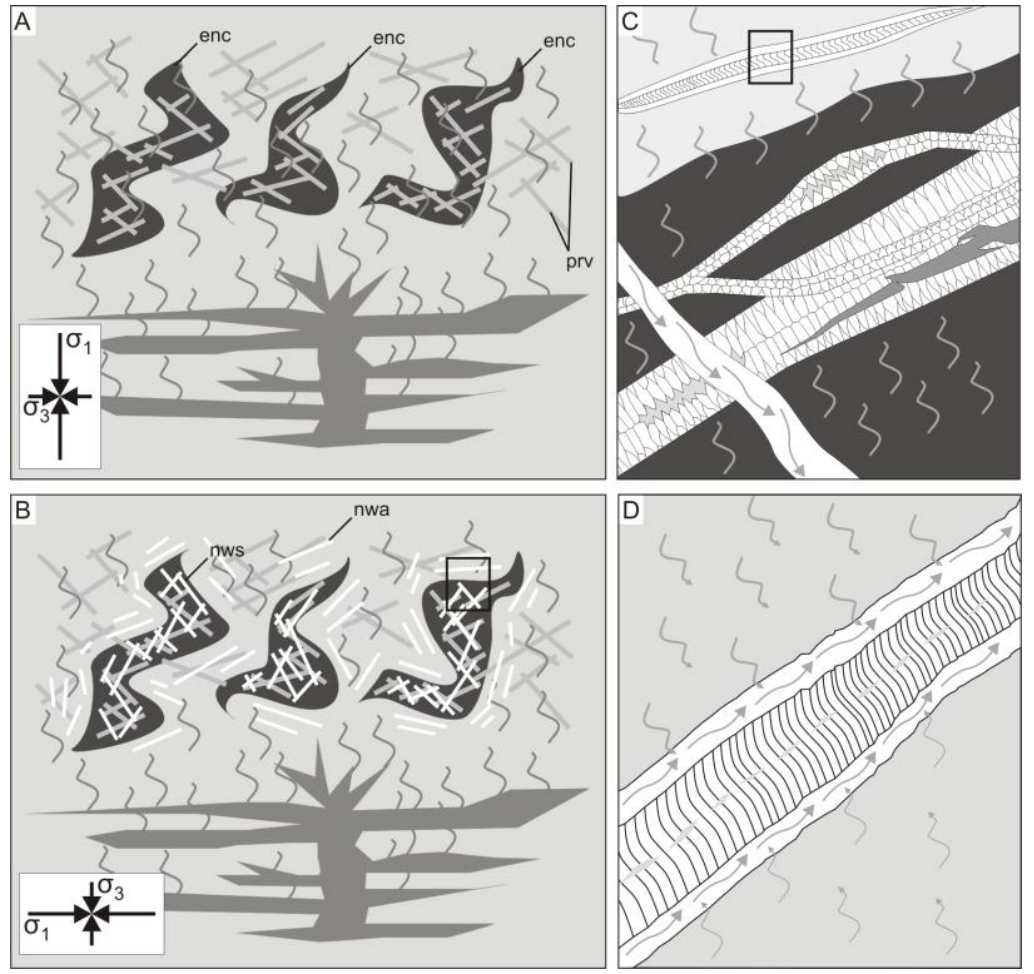

Figure 2.11. Process diagram of dyke emplacement-related flow events. (A) Escape during decompression and pervasion of fluids during the first stage of the Cretaceous volcanic activity in an extensional stress regime. Calcite deposition occurred in remnant voids of the pre-existing vein system and along grain boundaries in the host rocks, forming thin films around the single grains. Wavy lines in the host rock symbolise pervasion of fluids. (B) In the second stage, pervasion of fluids continued, but the tectonic regime became compressional. The limonite-stained calcite parent fluids flowed advectively in several-mm-wide fractures in the amphibolites enclaves, and percolated through the host rocks. Antitaxial veins opened parallel to foliation in the mylonite gneiss and were sites of deposition. The two fracture system did not communicate. enc, amphibolites enclave; prv, pre-existing veins (grey stripes); nwa, newly opened antitaxial veins; nws, newly opened syntaxial veins (white stripes). Inset indicates the position of C. (C) Fracture in the amphibolite (dark grey) is several mm wide and acts as a rapid fluid-flow conduit (fracture-channelised flow). The simultaneously opening increment in the antitaxial vein crosscutting the gneissic host (light grey) is only about ten micron. Inset indicates the position of D. Not to scale. (D) Opening increment of the antitaxial vein occurs along the interface between the pre-existing vein and the gneissic host (antitaxial growth). Percolating fluids invade the newly opened volumes along the vein-host interface (Hilgers \& Urai 2002a), and fracture-channelised flow occurs in the newly opened space between the pre-existing vein and the host. Grain boundaries of the pre-existing vein are curved, indicating the opening directions during vein growth (Bons 2000). Not to scale. 
The early stage records pervasion of volcanic fluids in an extensional regime. Dyke emplacement itself typically indicates an extensional tectonic regime, with the trend of the newly opened dykes parallel to the horizontal $\sigma 2$ axis and perpendicular to the $\sigma 3$ axis (also horizontal; Best, 2003). In the MZ, volatile-related fluids ruptured the rock along individual grain boundaries and deposited calcite films (Fig. 2.11A), similar to the Mórágy Granite to the south (Balla et al. 2009). In the later stage, the regional stress field became compressional (Early Albian, Fig. 2.10) but, according to cross-cutting relations between dykes and folded structures in the Mecsek Mountains, dyke emplacement did not cease. The volatile origin of the limonitestained carbonates (Balla et al., 2009) and the formation of the $\mathrm{Cal}_{\mathrm{ANT}}$ veins in a compressional regime, as implied by vein textures and fluid-inclusion microthermometry (Dabi et al., 2009b), suggest that the deposition of the limonite-stained calcites occured in the second, compressional stage (Fig. 2.11B).

The deposition of limonite-stained calcites with basically different textures in the amphibolite (syntaxial $\mathrm{Cal}_{\mathrm{EB}} 2$ ) and in the gneissic host (antitaxial, $\mathrm{Cal}_{\mathrm{ANT}}$, Fig. 2.11C,D) calls for a rock-dependent hydraulic model in the compressional stage. Rock-dependent hydraulic behaviour is also indicated by the different extent of buffering of the parent fluids, as implied by different ranges of isotope compositions for the two textural types (Fig. 2.9A).

Crack-seal textures in antitaxial veins suggest subsequent fluid batches in a sequentially dilating vein or vein system (Bons, 2000; Hilgers and Urai, 2005). The extent of the individual opening increments is on the order of tens of microns in the studied veins (as implied by distance between solid inclusion bands). Syntaxial counterparts in the amphibolite bodies indicate quasi-continuous singleflow events, where the apertures of the single fractures are on the order of thousands of microns. This difference in aperture of the singular-flow pathways is consistent with much longer flow distances, assuming a similar level of calcite saturation for both parent fluids (Lee et al., 1996; Lee and Morse, 1999). The smaller range of stable-isotope compositions in syntaxial veins, compared to antitaxial veins, implies that fluids of the same origin were not connected in the two rock types. Hilgers and Urai (2002a) described antitaxial en echelon veins; their observations imply that the parent fluids entered the site of precipitation along the pre-existing vein-host interface. The veins that they studied were isolated in three dimensions. Although the entire lengths of the MZ antitaxial veins could not be observed due poor outcrop exposure, their maximum thickness is ca. $5 \mathrm{~mm}$. Thus, assuming a lens-like shape, their insularity is likely, at least in places where they do not 
occur in vein systems. The wide range of isotopic compositions implies a high degree of rockbuffering of the antitaxial parent fluids, while the narrow range in syntaxial veins is interpreted to be inherited from the source (Rye and Bradbury, 1988). If the coexisting fluids of the two subsystems were connected, then a similar range of isotope compositions should be expected to evolve as a result of mixing. Thus, we assume that the amphibolite bodies acted as rapid longdistance flow systems with a small degree of fluid buffering and direct connection to the source. At the same time, the vein system of the surrounding gneissic rocks contained batches of fluids from the same source, but with varying lengths of pervasion through the host rock (compare Fig. 2.11C,D). The two vein systems were not connected during vein development. Similar compartmentalised fluid flow is described in the Szeghalom Dome, in the northeastern part of the TMU (M. Tóth et al., 2004; Schubert et al., 2007), where vein minerals shed light on the distinct fracture systems of gneissic rocks and embedded amphibolite bodies.

Similar hydraulic behaviour has been described from limestones in a Pyrenean thrust ramp, although there the antitaxial veins preceded the syntaxial veins (Rye and Bradbury, 1988). Both in the Pyrenean thrust and in the MZ, antitaxial veins are assumed to form in an active compressional tectonic regime. In the Pyrenean limestones, the fluid flow appears to be concentrated along contemporaneous syntectonic stylolites. In case of the MZ crystalline rocks, active compression presumably led to extensive pervasion of the parent fluids by keeping microfractures open (Lespinasse, 1999). The lack of antitaxial veins in the studied amphibolite bodies may result from its brittle behaviour versus the more ductile behaviour of the mylonitic gneiss. The present results raise the possibility that the formation of antitaxial veins suggests a compressional regime.

\subsection{Conclusions}

A two-stage palaeohydrological evolution has been reconstructed for the Mecsekalja Zone, the first of which is characterised by fluids possibly related to marine carbonaceous formations, basinal brines and meteoric waters. This stage is consistent with the shallow crustal position of the MZ until the Early Jurassic. In the second stage, the rock mass was intruded by fluids related to the Cretaceous volcanism, as implied by compatibility between the $\mathrm{Cal}_{\mathrm{SF}}$ calcite and pervasive, volatile-related fluids, and the direct connection between dykes and limonitic carbonates $\left(\mathrm{Cal}_{\mathrm{EB}} 2, \mathrm{Cal}_{\mathrm{ANT}}\right)$. This second stage was synchronous with the 
Middle Jurassic to Late Cretaceous subsidence. Similarity between the second- stage parent fluids and fluids entrapped in FIPs of rockforming quartz in the granite to the south suggests pervasive fluids in the second stage. Cathodoluminescence microscopy analysis revealed brecciation of earlier carbonates and possible hydrofracturing because of over-pressurisation during the production of massive calcite $\left(\mathrm{Cal}_{\mathrm{SF}}\right)$. The possibility of episodic overpressure is supported by the similar chemistry but differing densities of primary and secondary fluids as suggested by microthermometry. Antitaxial crack-seal textures and curved grain boundaries of the youngest vein generation suggest a compressional tectonic regime, possibly related to the pre-Gosau tectonic movements in the Late Cretaceous. The stable-isotope compositions imply pervasive flow of parent fluids through the host rock of the antitaxial veins. Stable-isotope compositions of the same vein generation (including syntaxial counterparts in the amphibolites) imply distinct action of the two contemporarily developing vein systems and differing hydraulic behaviour of the mylonitic gneiss and the amphibolite bodies. 


\section{Chapter 3.}

The hydraulic behavior of a crack-seal vein producing fluid-rock system*

*Extended conference abstract, Dabi, G., Czuppon, Gy., Schubert, F., M. Tóth, T., $14^{\text {th }}$ Water-Rock Interaction triennial symposium, Avignon, France. Procedia Earth and Planetary Science, in press. 


\begin{abstract}
The Mecsekalja Zone crystalline metamorphic rocks are crosscut by a crack-seal texture vein generation. Crack-seal textures are indicative of intermittent hydraulic behavior of a fluid-rock system and of the fluid pressure fluctuation. Herewith microthermometric and $\delta \mathrm{D}$ composition data from primary fluid inclusions of the crack-seal veins are presented together with earlier published stable isotope compositions of the vein calcite to reveal some features of the hydraulic behavior of the fluid-rock system during the crack-seal process.
\end{abstract}

\title{
3.1. Introduction
}

Crack-seal textures occur in veins in various geological setting, they are considered to be the indicators of the intermittency during formation, i.e. textures that form as a succession of opening increments and subsequent precipitation from the fluid intruded in the newly opened vein volume (Bons, 2000). Studies concerning the above process generally focus on the formation of the crack-seal geometry on a local scale without the aim to understand the hydraulic behavior of the fluid-rock system and its interrelation with the local phenomenon. Herewith stable isotope and fluid inclusion data from crack-seal veins are presented with the aim to reveal some important features of a fluid-rock system characterized by intermittent behavior. The features discussed here are successfully explained by the seismically related fluid-redistribution models of Scholz et al. (1973) and Sibson et al. (1975) and shed light on some aspects of a seismically driven hydraulic system.

\subsection{Geological background}

The Mecsekalja Zone (from here on abbreviated as MZ) is a narrow metamorphic belt that can be tracked in the south foreland of the Mecsek Mountains (SE Hungary). At the outcrops near Ófalu village the MZ is built up of crystalline limestone, serpentinite and amphibolite bodies as enclaves in a gneissic mass. The metamorphic belt has tectonic contacts both towards the Jurassic marl to the north and towards the Carboniferous granite to the south. In the Early Cretaceous time vigorous volcanic activity occurred in the region, what was preceded by pelagic marl deposition in the Jurassic from the Sinemurian (Jáger et al., 2012). Subvolcanic dykes are frequent in the MZ and in the Mórágy Granitoid Complex to the south, where related hydrothermal phenomena are also described (Balla et al., 2009).

The gneissic rocks of the MZ are cross cut by a generation of antitaxial crack-seal calcite 
veins, the parent fluid of which is related to the Early Cretaceous dyke emplacement (Dabi et al., 2011). The same fluid produced a vein generation with syntaxial vein geometries, the stable isotope composition of which suggest different flow paths and degrees of fluid-rock interactions from those of the crack-seal veins (Fig. 3.1A, Dabi et al., 2011).
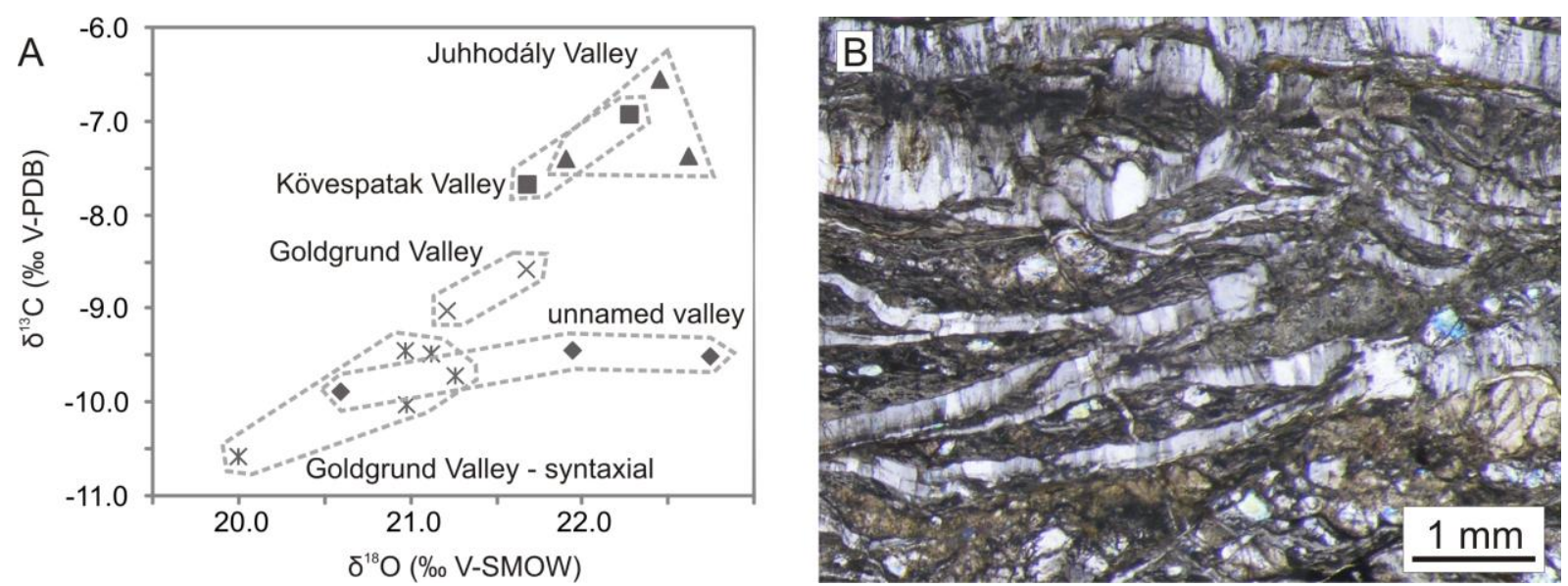

Figure 3.1. (A) Stable isotope compositions of the discussed crack-seal vein generation and their syntaxial counterparts, published by Dabi et al., 2011. (B) Pervasive crack-seal vein system in a feldspathic gneiss sample.

\subsection{Methods}

Fluid-inclusion studies were carried out at the Department of Mineralogy, Geochemistry and Petrology, University of Szeged, on a Linkam THMSG 600 heating-freezing stage mounted on an Olympus BX41 microscope. Calibration of the heating-freezing stage was carried out using synthetic inclusions of pure $\mathrm{H}_{2} \mathrm{O}\left[T_{\mathrm{m}}(\right.$ Ice $\left.)=0^{\circ} \mathrm{C}, T_{\mathrm{h}}=374^{\circ} \mathrm{C}\right]$ and $\mathrm{H}_{2} \mathrm{O}-\mathrm{CO}_{2}$ inclusions $\left[T_{\mathrm{m}}\left(\mathrm{CO}_{2}\right)=56.6^{\circ} \mathrm{C}\right]$ entrapped in quartz.

The $\delta \mathrm{D}$ values of the inclusion-hosted fluids were measured at the Institute for Geological and Geochemical Research, Research Centre for Astronomy and Earth Sciences, Hungarian Academy of Sciences. Details of the procedure can be found at Demény and Siklóssy (2008). These $\delta \mathrm{D}$ data are presented and interpreted here with $\delta^{13} \mathrm{C}$ and $\delta^{18} \mathrm{O}$ values of the studied vein generation, published by Dabi et al. (2011). 


\subsection{Results}

\subsubsection{Macroscopic and microscopic vein geometries}

Field experience and sampling campaigns suggest that different gneissic types are transected by antitaxial crack-seal vein systems with different vein densities. Micaceous gneisses seem to be rarely intersected by this vein generation, while the studied feldspathic gneiss contains pervasive vein system with a range of vein thicknesses from the submillimeter scale to several millimeters (Fig 3.1B).

The veins microscopic structure is generally characterized by bands and trails of solid inclusions dragged off from the vein wall (Fig 3.1B), indicative of the crack-seal process during growth. Average distances between solid inclusion bands (ca. $6 \mu \mathrm{m}$ ), and the maximum vein widths of 3-5 mm suggests several hundred subsequent opening increments.

\subsubsection{Fluid inclusion microthermometry}

Primary inclusions homogenize to the liquid phase between 50 and $240{ }^{\circ} \mathrm{C}(\mathrm{N}=103)$. Most of these inclusions are metastable, i.e. fail to nucleate vapour during subsequent lowering of the temperature back to room temperature or lower. Those inclusions in which nucleation of the vapour phase occurred after homogenization temperature measurements $(\mathrm{N}=11)$ were capable to yield final melting temperatures. The measured inclusions final melting temperatures are in a very narrow range between -0.3 and $-0.1{ }^{\circ} \mathrm{C}$ (inclusions with homogenization temperatures between 70 and $192^{\circ} \mathrm{C}$ ), i.e. the fluids are of uniform salinity.

\subsubsection{Hydrogen isotope compositions of the studied inclusions}

Only four samples contained fluid inclusions in sufficiency for the measurement of the entrapped fluids hydrogen isotopic composition. These fluids have $\delta \mathrm{D}$ values between -39.6 and $-75.8 \%(\mathrm{~N}=4)$, what is basically the composition range of magmatic fluids (from $-80 \%$ to $-40 \%$, Sheppard, 1986).

\subsection{Discussion}

The very narrow range of final melting temperatures in samples from different locations 
confirms that a fluid of uniform composition flushed the system during the flow event. The very wide range of homogenization temperatures can hardly be explained by the temperature drop of the fluid alone. Since the homogenization temperatures represent fluids of different densities, it is plausible to assume that the wide range of homogenization temperatures represent changing fluid pressures and densities during vein growth, which is inherent in crack-seal models (Bons, 2000). However the validity of the data is problematic, since stretching of the fluid inclusions is possible during the recurrent pressure drops (vein opening).

Fig. 3.1 A shows stable isotope compositions of the vein calcite. It can be seen that samples from different outcrops display clustered isotope compositions. This implies local, possibly rock type dependent fluid-rock systems, a feature of the data set not discussed in Dabi et al. (2011).

The fluids magmatic origin (as discussed by Dabi et al. (2011) and as constrained here by the measured $\delta \mathrm{D}$ values) can explain its overpressure but does not explain the dynamics of the crack-seal process, i.e. several hundred recurrent drop and subsequent increase of the fluid pressure. It is also a striking feature of the vein systems that they remain closed during subsequent opening increments. Taking together the above features the crack-seal process cannot be well explained as being governed by the fluid pressure alone and an external factor should be evoked to explain the crack-seal process.

Sedimentary features of Cretaceous limestones contemporaneous with the Eastern Mecsek volcanism are indicative of vigorous seismicity in the area Jáger et al. (2012). Scholz et al. (1973) have evolved a model that explains a group of phenomena precursory to earthquakes with microcrack dilatancy in the broader environment of an active fault. Herewith we propose that the same model satisfactorily explains several features of the crack-seal process at the study area. The very similar salinities of the fluids at different locations where isotope compositions suggest local water-rock systems implies that the fluid effectively flushed the system, but could not homogenize isotope perturbations due to local isotope exchange. The efficiency of fluid flushing was probably aid by enhanced microcrack porosity during the preearthquake dilatancy. The release of stress accompanying the earthquake results in the elastic closure of the microcrack system (Sibson et al., 1975) which causes the fluid pressure to rise and the antitaxial veins to reopen. However the newly formed fracture porosity systems are closed local systems, what implies that the main flow media is the dilatant microcrack system in the pre-earthquake stage of the seismic cycle. 


\subsection{Conclusions}

The above described model rests on the early seismic fluid redistribution models, the relevance of which is constrained by sedimentary features contemporaneous with the Early Cretaceous volcanism (Jáger et al., 2012). Fluid inclusion data suggest the enhanced efficiency of the fluid in flushing the system, what can be explained by enhanced microcrack porosity during the pre-earthquake period (Scholz et al., 1973). The recurrent opening increments along the veins can be interpreted as local hydraulic failures due to the increase of fluid pressure associated with the elastic closure of the microcracks due to earthquake stress release (Sibson et al., 1975).

The available data only make some qualitative ascertainments to be deduced, and are not capable to constrain the boundary conditions of the process narrower, i.e. depth, fluid pressure at vein opening, etc... The authors find reasonable to assume that the mechanical properties of the host rock determine its sensibility to the crack-seal process, and provide the possibility to adumbrate in its details. 


\section{Chapter 4.}

The origin and role of a calcite-filled microcrack system in a metamorphic crystalline complex: insight into interseismic fluid evolution*

\footnotetext{
* Submitted to Tectonophysics on 25. january, 2013. Authors: Dabi, G., Bajnóczi, B., Schubert F., M. Tóth, T.,
} 


\begin{abstract}
Cathodoluminescence images of the Mecsekalja Zone gneissic rock types reveal the occurrence of a pervasive calcite-filled microcrack system in the Ófalu gneissic rocks. This is similar to the calcite infiltration in the Mórágy Granite to the south described by previous authors. The patterns of the studied microcrack systems suggest rock-type-dependent extension and connectivity of the microcracks. Stable isotope data from the microcrack calcite display a linear trend with oxygen isotope compositions between $14.6 \%$ and $25.1 \%$ and carbon isotope compositions between $-9.4 \%$ and $-1.0 \%$. Fluid inclusions homogenise to the liquid phase between 64 and $110^{\circ} \mathrm{C}$ in the banded gneiss and in a similar range of between 69 and $140{ }^{\circ} \mathrm{C}$ but with a very narrow maximum between 100 and $115{ }^{\circ} \mathrm{C}$ in the feldspathic gneiss (the final melting temperatures are similar in the two textural types). This study is a venture to resolve the formation mechanism of the microcrack system and to understand its relationship with the fluid present during and after cracking. Our results highlight the role of earthquake activity in the formation of the microcrack system and suggest the subsequent detachment of rock-type-dependent fluid-rock subsystems. The interpretation of the data suggests the formation of two hydraulic subsystems: one in which the fluid properties are determined by deformation and the other connected to an external fluid container during deformation. The model involves the seismic suction pumping model proposed by Lin et al. (2003) and highlights the role of deformation-related fluid pumping accompanying postearthquake stress recovery in the feeding of seafloor sulphate chimneys. This model is different from that of Sibson (1975) in that it involves the deformation of a saturated seismic damage zone in fluid pumping.
\end{abstract}

\title{
4.1. Introduction
}

Fluids in the Earth's crust have important effects on large-scale processes through their influence on the mechanical properties of rocks (e.g., Sibson, 1998; Zoback and Townend, 2001). Similarly, deformation of the crust has strong effects on the fluids present in rock pores, by governing microcrack dilatancy and permeability, which can be observed directly with conventional triaxial or uniaxial apparatus (e.g., Zoback and Byerlee, 1975a; b). The closure of the initial microcrack system at the onset of stressing of the rock is a characteristic feature of stress-strain diagrams (Cai, 2009), even in crystalline rocks with very low porosity (Zoback and Byerlee, 1975a; b; Lajtai, 1998). During further increase of stress, the formation 
of microcrack populations start at the crack initiation stress and continues until strain localisation occurs in the sample and macroscopic failure occurs (Gottschalk et al., 1990; Shea et al., 1993; Rawling et al. 2002). It is obvious that the process of microcrack formation implies a very sensitive interaction between fluid properties and deformation in a crustal volume saturated with fluids, i.e., the increase of the quantity of pore fluids during dilatancy and microcrack formation, or the increase of fluid pressure during microcrack closure. The accumulation of tectonic stress and the associated dilatancy cause precursory effects before shallow earthquakes, such as the decrease of seismic compressional velocity, radon emission, or anomalous crustal movements (Scholz et al., 1973). However, it is not only the well described systematic behaviour during the gradual increase of stress in triaxial experiments that results in the formation of microcracks. Seismic phenomena (seismic anisotropy and the increase of delay time between fast and slow wavelets) around recently active tectonic faults are interpreted to be the result of damage and cracking of rocks in the surroundings of the fault (Hiramatsu et al., 2005; Li et al., 2006). As the crust is saturated with respect to fluids, the perturbation of crustal flow systems is inherent during seismicity in active stress regimes, as documented by Weise et al., (2001). At the KTB (drill hole, fluid pressure generated by fluid injection, several megapascals in excess of hydrostatic, was sufficient to produce earthquakes (Zoback and Harjes, 1997; Townend and Zoback, 2000). Furthermore, following the application of the Coulomb failure criterion, Zoback and Townend (2001) stated that the brittle crust is in a state of failure equilibrium governed by crustal fluids.

A consequence of the dilatancy/fluid diffusion mechanism for shallow earthquakes is that considerable volumes of fluid are rapidly redistributed in the crust following seismic faulting, which is borne out by outpourings, according to the seismic pumping model of Sibson et al. (1975). However, the lowering of groundwater levels around fault zones during earthquakes suggests the infiltration of surface waters into the deep fault zone, which is proven by the mineralogy and stable isotope compositions of gauge materials and vein calcites associated with seismically active faults (Lin et al., 2003).

Previous textural investigations of the granitoid rocks of the Mórágy Granitoid Complex (SW Hungary) revealed the occurrence of a remarkable calcite infiltration (Balla et al., 2009) and explained it by citing the release of volatiles associated with the Early Cretaceous dyke emplacement. Dabi et al. (2011) described a similar phenomenon in the rocks of the Ófalu metamorphic belt, northwest of the Mórágy Granitoid Complex and identified it with vein calcite generation. Here the patterns of calcite-filled microcrack systems of the different 
gneissic rock types of the Ófalu metamorphic complex are presented with the aim of understanding their formation.

\subsection{Geological Background}

\subsubsection{Regional Geology}

The study area is representative of the metamorphic complexes of the Tisza Mega-unit (TMU, Haas and Péró, 2004), or Tisza terrane (Csontos and Vörös, 2004), a large composite lithospheric block with complex internal structure made up of nappe systems (Fig. 2.1A, Kovács et al., 2000; Haas and Péró, 2004). The TMU is the basement of the Pannonian Basin overlaid by thick Cenozoic sequences and has scattered surface exposures in the PapukKrndija, Moslavaćka Gora (NE Croatia), the Mecsek, Villány (SE Hungary) and Apuseni Mountains (Romania). Units of the TMU are built up of Variscan crystalline complexes beneath Upper Carboniferous to Triassic overstep sequences. Variscan granitoids and crystalline complexes of the TMU might be correlated with the Moldanubian (-Helvetic) Zone, which means that during the Variscan Orogeny, the TMU was an integral part of the Variscan Mountain Range (Haas and Péró, 2004) and thus, in its present position, the TMU is an exotic terrane of European Plate origin. Its Alpine evolutionary stages include: Bathonian separation from the European Plate (because of the opening of the Penninic-Vahic ocean branch), Cretaceous continental rift-type alkali basalt volcanism and Late Cretaceous nappestacking (Haas and Péró, 2004). The main nappe-stacking stage was in the TuronianConiacian (pre-Gosau phase).

\subsubsection{Cretaceous volcanic activity in the Mecsek Mountains and in the Mórágy Granite}

The Early Cretaceous sequence in the Eastern Mecsek starts with marine limestone followed by thick basaltic sequences (Mecsekjánosi Basalt Formation), at some places reaching a thickness of $1000 \mathrm{~m}$. The main rock types define a basanitic to alkali basaltic group and a group with endmembers between Na-basanites and phonolites, of shallow marine effusive and sub-volcanic character, respectively (Harangi and Árva-Sós, 1993). K/Ar data from the basaltic rocks indicate that the main period of volcanic activity was between 135 and $110 \mathrm{Ma}$ (Harangi and Árva-Sós, 1993). Mineral chemistry of rock-forming minerals suggests that the two groups have a similar mantle source but different degrees of partial melting 
(Harangi and Árva-Sós, 1993). The major and trace element characteristics of the basalts indicate their intraplate origin (Harangi, 1994) and their origin is interpreted to be consistent with the Early Createous (Tithonian) opening of the Vahic oceanic basin (Haas and Péró, 2004). In the Villány Mountains, ca. $50 \mathrm{~km}$ south from the study area, subsequent dyke emplacement occurred (76 Ma) in the short extensional phase between the main nappestacking events of the Late Creataceous (Nédli et al., 2010). Jáger et al. (2012) described a $160 \mathrm{~m}$ thick layer of intrusive pillow basalts and hialoclastite with associated sulphide chimney structures (Mecsekjánosi Basalt Formation) in a Bathonian to Lower Valanginian sequence, $7.5 \mathrm{~km}$ southwest from the study area. This Cretaceous marine sequence is situated above the south-western continuation of the Mecsekalja Zone. Sedimentary features, i.e., intraclastic beds and abundant wood fragments in Lower Cretaceous bathial turbidites, limestones and also in clastic formations, indicate intensive earthquake activity (Jáger et al., 2012).

Sub-volcanic dykes are frequent in the study area and in the Mórágy Granite Formation immediately to the south. These dykes are defined as alkali basalt, alkali trachyte and alkali rhyolite (Balla et al., 2009). The sub-volcanic phenomena include intrusive breccias, i.e., brecciated zones, the formation of which are ascribed to high pressure volatiles and hydrothermal phenomena, in conjunction with alkali volcanites. The latter includes pervasive carbonate infiltration of the granitoid rocks and was described as follows; "very fine grained carbonate mineral almost bursts the rock along the individual, formerly dynamically recrystallised grain boundaries, while the rock cohesion does not cease. The fine grained carbonate usually forms films around the single grains..." (Balla et al., 2009). Another important phenomenon is the gradual transition from thinner dykes to fractures filled with carbonate and limonitic material. Trace element and rare earth element composition of the dykes in the Mórágy Granite suggest their relation to the fractionated tephryphonolitephonolite series of the Eastern Mecsek sub-volcanic series (Nédli and Szabó, 2007).

\subsubsection{The Mecsekalja Zone (Ófalu Group)}

The Mecsekalja Zone (MZ) is a ca. $1.5 \mathrm{~km}$ wide, NE-SW trending zone located in the Eastern Mecsek Mountains, Hungary (Fig. 2.1B), which can be traced in boreholes to the northeast and to the southwest under a thick cover of overlying Cenozoic to Quaternary sediments. At the study area, the MZ is bordered by tectonic contacts both to the north and 
south; the neighbouring rocks are Liassic marls (Vasas Marl Formation, Császár et al., 2007) and Variscan granites (Mórágy Granite Formation, Király and Koroknai, 2003; Balla et al., 2009), respectively (Fig. 2.1B,C). The tectonic contact to the north is the Mecsekalja tectonic line (Császár et al., 2007).

The MZ includes a very heterogeneous metamorphic rock assemblage displaying intense folding and greenschist facies mylonitisation (M. Tóth et al., 2005). The recognised build-up of the study area (Fig. 2.1C) has a considerable degree of uncertainty due to poor outcrop conditions and reflects the approximate quantitative relationships of the main rock types (Balla et al., 2009). The predominant outcrops expose intensively mylonitised gneissic rock types, which enclose the outcrop- or map-scale elongated, lens-shaped bodies of amphibolite, serpentinite and crystalline limestone (Fig. 2.1C). According to Balla et al. (2009), the southern part is built up mainly of metamorphic rocks of sedimentary origin (including the crystalline limestone body, Fig. 2.1C) with phyllonite as the enclosing "matrix" of the lenslike rock bodies. The gneissic rocks of the northern part are of magmatic origin, based on zircon morphology (M. Tóth et al., 2005) and are grouped into different types, i.e., biotite gneiss, banded gneiss, augengneiss, white gneiss and phyllonite. These types are basically different in their texture and their mineralogical compositions are very diverse, even within the same type. In general, the micaceous gneiss and the banded gneiss contain more chlorite than does the more feldspathic augengneiss. With the compositional differences in mind, especially the different mica content, one should expect different mechanical behaviour during microcrack formation (Shea et al., 1993). The MZ is a zone of intense mylonitic shear (Lelkes-Felváry et al., 2000; M. Tóth et al., 2005); mica fishes, 'V'-pull-aparts of feldspars, dynamically recrystallised quartz ribbons and seams are ubiquitous in thin sections.

\subsubsection{Regional palaeohydrogeology}

Dabi et al. (2009a; 2011) described a six stage palaeohydrogeologic evolution of the MZ crystalline rocks based on textural features, microthermometric and stable isotope data of fracture filling minerals. Based on the similarity of the stable isotope composition of the first calcite phase to marine carbonates and the commencement of the Triassic carbonate sedimentation in the region the described sequence started to evolve in the Triassic, or later. The second and third flow events were considered to be basinal and meteoric in origin, respectively. The three youngest vein calcite phases were considered to be associated with the 
Early Cretaceous volcanic activity, partly based on similarities to phenomena described in the Mórágy Granite. Connections of the hydraulic events described in the MZ to those described from the Mórágy Granite to the south (Szabó et al., 2008; Poros et al., 2008) were assumed, based on similarities of the fluid properties. Recently, the microthermometric studies of Tóth (2012) on fluid inclusion planes entrapped in lateral secretion quartz samples of the MZ have suggested further flow events, possibly related to those early flow events described from the Mórágy Granite Complex by Poros (2007). Dabi et al. (2011) described the presence of orange luminescent calcite disseminated in the rock matrix (the phenomenon being described and interpreted in the present study) and identified it with the fourth vein-filling generation ( $\mathrm{Cal}_{\mathrm{SF}}$, subscript SF stands for "space filling"). The parent fluid of $\mathrm{Cal}_{\mathrm{SF}}$ was interpreted to be entrapped in cloud-like inclusion clusters, having final melting temperatures between -2.6 and $-0.5^{\circ} \mathrm{C}$ (with homogenisation temperatures between 85 and $120^{\circ} \mathrm{C}$ ). The last fluid flow event that produced both syntaxial and antitaxial veins in the MZ has final melting temperatures between -0.1 and $-0.3{ }^{\circ} \mathrm{C}$ (Dabi et al., 2009b). The final melting temperature range defined by the above fluids is the same as the flow event defined as " $3 a$ " and " $3 b$ " (see details later) by Poros et al. (2008) from the Mórágy Granite Formation, south of the MZ.

Szabó et al. (2008) and Poros et al. (2008) described the palaeofluid evolution of the Mórágy Granite Formation based on detailed petrographic and microthermometric analyses of vein minerals and fluid inclusion planes (FIP) of the rock-forming quartz. Based on their results, a profound fluid history of the granitoid complex can be outlined, both with respect to pervasive and fracture channelised fluid flow events and to their connections. According to their results, the first fluids were high temperature ( $T_{\mathrm{h}}$ between 260 and $290{ }^{\circ} \mathrm{C}$ ) pegmatitic fluids, followed by high salinity ( $T_{\mathrm{m}}(\mathrm{Ice})$ between -19 and $-25^{\circ} \mathrm{C}$ ) fluids of pervasive nature and possibly metamorphic or basinal origin. Their " $3 a$ " and " $3 b$ " fluid flow events were both detected in primary inclusions of vein minerals and fluid inclusion planes in quartz of the granite and were assigned to be the product of the Cretaceous dyke emplacement and related release of volatiles. The compositions of the " $3 a$ " and " $3 b$ " fluids were interpreted to be a trend of fluid dilution. The microthermometric studies of Szabó et al. (2008) were carried out from three different quarries, surrounding the study area of Poros et al. (2008). According to their measurements on FIPs and primary inclusions of vein calcite, they were able to define a regional fluid flow event with a range of homogenisation temperatures between 129 and 253 ${ }^{\circ} \mathrm{C}$ (with different ranges between different areas) and final ice melting between -0.8 and -2.7 ${ }^{\circ} \mathrm{C}$. This is similar to the salinities of the "3b" flow event of Poros (2007). The fourth and fifth 
flow events were defined in secondary inclusions of vein-filling minerals and FIPs of the granite quartz grains and were assigned to be late flow events of basinal and meteoric origin, respectively.

\subsection{Methods}

Cathodoluminescence microphotographs were taken at the Institute for Geological and Geochemical Research, Research Centre for Astronomy and Earth Sciences, Hungarian Academy of Sciences, using a Reliotron (cold cathode) instrument mounted on a Nikon Eclipse E600 microscope, using a Nikon 4500 digital camera. The cathodoluminescent apparatus was operated at 7-8 $\mathrm{keV}$ accelerating voltage and $0.25-0.63 \mathrm{~mA}$ beam current.

Fluid-inclusion studies were carried out at the Department of Mineralogy, Geochemistry and Petrology, University of Szeged, on a Linkam THMSG 600 heating-freezing stage mounted on an Olympus BX41 microscope. Doubly polished 60 - to $70-\mu \mathrm{m}$-thick chips were first mapped for fluid inclusions. Initial heating of samples was carried out to avoid the stretching of inclusions resulting from the freezing of the aqueous liquid phase. Metastable equilibrium (lack of a vapour phase at temperatures of liquid and vapour coexistence) during cooling after homogenisation is common in the studied inclusions. This inhibits $T_{\mathrm{h}}$ measurements, especially at lower homogenisation temperatures, if homogenisation temperatures of inclusions are measured separately. Therefore, stepwise $1{ }^{\circ} \mathrm{C}$ heating was applied, checking all the studied inclusions between steps, both to avoid the loss of the vapour phase before the homogenisation temperature is measured and to avoid stretching of inclusions at lower homogenisation temperatures. Final melting temperature measurements were undertaken via the cycling technique (Goldstein and Reynolds, 1994). Metastable behaviour of the inclusions after homogenisation (i.e., the monophase presence of fluid after lowering the temperature below the homogenisation) prevents the measurement of final melting temperatures (which needs the presence of ice, brine and vapour at the same time). Thus, after homogenisation measurements, systematic overheating of the studied inclusions was carried out to stretch them and thus, facilitate the nucleation of the vapour phase. Calibration of the heating-freezing stage was carried out using synthetic inclusions of pure $\mathrm{H}_{2} \mathrm{O}\left[T_{\mathrm{m}}(\mathrm{Ice})=0{ }^{\circ} \mathrm{C}, T_{\mathrm{h}}=374{ }^{\circ} \mathrm{C}\right]$ and $\mathrm{H}_{2} \mathrm{O}-\mathrm{CO}_{2}$ inclusions $\left[\mathrm{Tm}\left(\mathrm{CO}_{2}\right)=56.6^{\circ} \mathrm{C}\right]$ entrapped in quartz.

Whole rock powder was used for calcite stable-isotope measurements. Stable-isotope 
compositions of the evolved $\mathrm{CO}_{2}$ gas were measured using a ThermoFinnigan delta plus XP continuous-flow mass spectrometer, using a GASBENCH II preparation device as an inlet port, at the Institute for Geological and Geochemical Research, Research Centre for Astronomy and Earth Sciences, Hungarian Academy of Sciences. Results are expressed using standard $\delta$ notation relative to V-PDB for $\mathrm{C}$ and V-SMOW for $\mathrm{O}$ in \% . The reproducibility for both $\mathrm{C}$ and $\mathrm{O}$ isotope analyses is better than $0.15 \%$, based on replicate measurements of standards and samples.

\subsection{Results}

\subsubsection{Texture of the studied samples and cathodoluminescent images}

The cathodoluminescent images of the different gneissic rock types reveal pervasive calcite-filled microvein systems of different extension and connectivity in different rock types of the MZ, from here on abbreviated as $\mathrm{Cal}_{\mathrm{MC}}$ (microcrack calcite).

The MZ provides a good opportunity to study the microcrack system of foliated rocks with varied mica content and texture. In order to examine the possible relation between mica content and microcrack geometry, samples of chlorite gneiss (phyllonite), banded gneiss and feldspathic gneiss were studied. It is important to note that according to our observations, the widely occurring mica is chlorite, in contrast to the descriptions of Balla et al. (2009). The "augengneiss" (Balla et al., 2009) is basically a feldspathic gneiss variety with minor quartz (generally as dynamically recrystallised ribbons) and mica (chlorite and muscovite, Fig. 4.1A). The samples discussed here have a character that is more chloritic. The chlorite gneiss is composed of fragmented feldspar grains, minor quartz (Fig. 4.1B), minor muscovite and abundant apatite and opaque, in addition to the most abundant chlorite. The mineral composition of the banded gneiss is similar; the main difference is the grain size, i.e., both the chlorite and feldspar grains are less fragmented (Fig. 4.1C). In some places the mica bands are several millimetres thick, continuous across the whole thin section and mixed with elongated quartz seams. Feldspar grains with diameters of the order of millimetres are more frequent in this type, than in the chlorite gneiss but these are separated from each other. It is plausible to consider these textural types as being the result of various degrees of feldspar fragmentation in a mylonitic shear zone with heterogeneous intensity. A less foliated micaceous gneiss is also studied, in which the feldspar grains are less fragmented and form more equigranular grains (Fig. 4.1D). This textural type possibly represents, or approximates the precursor of the 
micaceous gneiss types. Previous triaxial and uniaxial tests of transversely anisotropic crystalline rocks have been carried out by Gottschalk et al. (1990), Shea et al. (1993) and Rawling et al. (2002) to reveal the principles of microcrack evolution caused by stressing. The experiments of Shea et al. (1993) have proven the fundamentally important role of biotite (and generally mica) on the formation of microcracks in transversely foliated crystalline rocks.
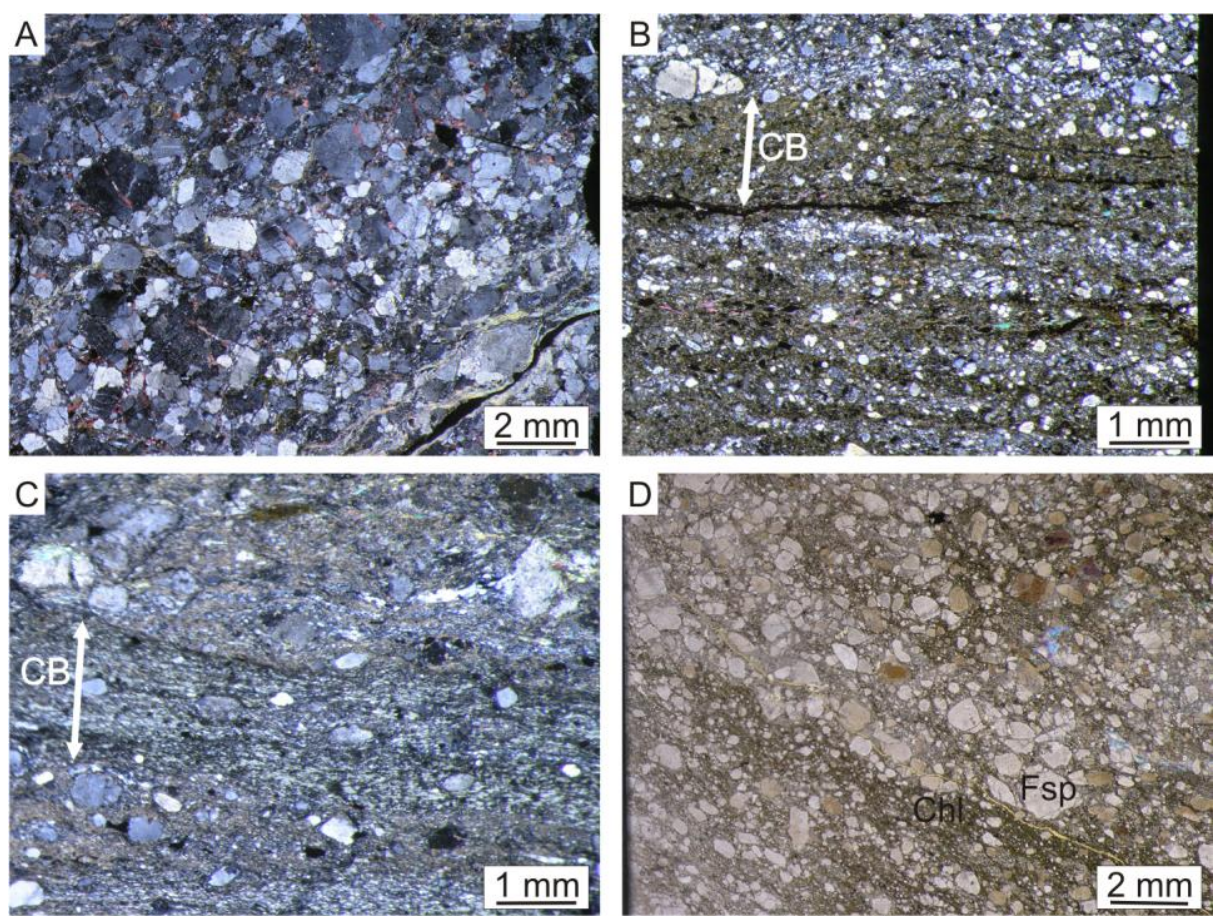

Figure 4.1. Textural variations of the studied gneissic rocks. (A) Feldspathic gneiss, Goldrund Valley, eastern side valley (Fig. 4.1C). The major constituent is feldspar; minor constituents are quartz and mica in the intragrain domains. Red seams are microcracks filled with dyed calcite. Feldspar clasts are in direct contact, single feldspar grains can have diameters up to $2 \mathrm{~mm}$. (B) Chlorite gneiss, unnamed valley (Fig. 4.1C). Micaceous bands contain small feldspar clasts with maximum grain size of $0.3 \mathrm{~mm}$ and with rare clasts with diameters of the order of $1 \mathrm{~mm}$. Dynamically recrystallised quartz ribbons and muscovite flakes are minor constituents in addition to feldspar and chlorite. (C) Banded gneiss, Goldrund Valley, eastern side valley. Thick micaceous bands contain abundant feldspar grains with average maximum diameter between 0.5 and $1 \mathrm{~mm}$. Feldspars clasts are rarely connected. (D) Less foliated micaceous gneiss, northern part of the Juhhodály Valley, possibly close to the contact. Feldspar clasts are less fragmented and more equant; the samples have feldspar-rich and mica-rich zones.

In the studied samples, the microcrack calcite has varying textural appearance and in some samples, it is not luminescent. The most extensive calcite cemented microcrack systems occur in feldspathic gneisses, where the interconnected crack system resembles brecciation of the sample (Fig. 4.2A). However, if micaceous subdomains occur, then calcite-filled microcracks bypass these zones (Fig. 4.2A). In the chlorite gneiss, the calcite is generally present as small 
disseminated patches (Fig. 4.2B). Feldspar clasts are cracked at some places but these small crack systems are confined to individual grains. In the studied banded gneiss samples, the presence of microcrack calcite (non-luminescent) is confined to small cracks at the thin neck of elongated lens-like feldspar clasts. The less foliated micaceous gneiss type has an extensive calcite-filled microcrack system similar to that of the feldspathic gneiss.
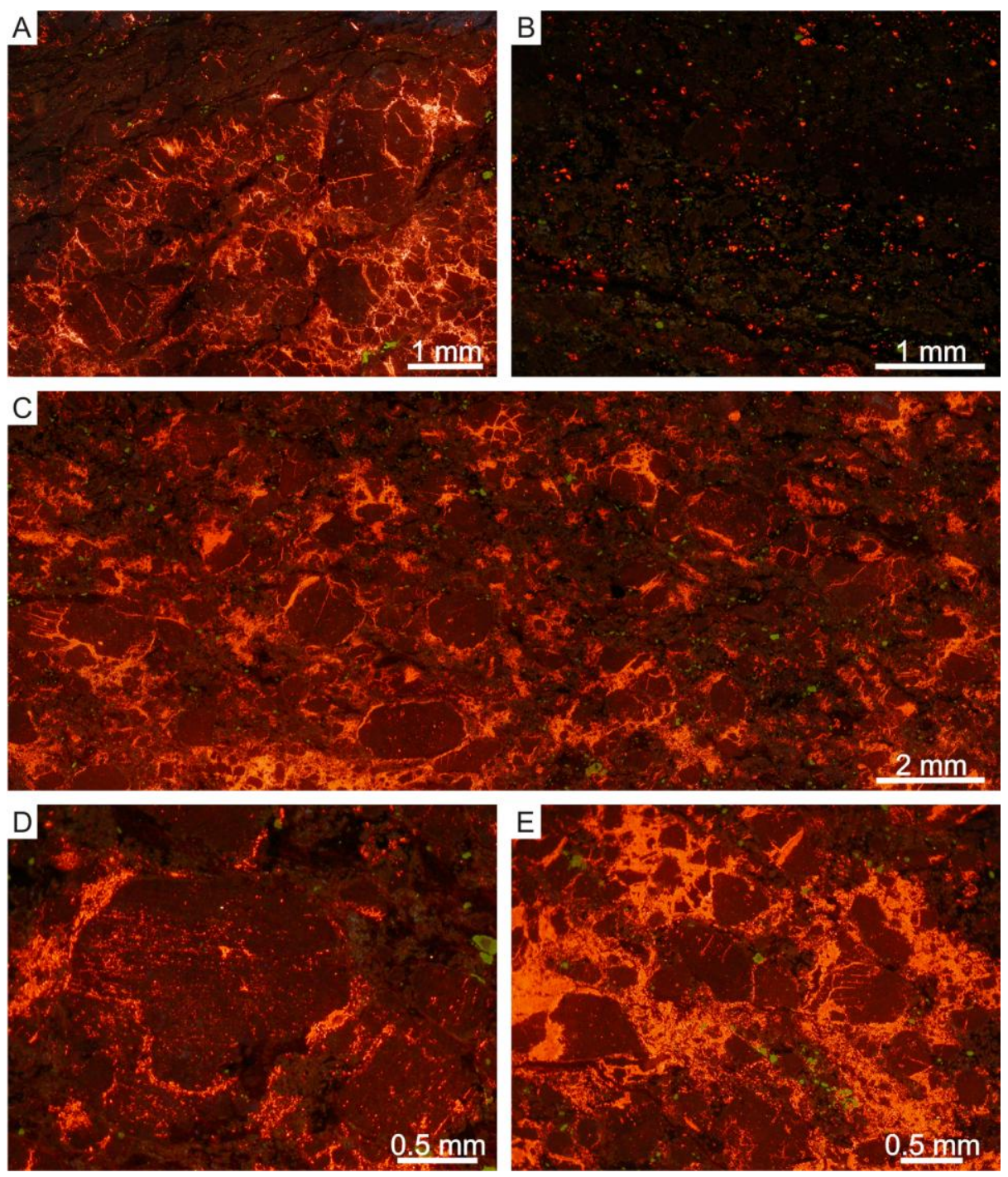

Figure 4.2. Cathodoluminescent images of the studied gneissic rocks. (A) Feldspathic gneiss. The microcrack system resembles brecciation of the sample; the microcracks are extensive and interconnected. Biotite-rich domain in the left-hand upper corner is less pervaded by the microcracks. (B) Chlorite gneiss contains calcite as disseminated microscopic patches. (C) The less foliated micaceous gneiss has very similar microcrack system to that of the feldspathic gneiss. (D) Cleavage parallel calcite seams and patches in a feldspar clast. (E) Breccia-like subdomain in cluster of fragmented feldspar clasts.

Cathodoluminescent images of the least foliated micaceous gneiss samples and those of the feldspathic gneiss display the most extensive microcrack systems. The microcrack systems 
have diverse textural appearance. These textural variations include small disseminated patches in feldspar (Fig. 4.2C,D), thin parallel calcite seams along feldspar cleavage (Fig. 4.2C,D), thicker cracks (in comparison with the thin cleavage parallel seams) in fragmented feldspar grains (Fig. 4.2,C) and breccia-like subdomains (Fig. 4.2,E). The latter are possibly pseudobreccias and indicate preferential damage of the rock along fragmented feldspar zones produced by the mylonitisation.

\subsubsection{Fluid inclusion petrography and microthermometry}

The outcrop in the eastern side valley of the Goldgrund Valley provides the opportunity to study the microcrack calcite of two different gneiss types in close proximity (separated by a thin, elongated amphibolite body several metres wide, Fig. 2.1C). These two types have fundamentally different calcite content. The feldspathic gneiss contains abundant luminescent calcite in the form of brecciated subdomains and as inter- and intragrain seams (Fig. 4.2A). The banded gneiss contains much less non-luminescent calcite, generally in the vicinity of the necks of elongated feldspar clasts. During fluid inclusion petrography it became obvious that the samples contain calcite only in small disseminated cracks.

The studied fluid inclusions do not display any regular clustering in the host calcite. Thus, petrographic interpretation of the host calcite inclusions is not unequivocal. Secondary inclusion trails could not be defined, which supports the primary origin of the studied inclusions. Fluid inclusions homogenise to the liquid phase between 64 and $140{ }^{\circ} \mathrm{C}(\mathrm{N}=52)$ with only three inclusions having homogenisation temperatures above $115{ }^{\circ} \mathrm{C}$ (Fig. 4.3A). However, the two studied samples represent distinct ranges of homogenisation temperatures with lower values between 64 and $112{ }^{\circ} \mathrm{C}$ in the banded gneiss sample (Fig. 4.3A). The fluid inclusions entrapped the microcrack calcite of the feldspathic gneiss sample homogenised to the liquid phase between 84 and $140{ }^{\circ} \mathrm{C}(\mathrm{N}=26)$ with a very narrow maximum between 100 and $115{ }^{\circ} \mathrm{C}(\mathrm{N}=20$, Fig. $4.3 \mathrm{~A})$ and with only two data above $120{ }^{\circ} \mathrm{C}$. The unwillingness to nucleate the vapour phase during cooling after homogenisation is common to all the studied inclusions. Those which nucleated vapour after thermal stretching all have final melting temperatures between -2.5 and $-1.8{ }^{\circ} \mathrm{C}$ in both samples $(\mathrm{N}=14)$, (Fig. 4.3B). The difference of the homogenisation temperature maxima in the two samples displays different fluid densities and possibly represents distinct fluid-rock subsystems with different fluid pressures in the case of the two textural types. 

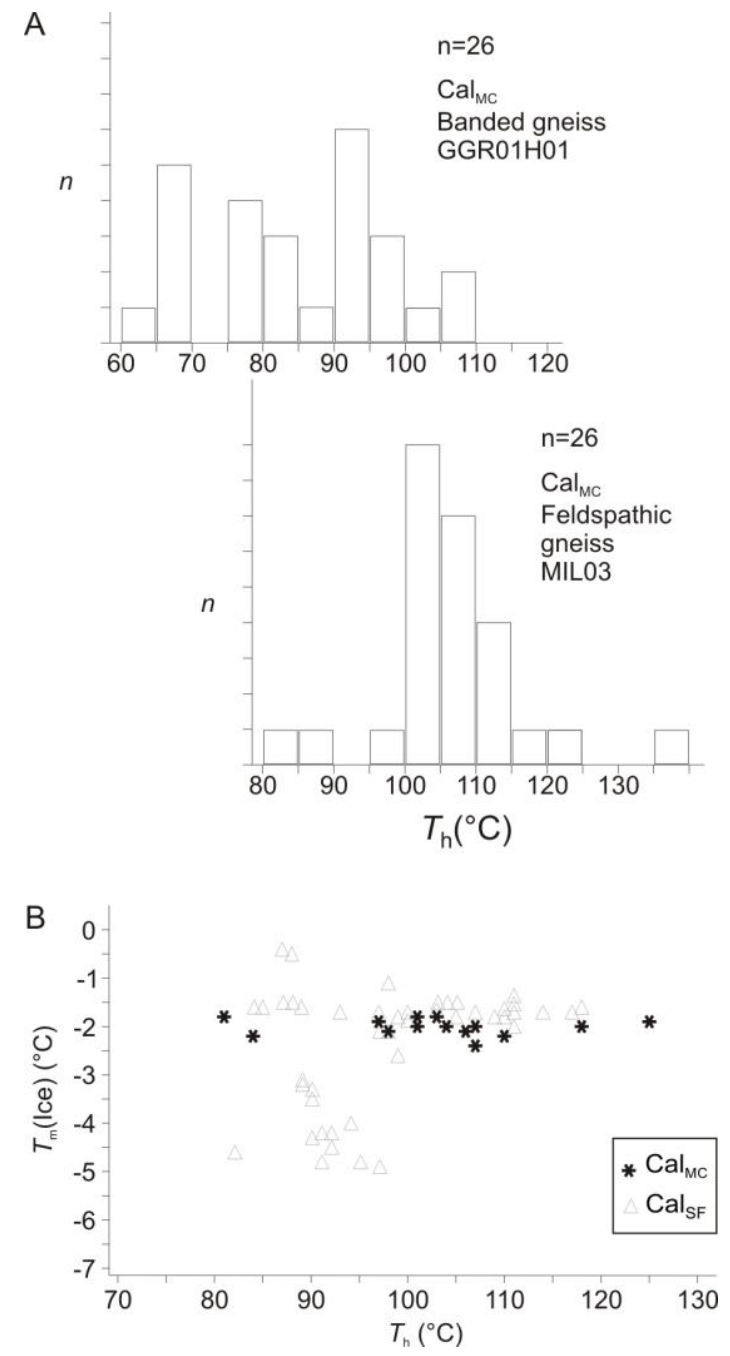

Figure 4.3. (A) Histograms of measured homogenisation temperatures in inclusions entrapped in microcrack calcite of a banded gneiss and a feldspathic gneiss sample. The two histograms are synchronised with respect to temperature. (B) Homogenisation vs. final melting temperature diagram of inclusions entrapped in $\mathrm{Cal}_{\mathrm{MC}}$. Data from the vein-filling $\mathrm{Cal}_{\mathrm{SF}}$ calcite are also displayed (see text for explanation). Final melting temperatures are in the same range in the two studied samples.

\subsubsection{Stable isotope composition of the microcrack calcite}

The measured oxygen and carbon isotope compositions $(\mathrm{N}=7)$ of the microcrack calcite are presented together with rock type and sample location in Table 4.1. Oxygen isotope compositions range between $14.6 \%$ and $30.3 \%$, while carbon isotope compositions are between $-9.7 \%$ and $1.7 \%$. The measured data define a linear trend (Fig. 4.4), the most depleted compositions of which are concurrent with the stable isotope compositions of dyke ocelli from the Eastern Mecsek volcanic dykes (i.e., primary carbonate in the magma), published by Demény and Harangi (1996). The trend points towards the compositions of the first vein-filling calcite phase $\left(\mathrm{Cal}_{\mathrm{EB}} 1\right.$, Dabi et al., 2011, where EB stands for elongated blocky texture), which is the most widespread occurring carbonate phase in the northern part 


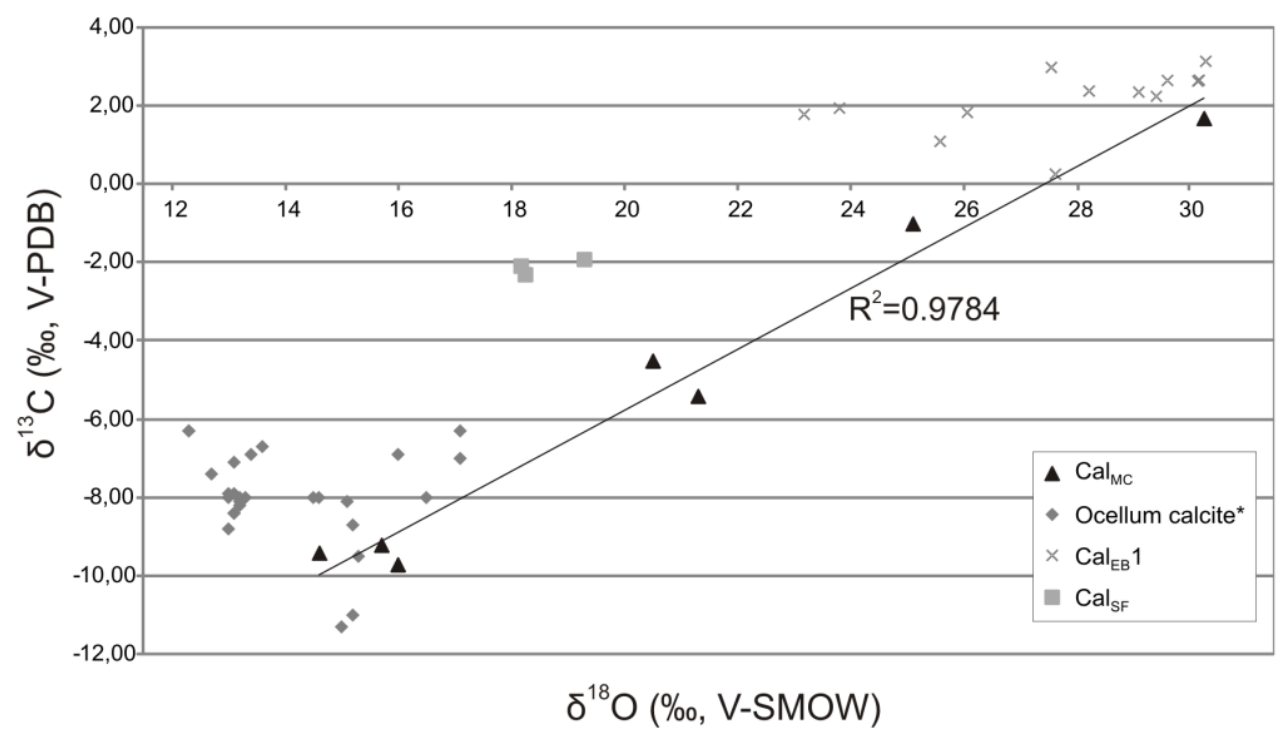

Figure 4.4. Stable isotope compositions of the microcrack calcites in whole rock samples. Stable isotope compositions of carbonate ocelli, published by Demény and Harangi (1996) and vein-filling calcite generations in the study area, published by Dabi et al. (2011), are also displayed.

of the study area, according to our field experience and sampling campaigns. Isotope compositions of the microcrack calcite from micaceous gneiss (Juhhodály Valley outcrop, samples of the least foliated chloritic gneiss type) are the most depleted; the only chlorite gneiss sample is located at the middle of the trend (Table 4.1). The only datum from amphibolite also falls at the middle of the trend. Calcite isotope compositions from the feldspathic gneiss samples display high variability of compositions with data at the most depleted, least depleted and medium values.

\begin{tabular}{llcc}
\hline Sample (location) & Rock type & $\boldsymbol{\delta}^{\mathbf{1 3}} \mathbf{C}$ (\%o V-PDB) & $\boldsymbol{\delta}^{\mathbf{1 8}} \mathbf{0}$ (\%o V-SMOW) \\
\hline VOL02vE (unnamed valley) & chlorite gneiss & -9.4 & 21.0 \\
Mil03 (Goldgrund valley) & feldspathic gneiss & -9.7 & 21.3 \\
Mil03b (Goldgrund valley) & feldspathic gneiss & 2.4 & 28.2 \\
Mil04 (Goldgrund valley) & feldspathic gneiss & 1.8 & 26.1 \\
AMF (Goldgrund valley) & amphibolite & 3.0 & 27.6 \\
JUH02H01 (Juhhodály valley) & chlorite gneiss & 2.0 & 23.8 \\
JUH02H01b (Juhhodály valley) & chlorite gneiss & -1.9 & 19.3 \\
\hline
\end{tabular}

Table 4.1. Isotope compositions of the studied samples. Sample location and the type of the host rock are also indicated. 


\subsection{Discussion}

\subsubsection{Interpretation of the microcrack system}

The studied cathodoluminescent images demonstrate the presence of a pervasive calcitefilled microcrack system in the rock types of the Ófalu crystalline rocks. No vein-filling calcite was found in the study area that had similar stable isotope compositions to that of the microcrack calcite and vein textures indicate that macroscopic fractures were completely filled and closed by the time of the microcrack calcite producing fluid flow event (see later). Thus, it is plausible to assume that the main medium of the fluid flow was the studied microcrack system, or other microporosity of the rock.

The formation of microcracks in gneissic rocks is generally studied with respect to failure, i.e., the studied microcrack systems are generated by bringing the samples to stresses near the peak stress in a triaxial or uniaxial ram (e.g., Gottschalk et al., 1990; Shea et al., 1993; Rawling et al., 2002). Consequently, the relation between the studied microcrack patterns with strain localisation and macroscopic failure structures are inherent in these experiments (e.g., Fig. 13. of Gottschalk et al., 1990). As macroscopic features associated with rock failure could not be identified in the studied outcrops or in the studied samples, we suggest that the microcracks produced in conventional rock mechanical experiments are not analogous to those described in this study. This is also constrained by the pattern of the studied crack system. Microcracks produced by triaxial experiments emanate from the micas of the rock samples either as wing crack, or as en echelon arrays connecting micas, depending on the angle between foliation and $\sigma 1$ (Gottschalk et al., 1990; Rawling et al., 2002). Thus, if similar microcracks were the precursor in the studied samples described by the above authors, similar patterns should be expected. In the studied gneissic samples, the microcrack directions are indiscriminate and are confined to feldspar grains or clusters of fragmented feldspars and avoid the micaceous zones. Therefore, taking together the above considerations, the implication is that the studied crack system is not analogous to those produced by conventional ram experiments. The extent and interconnection of the microcrack systems decreases with the average size of the feldspar grains and with the increase of the width of micaceous foliation planes. The segregation of feldspar clasts should play an important role in the extension and interconnection of the microcrack systems. 


\subsubsection{Interpretation of the microthermometric data}

The very different microcrack densities of the two samples should signify micromechanical differences during the formation of the microcrack system in the different rock types, which in turn should determine the fluid properties during later fluid flow, or the fluid flow itself.

The similar range of final melting temperatures in the studied samples (between -2.5 and $1.8^{\circ} \mathrm{C}$ ) demonstrates that the fluids are similar and possibly are of the same origin. The ranges of homogenisation temperatures are different in the two studied samples. Calcite in the banded gneiss contains inclusions with homogenisation temperatures between 64 and $110{ }^{\circ} \mathrm{C}$, while calcite in the feldspathic gneiss sample contains inclusions with a narrower and higher homogenisation range of between 100 and $115{ }^{\circ} \mathrm{C}$. The homogenisation temperatures represent different fluid densities and these densities are inherited from fluid pressures during the precipitation of calcite and fluid entrapment. Thus, by constructing the appropriate isochores for the measured densities, we obtain fields in the pressure-temperature space relevant of the entrapment process (Fig. 4.5). To do this, the programs BULK and ISOC were applied here (Bakker, 2003). It can be seen from Fig. 4.5 that higher fluid pressures or lower temperatures evolved in the banded gneiss than in the feldspathic gneiss. At this point, the furthest-reaching explanation of the pressure difference is that the crack systems of the different rock types formed distinct subsystems of different internal fluid pressure, or temperature at least in the time interval of calcite precipitation and occlusion of the microcrack system. However, with respect to the distinct subsystems, it is sound to state that the interconnection of the banded gneiss crack system was too low for the fluid to equilibrate and to develop uniform fluid pressure of the subsystem (see isochores in Fig. 4.5). However, the crack porosity of the feldspathic gneiss was sufficiently extended and interconnected for a uniform fluid pressure to form (Fig. 4.5).

Comparing the isochores relevant to the $\mathrm{Cal}_{\mathrm{MC}}$ parent fluid and the isochores constructed by the application of the homogenisation temperatures measured by Poros (2007) for fluids with similar salinities in the Mórágy Granite (up to $200{ }^{\circ} \mathrm{C}$ ), it is apparent that the same fluid flow event in the Mórágy Granite occurred under lower fluid pressure or higher temperature (Fig. 4.5).

The interpretation of fluid properties and the investigation of the entrapment conditions are rendered problematic by the following factors: (i) the possible magmatic source of the fluid temperature (by accepting the interpretation of the fluid's volcanic origin, what will be discussed in forthcoming section), (ii) the decrease of the fluid temperature towards that of the 
cooler rock after intrusion into the microcrack system, and possibly before, (iii) the possible role of mixing of two fluids with different temperature (discussed later). Thus we will return to the discussion of fluid properties after the evaluation of the stable isotope data in the hope that some conclusions will be drawn on the fluid-rock system that can aid the interpretation of the conformation of the fluid properties.

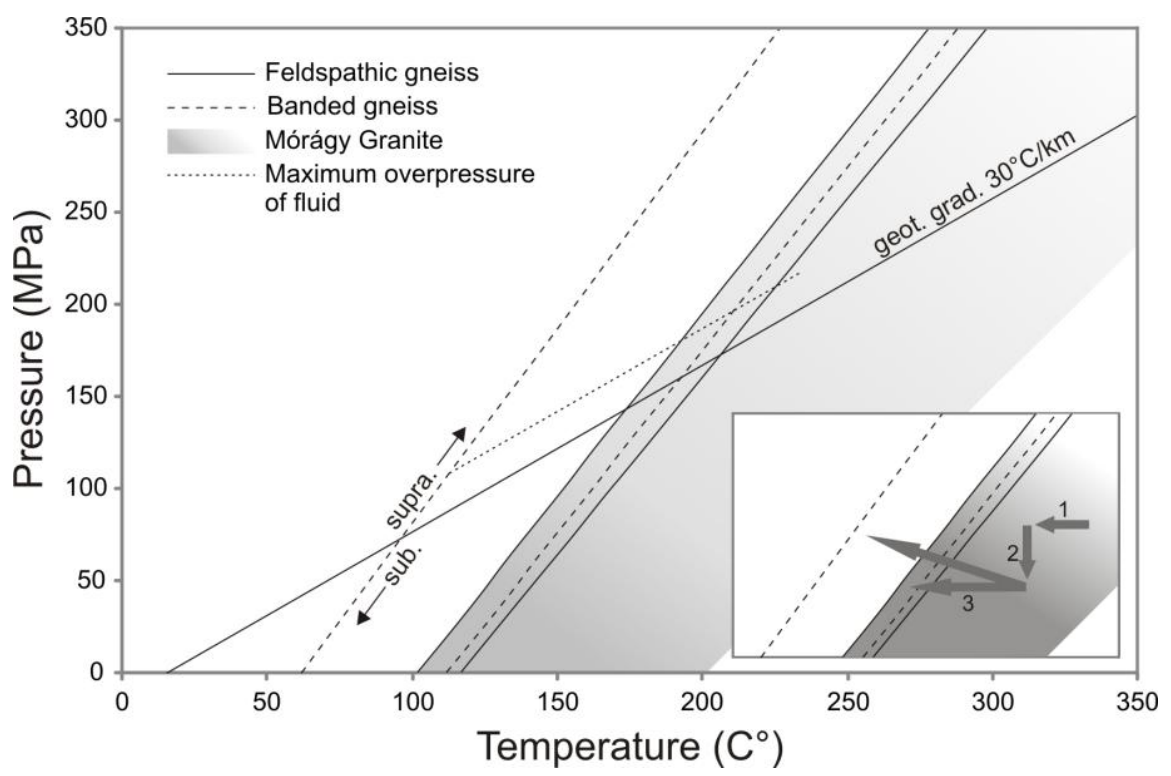

Figure 4.5. Isochores constructed based on homogenisation temperatures and measured salinities of the microcrack calcite parent fluids. The isochores indicate high fluid pressures in the banded gneiss, moderate and low fluid pressures in the feldspathic gneiss and the Mórágy Granite FIPs microcrack system, respectively. The Mórágy Granite fluid pressure-temperature field is constructed by application of the data of Poros (2007) with the application of the subset with similar final melting temperatures to those presented here. Supra and sublithostatic fluid pressures are separated by the intersection of the $60{ }^{\circ} \mathrm{C}$ isochore and the $30{ }^{\circ} \mathrm{C} / \mathrm{km}$ geothermal gradient. Inset shows the possible evolution paths of fluid properties: leftwards arrows indicate cooling, downward arrows indicate pressure drop. Stage 1: cooling after introduction of the volcanic volatiles in the initial microcrack system. Stage 2: pressure drop due to seismogenic microcrack formation. Stage 3: cooling of the fluid in the microcrack system of the feldspathic gneiss is governed by hydrostatic pressure and thus, is isobaric. The oblique arrow indicates synchronous cooling and pressure increase in the banded gneiss due to the stressing of the rock. The position and length of the arrows is arbitrarily chosen (see text for details).

However an average geothermal gradient is indicated on Fig. 4.5, with an arbitrarily chosen average tension strength of $20 \mathrm{MPa}$ for crystalline rocks (Lockner, 1995). The former designates the minima of possible fluid temperatures, by considering the fluid's magmatic origin and its higher temperature in comparison with the host rock. The latter designates the maxima of fluid pressures, taking into consideration that the maximum fluid pressure a rock can bear is equal to the sum of the vertical lithostatic pressure and the tension strength of the rock (Sibson, 1998). 


\subsubsection{Origin and connections of the microcrack calcite parent fluid}

Earlier studies on rocks of the Mórágy Granite to the south have described pervasive carbonatisation of the granitoid rocks and proposed its "direct relationship with the process of the Cretaceous volcanism, which triggered the explosion-like escape of the volatile components and induced an intensive carbonatisation" (Balla et al., 2009). However, the relationship between the dyke emplacement and the infiltrated calcite was not established by material testing. Dabi et al. (2011) described a similar phenomenon in the gneissic rocks at Ófalu.

Investigation of the microcrack calcite's isotopic compositions put constraints on the possible geochemical relations and on the source of the parent fluid. Carbon and oxygen isotope compositions of the host calcite define a linear trend, the most depleted compositions of which are concurrent with unaltered carbonate dyke ocelli from the Mecsek alkali basalt (Fig. 4.4). The trend defined by these data points towards compositions of the first vein calcite generation ( $\mathrm{Cal}_{\mathrm{EB}} 1$, Fig. 4.4), or carbonates precipitated from seawater (Prokoph et al., 2008). Thus, the trend can be interpreted in two ways: (i) it is formed during isotope exchange between the released volcanic volatiles and the carbonate phase most frequently occurring in the Ófalu crystalline rocks, i.e., antecedent vein calcite, $\mathrm{Cal}_{\mathrm{EB}} 1$; (ii) it is formed during mixing of the volcanic volatiles and formation fluids in isotope equilibrium with the mesozoic cover formations or seawater.

One of the medium compositions was measured in a sample from the Goldgrund valley amphibolite, where cathodoluminescent images of earlier formed vein calcites reveal intense alteration along grain boundaries (see Fig. 2.4B and A). During the fluids pervasion along grain boundaries, isotope exchange necessarily occurred. At the same time, during the fluid flow event discussed here, the previously formed vein system was completely sealed (see later); thus, for the host calcite parent fluids, the only flow paths available were the microporosity system of the rock mass and that of the completely closed vein system.

The measured final melting temperatures ( $T_{\mathrm{m}}\left(\right.$ Ice) between -2.5 and $-1.8{ }^{\circ} \mathrm{C}$ ) are very similar to those measured by Jáger et al. (2012) in primary inclusions of a sulphide chimney in Valanginian interpillow sediments at the Pusztakisfalu section, $10 \mathrm{~km}$ southwest of the study area $\left(T_{\mathrm{m}}\right.$ (Ice) between -2.1 and $\left.-1.8^{\circ} \mathrm{C}\right)$. Secondary inclusions in a brecciated calcite vein at Pusztabánya, $18 \mathrm{~km}$ west of the study area, with $T_{\mathrm{m}}$ (Ice) between -1.8 and $-1.5{ }^{\circ} \mathrm{C}$ were also published by the above authors. Poros (2007), Poros et al. (2008) and Szabó et al. (2008) studied the palaeohydrogeologic evolution of the Mórágy Granite to the south, based 
on microthermometry of fluid inclusions contained in vein minerals and fluid inclusion planes (FIP) of rock-forming quartz. Poros (2007) defined a fluid generation in FIPs with salinities between -4 and $-0.1{ }^{\circ} \mathrm{C}$ and homogenisation temperatures between 98 and $221^{\circ} \mathrm{C}$. The latter fluid flow event of Poros (2007) was interpreted to be the product of Cretaceous dyke emplacement, based on its high temperature, which was attributed to be the result of volcanic upheating. Although the aforementioned fluids identified by Poros (2007) have higher homogenisation temperatures (between 98 and $221^{\circ} \mathrm{C}$ ) than those entrapped in the Ófalu microcrack calcite, here it is assumed that the similar salinities signify their common origin, whereas the different densities represent different fluid pressures in the granite. The fluid generation entrapped in the FIPs of the Mórágy Granite display a range of final melting temperatures between those presented here and those measured in antitaxial veins of the MZ gneissic rocks ( $T_{\mathrm{m}}\left(\right.$ Ice) between -0.1 and $-0.3{ }^{\circ} \mathrm{C}$, Dabi et al., 2009b). Thus, it is plausible to assume that the Mórágy Granite FIPs had reactivated during subsequent flow events and that the fluid inclusion planes of the Mórágy Granite contain a mixture of different fluid generations. Taking into consideration the widespread occurrence of the discussed fluid and its close relation to the Cretaceous volcanic activity, the possible role of these fluids should be considered as a fluid "time horizon" for later palaeohydrogeologic studies in the region.

It is important to note that Dabi et al. (2011) have measured final melting temperatures and homogenisation temperatures in a vein calcite generation $\left(\mathrm{Cal}_{\mathrm{SF}}\right)$ of the Goldgrund valley amphibolite vein system, in the same range as those presented here being entrapped in the microcrack calcite. Petrographic features of the $\mathrm{Cal}_{\mathrm{SF}}$ fluid inclusions are ambiguous with definite secondary trails and cloud-like clusters with indefinite boundaries. Based on the cloud-like clusters, the discussed fluid was interpreted to be primary, i.e., it was interpreted to be the parent fluid of the abovementioned calcite generation and also, the microcrack calcite was assumed to be identical to the vein calcite (Dabi et al., 2011). As $\mathrm{Cal}_{\mathrm{SF}}$ calcites have distinct stable isotope compositions (Fig. 4.4), the earlier interpretation should be reconsidered. Thus, the fluids presented by Dabi et al. (2011) indicate the presence of the $\mathrm{Cal}_{\mathrm{MC}}$ parent fluid in the Goldgund valley vein system and its secondary origin in $\mathrm{Cal}_{\mathrm{SF}}$. This also implies that the $\mathrm{Cal}_{\mathrm{MC}}$ parent fluid pervaded after the complete sealing of the earlier vein system.

\subsubsection{Interpretation of the isotopic trend}

First, the trend is examined as being formed due to isotope exchange. Oxygen and carbon 
isotope compositions of the microcrack calcite define a linear trend pointing to the compositions of the oldest vein calcite generation of the study area $\left(\mathrm{Cal}_{\mathrm{EB}} 1\right.$, Dabi et al, 2011). Cathodoluminescent images of the same calcite phase and the range of isotope compositions also imply forceful interactions between the early vein-filling calcite and subsequent fluids. Field observations and sample collection campaigns suggest widespread occurrence of veins filled with $\mathrm{Cal}_{\mathrm{EB}} 1$ calcite in the Ófalu crystalline rocks. Taken altogether, the implication is that the microcrack calcite parent fluid developed its isotope composition during interaction with the $\mathrm{Cal}_{\mathrm{EB}} 1$ calcite. By assuming equilibrium fractionation between the parent fluids and the microcrack calcite, the members of the isotopic trend represent different degrees of the isotope exchange. Thus, the most depleted isotope compositions (furthest from the $\mathrm{Cal}_{\mathrm{EB}} 1$ composition) represent compositions closest to those being in equilibrium with the volcanic fluid, whereas the heaviest compositions are those that represent the most altered fluids.

In Fig. 4.6 the results of model calculations are presented. These models are constructed by the application of isotope exchange model of Sverjensky (1981) and Rye and Bradbury (1988). The model is modified for carbonates from Taylor (1978) and describes the change of a fluids isotopic composition due to isotope exchange with a carbonate of different isotopic composition.

For isotope exchange reactions:

$$
\mathrm{W} \delta^{18} \mathrm{O}_{\mathrm{H} 2 \mathrm{O}}^{\mathrm{i}}+\mathrm{R} \delta^{18} \mathrm{O}_{\mathrm{ROCK}}^{\mathrm{i}}=\mathrm{W} \delta^{18} \mathrm{O}_{\mathrm{H} 2 \mathrm{O}}^{\mathrm{f}}+\mathrm{R} \delta^{18} \mathrm{O}_{\mathrm{ROCK}}^{\mathrm{f}}
$$

can be written, where $\mathrm{W}=$ atom percent of water oxygen in the total system, $\mathrm{R}=$ atom percent of rock oxygen in the bulk system, i stands for initial and $f$ for final (Taylor, 1978). From this Sverjensky (1981) and Rye and Bradbury (1988) derived for oxygen isotope exchange between limestone and fluid:

$$
\begin{array}{r}
\mathrm{W} / \mathrm{R}=\mathrm{n}_{\mathrm{O}}\left(\delta^{18} \mathrm{O}_{\mathrm{Cal}}^{\mathrm{f}}-\delta^{18} \mathrm{O}_{\mathrm{Cal}}^{\mathrm{i}}\right) /\left(\delta^{18} \mathrm{O}_{\Delta-\delta}^{\mathrm{i}}-\delta^{18} \mathrm{O}_{\mathrm{Cal}}^{\mathrm{f}}\right) \\
\mathrm{W} / \mathrm{R}=\mathrm{n}_{\mathrm{C}} / \mathrm{X}_{\Sigma \mathrm{C}}\left(\delta^{13} \mathrm{C}_{\mathrm{Cal}}^{\mathrm{f}}-\delta^{13} \mathrm{C}_{\mathrm{Cal}}^{\mathrm{i}}\right) /\left(\delta^{13} \mathrm{C}_{\Delta-\delta}^{\mathrm{i}}-\delta^{13} \mathrm{C}_{\mathrm{Cal}}^{\mathrm{f}}\right)
\end{array}
$$

where $\mathrm{W}=$ atom percent of water oxygen/carbon in the total system, $\mathrm{R}=$ atom percent of rock oxygen /carbon in the bulk system, $\mathrm{n}_{\mathrm{O}}$ and $\mathrm{n}_{\mathrm{C}}$ are the number of moles of oxygen and carbon per mole of calcite, respectively. $\mathrm{X}_{\Sigma \mathrm{C}}$ is the number of moles of carbon in solution, $\delta^{18} \mathrm{O}_{\mathrm{Cal}}^{\mathrm{f}}$ 
and $\delta^{13} \mathrm{C}_{\mathrm{Cal}}^{\mathrm{f}}$ are the final, $\delta^{18} \mathrm{O}_{\mathrm{Cal}}^{\mathrm{i}}$ and $\delta^{13} \mathrm{C}_{\mathrm{Cal}}^{\mathrm{i}}$ are the initial oxygen and carbon isotope composition of the calcite, $\delta^{18} \mathrm{O}_{\Delta-\delta}^{\mathrm{i}}$ and $\delta^{13} \mathrm{C}^{\mathrm{i}}{ }_{\Delta-\delta}$ are $\delta^{18} \mathrm{O}$ value of calcite in equilibrium with the initial fluid.

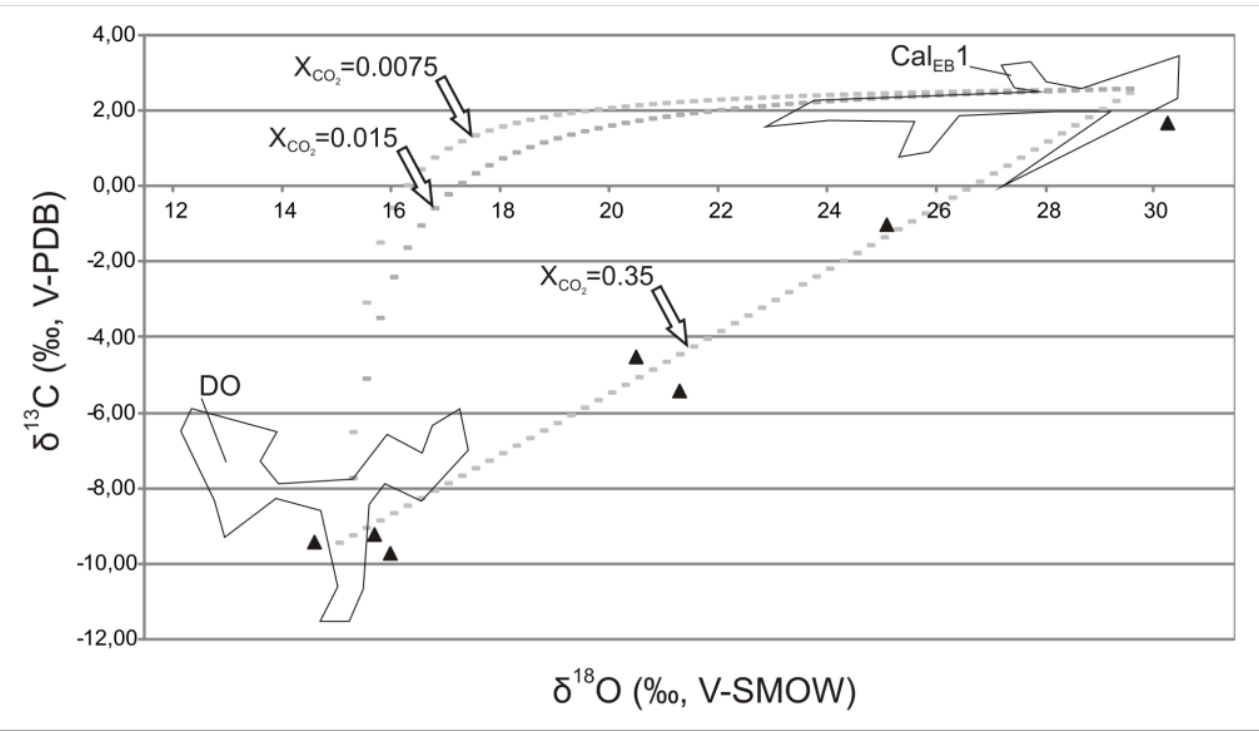

Figure 4.6. Theoretical isotope exchange trends with endmember compositions defined by the measured isotope compositions and different dissolved $\mathrm{CO}_{2}$ content of the fluid. The applied model produces similar trends to that measured with a dissolved $\mathrm{CO}_{2}$ of $\mathrm{X}_{\mathrm{CO} 2}=0.35$ (see text for details).

Substituting isotope compositions of $\mathrm{Cal}_{\mathrm{EB}} 1$ for $\delta^{18} \mathrm{O}^{\mathrm{i}}$ Cal and $\delta^{13} \mathrm{C}_{\mathrm{Cal}}^{\mathrm{i}}$ and the most depleted isotope compositions of $\mathrm{Cal}_{\mathrm{MC}}$ for $\delta^{18} \mathrm{O}_{\Delta-\delta}^{\mathrm{i}}$ and $\delta^{13} \mathrm{C}_{\Delta-\delta}^{\mathrm{i}}$ into the above equations we get the final isotope compositions of the $\mathrm{Cal}_{\mathrm{EB}} 1$ calcite as a function of different water/rock ratios and different moles of $\mathrm{C}$ in solution. By substituting the data gathered this way into equation (1) we get fluid isotope compositions during the isotope exchange process, from which the calcite compositions (i.e. hypothetical isotopic compositions) of $\mathrm{Cal}_{\mathrm{MC}}$ can be calculated with the appropriate $\Delta$ values. With the application of the above equations we get trends similar to that defined by the isotope data for $\mathrm{X}_{\Sigma \mathrm{C}}$ values around 0.35 (Fig. 4.6).

The amount of dissolved $\mathrm{CO}_{2}$ predicted by the isotope exchange model is inconsistent with the microthermometric data. The final melting temperatures of the microcrack calcite fluid inclusions make it possible to hedge in the amount of carbonate dissolved in the fluids entrapped in $\mathrm{Cal}_{\mathrm{MC}}$. Applying the freezing point depression of $1.86 \mathrm{~K} / \mathrm{mol}$ (Hedenquist and Henley, 1985) we get maximum $\mathrm{CO}_{2}$ molal concentrations of 1.34 and 0.968 (molecule ratios of 0.024 and $0.017 \mathrm{X}_{\mathrm{CO} 2}$, respectively). The above calculation is a simplification because it 
assumes that the fluid contains no other dissolved species than $\mathrm{CO}_{2}$. During microthermometric measurements no phases could be observed other than liquid and vapour, or ice and vapour; thus, the liquid entrapped belongs to the very low $\mathrm{X}_{\mathrm{CO} 2}$ type with $\mathrm{X}_{\mathrm{CO} 2}$ between 0 and 0.015 (Diamond, 2001). Thus, hereafter, a model composition with $\mathrm{X}_{\mathrm{CO} 2}$ of 0.015 is applied for the fluid composition entrapped in the microcrack calcite.

The assumption that the isotope exchange model is a relevant approach for the formation of the isotope trend implies that a massive loss of $\mathrm{CO}_{2}$ is inherent between the exchange process $\left(\mathrm{X}_{\mathrm{CO} 2} \approx 0.35\right)$ and fluid entrapment $\left(\mathrm{X}_{\mathrm{CO} 2}<0.015\right)$. As the solubility of $\mathrm{CO}_{2}$ is a function of fluid pressure, it is most plausible to assume that the opening of the now calcitefilled microcrack system provided the new grown volume in the fluid-rock system and a site of pressure drop of the inflowing $\mathrm{CO}_{2}$-rich fluid (stage 2 in Fig. 4.5). This model has several important consequences for the hydraulic behaviour of the fluid-rock system: (i) the flow path of the high pressure pre-failure fluid with high levels of dissolved $\mathrm{CO}_{2}$ (Fig. 4.5, stage 1) was confined to a less voluminous initial porosity system of the rock, than the now calcite-filled crack system. (ii) As the $\mathrm{CO}_{2}$-rich counterparts of the fluid with low levels of dissolved $\mathrm{CO}_{2}$ was not detected in the studied microcrack calcite (traces of heterogeneous entrapment could not be detected), the segregation of the $\mathrm{CO}_{2}$-rich phase and the openness of the system with respect to $\mathrm{CO}_{2}$ is also inherent in the model.

Here the possible role of fluid mixing in the formation of the trend should also be discussed. Assuming that the isotopic trend indicates mixing of two fluids, it is also necessary to presume that the two fluids had similar salinities; otherwise, one should expect a wide range between the two endmember compositions, i.e., volcanic volatiles and formational fluids of the cover formations or seawater. The sulphide chimneys at the Pusztakisfalu section and the presence of similar fluids in their primary inclusions to those presented here (Jáger et al., 2012) verifies the presence of a column of seawater above the study area at the time of microcrack formation. The possible process of effective seawater intrusion into the crystalline rocks is discussed in the following sections.

\subsubsection{Analogies}

To test the validity of the isotope exchange model and in order to understand some aspects of it, analogies in the literature were sought for different geological situations where the separation of $\mathrm{CO}_{2}$ had been observed, or where the appearance of excess $\mathrm{CO}_{2}$ reinforced the 
relevance of the above model. The infiltration of surface derived water (in this case seawater) into crystalline rocks is also discussed in evaluating the role of fluid mixing.

Numerous studies have discussed the concurrence of earthquake activity and the appearance of excess $\mathrm{CO}_{2}$ at exhalations and springs in seismoactive areas in both continental (Weise et al., 2001; Uysal et al., 2011) and oceanic environments (Johnson et al., 2000; Lilley et al., 2003; Seewald et al., 2003). Weise et al. (2001) mention the "general connection between fluid flow (predominantly $\mathrm{CO}_{2}$ ) and seismic activity in the crust". Sedimentary features in the limestone and marl formations of the Eastern Mecsek Mountains, contemporaneous with the volcanic activity, allude to vigorous seismic activity in the region (Jáger et al., 2012). Although the character of both contacts between the MZ and the adjacent Mórágy Granite and Vasas Marl Formation has not been clarified, the MZ is thought to be the focused zone of sinistral transcurrent movements in the geological past, based on the dislocation of the Permian and younger formations in its northern and southern surroundings (see Fig. 2.1B). It is well known from different seismic detection studies that large earthquakes damage rocks in and around rupture zones, generating defects, such as small faults and cracks (Hiramatsu et al., 2005; Li et al., 2006), which are in turn a reasonable explanation for the pervasive nature of the microcrack system and its textural deviations from those described in triaxial and uniaxial tests. Taking together the above considerations, the relation between the Early Cretaceous earthquake activity and the formation of the studied microcrack system and the associated flow event provides a reasonable explanation for the microcrack formation.

At the Juan de Fuca Ridge, it was shown that the post-seismic $\mathrm{CO}_{2}$ excess was the product of magma degassing and possibly, the seismic swarm was generated by magma movements beneath the oceanic crust (Lilley et al., 2003; Seewald et al., 2003). At the Vogtland seismoactive zone (East Germany), where two perpendicular fault systems crosscut each other in a continental setting, a temporal post-seismic crustal $\mathrm{CO}_{2}$ component was revealed in a thermal spring by Weise et al. (2001). The generation of the crustal $\mathrm{CO}_{2}$ was ascribed to the crushing of the crust and the release of $\mathrm{CO}_{2}$-rich fluids entrapped in fluid inclusions in the hypocentre of the swarm (Weise et al., 2001). The release of the earthquake swarm was assumed to be the disturbance of stress equilibrium by fluids related to magma intrusion (Špičák and Horálek, 2001). However, the local generation of excess $\mathrm{CO}_{2}$ in the hypocentre crustal volume and subsequent flow towards the surface, as described by Weise et al. (2001), is very similar to the model of Uysal et al. (2011), who interpreted a crack-seal vein formed 
near the surface as being precipitated from a sequence of pulses of seismically generated and separated $\mathrm{CO}_{2}$-rich and subsequent aqueous phases. Openness of the studied Ófalu hydraulic system towards the surface is also possible, because Jáger et al. (2012) measured final melting temperatures in primary inclusions of fossilised interpillow seafloor vents in the same range as those presented in our study. Here, it is important to emphasise that the vents studied by Jáger et al. (2012) are situated above the southwestern continuation of the MZ and possibly represent the overlying cover during the fluid flow event.

Lin et al. (2003) have studied stable isotopic compositions of gauge and vein-filling calcite in the recently active Nojima fault zone, Japan. Their data reveal that infiltration of seawater and meteoric water into the host granite during seismic activity is efficient up to depths of the studied section $(1800 \mathrm{~m})$. They also discuss the lowering of groundwater levels along fault traces following some moderate to large earthquakes (see references in Lin et al., 2003). Based on these observations, they suggest that the mechanics of seismic faulting act as a vacuum suction pump that causes the surface waters to be drawn down deep into the fault zone. If the $\mathrm{Cal}_{\mathrm{MC}}$ isotope trend is considered as being the result of fluid mixing, then the relevance of the suction pump model should be considered in the model. This model is consistent with the uniform fluid densities in the feldspathic gneiss and the inferred connection of the microcrack system to the external fluid container, i.e., the above seawater column, during subsequent build-up of the stress field.

\subsubsection{Formation and role of the microcrack system}

The geochemical data lead us to the interpretation of the microcrack system in conjunction with the seismic cycle. Dabi et al. (2009a) described an orange luminescent vein cross-cutting the vein system of the Goldgrund valley amphibolite body that displays ataxial growth morphology and crack-seal texture $\left(\mathrm{Cal}_{\mathrm{AT}}\right)$. Though the identity of this vein with the microcrack calcite is still to be confirmed, it indicates recurrent action, which confirms the possible role of seismic cycles. Scholz et al. (1973) enumerate seismic and geologic evidence and effects that precede earthquakes, which prove the general role of tectonically driven dilatancy preceding earthquakes. Thus, microcrack propagation is inherent in the general model of earthquake evolution. According to triaxial tests, in a transversely foliated rock this can be a very effective process, due to the presence of optimally oriented micas, and the formation of a regular microcrack system (Gottschalk et al., 1990; Shea et al., 1993; Rawling 
et al., 2002). The earthquake activity itself causes a sudden stress release, and the elastic closure of the stress induced microcracks occurs (Sibson et al., 1975). However a damage zone in the vicinity of the active fault also forms, with defects such as small faults and cracks (Hiramatsu et al., 2005; Li et al., 2006).

The authors conceive that the microcrack system, described in the present study, is not representative of the pre-earthquake stage of dilatancy, because the microcracks that form should resemble those produced by conventional ram tests (see Gottschalk et al., 1990; Shea et al., 1993; Rawling et al., 2002). The damage, caused by the earthquake in and around the rupture zone is more probably represented by the studied microcracks. The existence of suchlike zones is well-known (e.g. Hiramatsu et al., 2005; Li et al., 2006), but no rocks were yet described from a zone of this kind, at least according to our best knowledge. The nonsystematic patterns of microcracks suggest that their formation might be related to earthquake damage (Fig. 4.7A,B). However, this implies a rock-type-dependent seismic rheology, i.e., less damage in the more chloritic rocks and more damage in the feldspathic rock types.
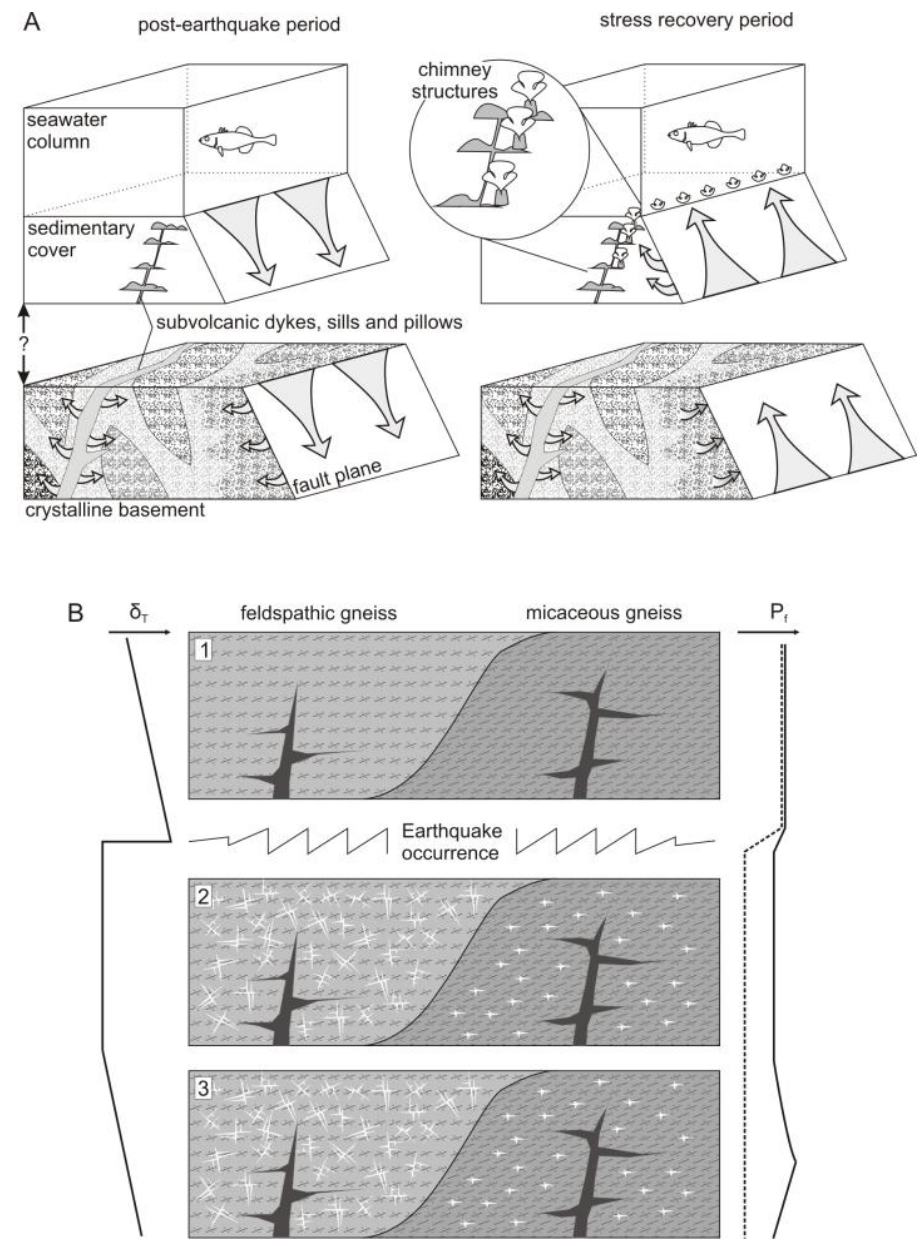

Figure 4.7. See next page for caption 
Furthermore, the presence of extensive microcrack systems, nearly $500 \mathrm{~m}$ from the supposed fault plane (the Mecsekalja Line), suggests that the crustal volume affected by seismic damage is very extensive around the fault zone and possibly capable of swallowing huge fluid volumes (Fig. 4.7A). The palaeostress analysis of the Mórágy Granite to the south (Maros et al., 2003) calls the attention on significant transcurrent movements in the Cretaceous what implies the same process in the formation of the pervasive calcite of the Mórágy Granite.

The $\mathrm{CO}_{2}$ degassing model is still to be confirmed, for example, by the microthermometric analysis of fluid inclusions of the dyke ocellum carbonates, to test the validity of high $\mathrm{CO}_{2}$ content of the original volatile. Nevertheless, the model described above, i.e., $\mathrm{CO}_{2}$ separation due to pressure drop accompanying seismic damage, is a viable explanation for seismically released $\mathrm{CO}_{2}$, which is a general phenomenon associated with seismic activity (Johnson et al., 2000 and references therein; Weise et al., 2001; Uysal et al., 2011). However, it is applicable only to systems where the presence of high $\mathrm{CO}_{2}$ fluids is a reasonable assumption before seismic activity.

The narrow range of fluid densities in the feldspathic gneiss with the more extensive crack system suggests connection to a hydrostatic fluid reservoir, possibly the seawater above the rock column during post-earthquake stress recovery and deformation. The cover of the study area at the time of the formation of the microcrack system is possibly represented by the Bathonian to Lower Valanginian marine carbonate sequence, including a $160 \mathrm{~m}$ thick sequence of hyaloclastite and intrusive pillow basalt and associated sulphide chimney

Figure 4.7. (previous page) Fluid redistribution model at the Ófalu tectonic line during the microcrack formation. (A) Exploded view of the crustal volume around the fault. Question mark indicates that the depth of the crystalline-sedimentary interface and the width of the sedimentary cover are unknown at the time of the microcrack formation. Differently dotted volumes represent different rock types and microcrack systems. Arrows indicate fluid flow directions. In the post-earthquake period, fluid flow occurs both from the volcanic dykes and from the seawater column above, towards the microcrack system. In the stress recovery period, the expusion of the fluids contained in the microcrack system occurred. These fluids possibly discharged along intrasedimentary chimneys of the above sedimentary layers. (B) Relative fluid pressure conditions in different rock types. $\delta_{\mathrm{T}}-$ tectonic stress, $\mathrm{P}_{\mathrm{f}}-$ fluid pressure. 1. Fluid flow from the volcanic dykes occurs towards the pre-existing microcrack system of the crystalline rocks. 2. At the time of the earthquake activity, microcrack systems of rock-type-dependent extension and connectivity forms in the damage zone around the fault. The earthquake causes the tectonic stress to release, while the newly-formed microcrack system causes the drop of the internal fluid pressure. This drop is possibly different in the different rock types. 3. Subsequent stress recovery causes the closure of the microcrack system and the contained fluids to be expelled. However, the fluids contained in the less interconnected microcrack system of the banded gneiss cannot discharge, which causes the internal fluid pressure to increase. This pressure increase is ceased, when the sum of the tectonic stress and the horizontal stress attain the crack initiation stress of the banded gneiss. 
structures (Fig. 4.7A, Jáger et al., 2012). Liassic sediments are also known at the Pusztakisfalu area (Jáger, personal communication). Thus, a thick sedimentary cover possibly existed above the microcrack system during its formation, not to mention the crystalline column possibly denuded in the geologic past. Lin et al. (2003) have demonstrated that the infiltration of meteoric and seawater can be efficient to depths of $1800 \mathrm{~m}$ in a granitic rock, if assisted by seismicity and associated faulting, which exerts a vacuum suction pumping role. The data of Tsunogai and Wakita (1995) also raise the role of microcracks formed during the Kobe earthquake and the introduction of shallow subsurface water into artesian reservoirs. The studied microcrack system possibly provided an additional factor of this effect at the study area.

The different ranges of fluid densities in the studied rock types can be explained by the different sensitivities of the two fluid-rock systems to the post-seismic stress recovery and associated deformation of the newly-formed porosity. Accordingly, the microporosity of the banded gneiss was undrained and the fluid could not discharge to lower its pressure (Fig. 4.7B). This is analogous with the interdependent role of fluid viscosity and critical strain rate on fracture strength (Paterson and Wong, 2005). Expulsion of the fluids contained in the seismic microcrack porosity of the feldspathic gneiss is constrained by the interpillow sulphide chimneys at the Pusztakisfalu section (Fig. 4.7A, Jáger et al., 2012). These considerations aid the relevance of a stress-governed hydraulic system, the hydraulic basement of which is the fluid saturated seismogenic microcrack system of the crystalline rocks and the discharge of which possibly built chimney structures along the trail of the fault (still preserved at the southwestern continuation of the Mecsekalja Zone).

According to the above considerations, the fluid densities presented are representative of the evolutionary stages of a seismically active area after earthquake occurrence. If the earthquake activity is assumed to be a recurrent process, then the dilatancy preceding earthquakes (Scholz et al., 1973) should also be preceded by microcrack closure due to the stress recovery around the fault.

Furthermore the preseismic stress induced opening of microcracks is more efficient in a transversely foliated rock, where the optimally oriented micas are the plentiful source of wing-cracks (Gottschalk et al., 1990, Shea et al., 1993). Thus the higher limit of deformation governed fluid pressures is possibly staked off by the rock-specific crack initiation, and thus is a matter of rock mechanics. This means that in the post-seismic period of the seismic cycle is a period of fluid pressure increase due to the initial crack-closure stage of the rock. This stage 
possibly terminated by the crack initiation stage, when the wing cracks start to evolve around preferentially oriented micas and the fluid pressure in the microporosity starts to decrease (indicated by a break in the line representing the fluid pressure inside the banded gneiss on Fig. 4.7B). Thus the lowest homogenization temperature isochors possibly represent this stage of the seismic cycle.

In summary, the focused damage and microcrack formation in a fluid-saturated crustal volume around a seismically active fault and subsequent stress recovery seems to provide an optimal environment for fluid pressure fluctuation and for the redistribution of crustal fluids. This model applies the seismic suction pump model proposed by Lin et al. (2003) in a postearthquake damage zone and subsequent closure of the damaged microcracks due to stress recovery, as the main process that governs hydraulic processes. This is different from the seismic pumping model of Sibson (1975), where the fluid redistributes due to the collapse of the pre-earthquake dilatant zone.

\subsection{Conclusions}

The crack geometries revealed by the cathodoluminescent images are different from those described by conventional triaxial tests and are interpreted to be seismogenic. However, the rock-type-dependent extension (density and connectivity) of the crack systems suggests the validity of the earlier confirmed relation between microcrack formation and mica content (Shea et al., 1993); the key parameters are the connection of feldspar clasts and the width of micaceous bands.

The pervasive "calcite infiltration" described in granitic rocks of the Mórágy Granite by previous authors (Balla et al., 2009) is similar to that described in the present study. Our stable isotope data constrain the former assumption that the parent fluid of the microcrack calcite is related to the Early Cretaceous dykes. Furthermore, the trend of the data implies extended interaction of the fluid with the antecedent vein calcite before and mixing with extraneous fluids, possibly seawater, after failure and microcrack formation. The role of isotope exchange with the most abundant vein calcite phase is in concordance with earlier description and interpretation of the vein textures (i.e., metasomatism along grain boundaries within the early calcite veins, as described by Dabi et al., 2009a; 2011). The exchange model produces a trend similar to that defined by the measured data with a dissolved $\mathrm{CO}_{2}$ concentration of $\mathrm{X}_{\mathrm{CO} 2}=$ 0.35, which is in conflict with the microthermometric data. According to microthermometry, 
the highest dissolved $\mathrm{CO}_{2}$ of the fluid entrapped in the calcite-filled microcracks is $\mathrm{XCO}_{2}=$ 0.015. Thus, a massive amount of $\mathrm{CO}_{2}$ is assumed to have escaped during the formation of the microcrack system and before calcite precipitation. Although the $\mathrm{CO}_{2}$ degassing model is still to be confirmed, it can be relevant to systems where the presence of fluids with high levels of dissolved $\mathrm{CO}_{2}$ can be reasonably assumed at the time of seismic activity.

Both the inferred loss of $\mathrm{CO}_{2}$ and the introduction of seawater raise the role of seismic activity in the formation of the microcrack system, based on recent analogies and similarities to fossilised seismic faults. Independent data, i.e., sedimentary features in Early Cretaceous marine formations to the SW of the study area also confirm seismic activity contemporaneous with the volcanism. The Mecsekalja tectonic line (the northern boundary of the Mecsekalja Zone) was possibly a focal plane of these tectonic movements and thus, the microcrack system is considered to be seismogenic in origin and representative of the damage zone around the former rupture zone.

Fluid inclusion microthermometry suggests rock-type-dependent fluid pressure conditions, either in comparison with the same fluid flow event in the Mórágy Granite. The densities of fluids entrapped in the calcite of the banded gneiss indicate a closed fluid-rock subsystem and effects of post-seismic stress recovery and associated deformation. The narrow range of fluid densities in the feldspathic gneiss is interpreted to be indicative of openness toward the surface and an interconnected microcrack system.

The possible role of seawater intrusion into the microcrack system highlights the role of the seismic suction pumping model of Lin et al. (2003) in the post-earthquake seismic phase and the deformation related closure of these microcracks in the expuulsion of these fluids. This is different from the seismic pumping model of Sibson et al. (1975), where the postseismic increase of fluid pressure is induced by the collapse of the pre-seismic dilatant zone. 


\section{Summary}

For the palaeohydrogeologic reconstruction of the Ófalu Metamorphic Complex, macroscopic (75 samples), microscopic (77 thin sections) and cathodoluminescence microscopic description, microthermometric (six vein mineral generations were successfully applied for fluid inclusion microthermometry) and stable isotope (44 stable isotope data, including 4 hydrogen isotope composition from fluid inclusions) measurements were carried out. See Table S1 for a detailed compilation of samples and measurements.

\begin{tabular}{|c|c|c|c|c|c|c|}
\hline Sample & type & $\begin{array}{l}\text { loca- } \\
\text { tion }\end{array}$ & host & $\begin{array}{l}\text { thin } \\
\text { section }\end{array}$ & $\begin{array}{l}\text { micro- } \\
\text { thermometry }\end{array}$ & stable i. \\
\hline Amf01 & vein & 1 & amphibolite & 1 & & $\mathrm{Cal}_{\mathrm{EB}} 2, \mathrm{Cal}_{\mathrm{EB}} 2 \mathrm{lim}$ \\
\hline $\mathrm{Amf02}$ & vein & 1 & amphibolite & 3 & & $\mathrm{CaI}_{\mathrm{EB}} 1(2 \mathrm{x})$ \\
\hline Amf03 & vein & 1 & amphibolite & 4 & & $\begin{array}{c}\mathrm{Cal}_{\mathrm{EB}} 1(3 \mathrm{x}) ; \mathrm{Dol}_{\mathrm{ZON}}(3 \mathrm{x}) \\
\mathrm{Cal}_{\mathrm{SF}} ; \mathrm{Cal}_{\mathrm{EB}} 2\end{array}$ \\
\hline Amf04 & vein & 1 & amphibolite & & & \\
\hline Amf05 & vein & 1 & amphibolite & & & \\
\hline Amf06 & vein & 1 & amphibolite & & & \\
\hline Amf07 & vein & 1 & amphibolite & & & \\
\hline Amf08 & vein & 1 & amphibolite & 1 & $\mathrm{Cal}_{\mathrm{SF}}$ & $\mathrm{Cal}_{\mathrm{SF}}(2 \mathrm{x})$ \\
\hline Amf09 & vein & 1 & amphibolite & 1 & & $\mathrm{Cal}_{\mathrm{EB}} 1(2 \mathrm{x})$ \\
\hline Amf10 & vein & 1 & amphibolite & 4 & & $\mathrm{Cal}_{\mathrm{EB}} 1(3 \mathrm{x})$ \\
\hline Amf11 & vein & 1 & amphibolite & 6 & & $\mathrm{CaI}_{\mathrm{EB}} 1(3 \mathrm{x}) ; \mathrm{Cal}_{\mathrm{EB}} 2\left(\mathrm{Cal}_{\mathrm{BL}}\right)$ \\
\hline Amf12 & vein & 1 & amphibolite & 1 & $\mathrm{Dol}_{\mathrm{ZON}}, \mathrm{Qtz}_{\mathrm{BL}}$ & \\
\hline AmfUNK & vein & 1 & amphibolite & 3 & & $\mathrm{Cal}_{\mathrm{EB}} 2$ \\
\hline MA & vein & 1 & amphibolite & 4 & & \\
\hline mil02 & vein & 1 & gneiss & 2 & & \\
\hline mil05 & vein & 1 & gneiss & 1 & & \\
\hline GGR04 & vein & 7 & serpentinite & 3 & & \\
\hline GGR03 & vein & 8 & cr. Limestone & 4 & & \\
\hline STU01 & host & 2 & gneiss & & & \\
\hline STU03 & host & 2 & gneiss & & & \\
\hline STU03v1 & vein & 2 & gneiss & 1 & & \\
\hline VOL01 & host & 3 & gneiss & & & \\
\hline JUH01v1 & vein & 4 & gneiss & 1 & & $\operatorname{Cal}_{\text {ANT }}(2 x)$ \\
\hline JUH01v2 & vein & 4 & gneiss & 6 & $\mathrm{Cal}_{\mathrm{ANT}}$ & $\mathrm{Cal}_{\mathrm{ANT}}(2 \mathrm{x}) ; \delta \mathrm{D}-\mathrm{inc}$. \\
\hline JUH01v3 & vein & 4 & gneiss & 1 & & \\
\hline JUH01v4 & vein & 4 & gneiss & 1 & & \\
\hline JUH01h & host & 4 & gneiss & 1 & & \\
\hline
\end{tabular}




\begin{tabular}{|c|c|c|c|c|c|c|}
\hline Sample & type & $\begin{array}{l}\text { loca- } \\
\text { tion }\end{array}$ & host & $\begin{array}{c}\text { thin } \\
\text { section }\end{array}$ & $\begin{array}{c}\text { micro- } \\
\text { thermometry }\end{array}$ & stable i. \\
\hline JUH02v1 & vein & 4 & gneiss & & & \\
\hline JUH02h01 & host & 0 & gneiss & & & \\
\hline KOV01 & vein & 5 & gneiss & & & \\
\hline KOV01B & vein & 5 & gneiss & & & \\
\hline KOV01C & vein & 5 & gneiss & & & \\
\hline KOV01D & vein & 5 & gneiss & 1 & & \\
\hline KOV01E & vein & 5 & gneiss & 1 & & \\
\hline KOV01F & vein & 5 & gneiss & & & \\
\hline KOV01G & vein & 5 & gneiss & 1 & & \\
\hline KoV01H & vein & 5 & gneiss & & & $\mathrm{Cal}_{\mathrm{ANT}}$ \\
\hline KOV01I & vein & 5 & gneiss & & & \\
\hline KOV01J & vein & 5 & gneiss & 1 & & \\
\hline KOV01K & vein & 5 & gneiss & & & \\
\hline KOV01L & vein & 5 & gneiss & & & \\
\hline KOV01M & vein & 5 & gneiss & 1 & & \\
\hline KOV01N & vein & 5 & gneiss & 1 & & $\mathrm{Cal}_{\mathrm{ANT}}$ \\
\hline VOL01vA & vein & 6 & gneiss & & & \\
\hline VOL01vB & vein & 6 & gneiss & & & \\
\hline VOL01vC & vein & 6 & gneiss & & & \\
\hline VOL01vD & vein & 6 & gneiss & 1 & & \\
\hline VOL01vE & vein & 6 & gneiss & 1 & & \\
\hline VOL01vF & vein & 6 & gneiss & 1 & $\mathrm{Cal}_{\mathrm{ANT}}$ & $\mathrm{Cal}_{\mathrm{ANT}}(2 \mathrm{x}) ; \delta \mathrm{D}-$ inc. \\
\hline VOL02v1 & vein & 6 & gneiss & 1 & & \\
\hline VOL02vB & vein & 6 & gneiss & 1 & & \\
\hline VOL02vC & vein & 6 & gneiss & 1 & & \\
\hline VOL02vD & vein & 6 & gneiss & 1 & & \\
\hline VOLO2vE & vein & 6 & gneiss & 1 & $\mathrm{Cal}_{\mathrm{EB}} 1$ & \\
\hline VOL02vF & vein & 6 & gneiss & 1 & & \\
\hline GGR01v01 & vein & 1 & gneiss & 2 & & $\mathrm{Cal}_{\mathrm{ANT}} ; \delta \mathrm{D}$ - inc. \\
\hline GGR01v0X & vein & 1 & gneiss & & & $\mathrm{Cal}_{\mathrm{ANT}}$ \\
\hline GGR01v03 & vein & 1 & gneiss & & & \\
\hline GGR01v04 & vein & 1 & gneiss & & & \\
\hline GGR01v05 & vein & 1 & gneiss & & & \\
\hline GGR01v06 & vein & 1 & gneiss & & & \\
\hline GGR01v07 & vein & 1 & gneiss & & & \\
\hline GGR01v08 & vein & 1 & gneiss & & & \\
\hline mil03 & host & 1 & gneiss & 5 & $\mathrm{Cal}_{\mathrm{MC}}$ & $\mathrm{Cal}_{\mathrm{MC}}$ \\
\hline mil04 & host & 1 & gneiss & & & $\mathrm{Cal}_{\mathrm{MC}}$ \\
\hline $\mathrm{amf}$ & host & 1 & amphibolite & 2 & & $\mathrm{Cal}_{\mathrm{MC}}$ \\
\hline VOL02E & host & 6 & gneiss & & & $\mathrm{Cal}_{\mathrm{MC}}$ \\
\hline
\end{tabular}




\begin{tabular}{ccccccc}
\hline Sample & type & $\begin{array}{c}\text { loca- } \\
\text { tion }\end{array}$ & host & $\begin{array}{c}\text { thin } \\
\text { section }\end{array}$ & $\begin{array}{c}\text { micro- } \\
\text { thermometry }\end{array}$ & stable $\mathrm{i}$. \\
\hline GGR02H01 & host & 1 & gneiss & 2 & $\mathrm{Cal}_{\mathrm{MC}}$ & $\mathrm{Cal}_{\mathrm{MC}}(2 \mathrm{x})$ \\
$\mathrm{JUH} 02 \mathrm{H} 01$ & host & 4 & gneiss & & & \\
$\mathrm{JUH} 04 \mathrm{H} 01$ & host & 4 & gneiss & 1 & & \\
ADY01v7 & vein & 9 & amphibolite & 1 & & \\
\hline
\end{tabular}

Table S1. Recapitulative table of the studied samples and methods.

The studies were commenced with the textural characterization of the vein system of the Goldgrund valley amphibolite body, where eight vein filling mineral phases could be distinguished. The textural relations made possible to define the relative sequence of the mineral generations. In the next phase sample collection campaigns were expanded towards the whole study area. In the course of the microscopic description of the vein samples, gathered during the later runs it turned out that the vein types in the gneissic rocks can be identified with those of the amphibolite body, but with different textures in case of the late veins. The stable isotope composition measurements were planned and carried out to provide data on the mineral generations distinguished based on their textural features and to characterize them. The measured stable isotope compositions traced out distinct groups in accordance with the textural types. The microthermometric data in conjunction with the stable isotope data made the impoundment of the affinity of some parent fluids possible, and in some cases provide evidence of their source. Trends and clustering of the isotope data could also be used in the interpretation of the hydraulic behaviour of the parent fluid in several cases. These hydraulic behaviour models were of course developed with the integration of textural features (including cathodoluminescent textures), and were collated with the relevant literature on the appropriate textural types. Relations with fluid flow events described in the region were also given heed to.

The early textural observations revealed that several vein phases display textures well described and interpreted in the literature, e.g. veins with syntaxial and antitaxial growth morphology, crack-seal patterns, while some textures were found which are not discussed by other authors, e.g. the massive calcite $\left(\mathrm{Cal}_{\mathrm{SF}}\right)$, or the pervasive calcite filled microcrack systems. For an overview see Table S2. In the next section a brief description of the vein filling mineral generations and the reconstructed fluid flow events are given. The interpretation is also discussed. 


\begin{tabular}{|c|c|c|c|c|c|c|}
\hline $\begin{array}{l}\text { Flow } \\
\text { event }\end{array}$ & $\begin{array}{l}\text { Mineral } \\
\text { phase }\end{array}$ & $\begin{array}{c}\text { Fluid (inclusion } \\
\text { petrography, } \\
\text { temperature) }\end{array}$ & Origin of fluid & $\begin{array}{l}\text { Fluid flow } \\
\text { mechanism }\end{array}$ & Age & Affinity \\
\hline 1. & $\mathrm{Cal}_{\mathrm{EB}} 1$ & primary, $<50^{\circ} \mathrm{C}$ & $\begin{array}{c}\text { formation fluid in } \\
\text { marine } \\
\text { carbonates }\end{array}$ & $\begin{array}{l}\text { advective (frac- } \\
\text { ture chennelized) }\end{array}$ & $\begin{array}{l}\text { Triassic or } \\
\text { younger }\end{array}$ & \\
\hline 2. & $\mathrm{Dol}_{\mathrm{ZON}}$ & primary, $>95^{\circ} \mathrm{C}$ & basinal brine & percolative & & \\
\hline 3. & $\mathrm{Qtz}_{\mathrm{BL}}$ & primary, $<50^{\circ} \mathrm{C}$ & meteoric & $\begin{array}{l}\text { advective (frac- } \\
\text { ture chennelized) }\end{array}$ & & \\
\hline 4. & $\mathrm{Cal}_{\mathrm{SF}}$ & & & percolative & & \\
\hline 5. & Cal $_{\text {MASS }}$ & secondary in $\mathrm{Cal}_{\mathrm{SF}}$ & & & Cretaceous & $\begin{array}{c}\text { Mórágy } \\
\text { Granite, } \\
\text { Pusztakisfalu }\end{array}$ \\
\hline 6,7 & $\begin{array}{l}\mathrm{Cal}_{\mathrm{MC}} \\
\mathrm{Cal}_{\mathrm{AT}}\end{array}$ & $\begin{array}{c}\text { primary, } \\
\text { secondary in Cal }\end{array}$ & $\begin{array}{l}\text { volcanic dyke } \\
\text { emplacement }\end{array}$ & $\begin{array}{l}\text { percolative, seiz- } \\
\text { mically governed }\end{array}$ & Cretaceous & $\begin{array}{l}\text { Mórágy } \\
\text { Granite }\end{array}$ \\
\hline 8. & $\begin{array}{l}\mathrm{Cal}_{\mathrm{ANT}} \\
\mathrm{Cal}_{\mathrm{EB}} 2\end{array}$ & primary & $\begin{array}{l}\text { volcanic dyke } \\
\text { emplacement }\end{array}$ & $\begin{array}{l}\text { percolative, seiz- } \\
\text { mically governed }\end{array}$ & Cretaceous & $\begin{array}{l}\text { Mórágy } \\
\text { Granite }\end{array}$ \\
\hline
\end{tabular}

Table S2. Recapitulative table of the distinguished mineral generations and their interpretation

1) $\mathrm{Cal}_{\mathrm{EB}} 1$ (elongate blocky calcite): the earliest calcite built up of elongate blocky crystals and display syntaxial growth morphology (Table S2). The fluid flowed advectively along fractures of widths up to $2 \mathrm{~cm}$ (fracture channelized flow). The vein system clogged before complete filling and remnant voids subsided. The stable isotope composition suggests the parent fluid's affinity to marine carbonates. Taking into consideration the Triassic commence of carbonate deposition in the region, the development of the vein system couldn had started earlier.

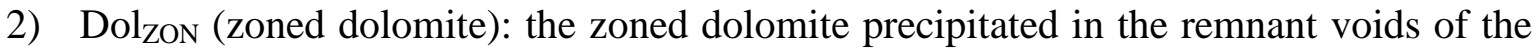
pre-existing vein system filled with $\mathrm{Cal}_{\mathrm{EB}} 1$ calcite. The phase is the syntaxial overgrowth of the $\mathrm{Cal}_{\mathrm{EB}} 1$ crystals, possibly the parent fluid got to the site of precipitation via percolative flow. At least locally this is constrained by metasomatised zones in the $\mathrm{Cal}_{\mathrm{EB}} 1$ crystals, as revealed by cathodoluminescence. Cathodoluminescence images also reveal a subzone of oscillatory zonation, indicating precipitation in a closed system. The primary fluid inclusions entrapped in the dolomite imply that the minimum temperature of precipitation was $95^{\circ} \mathrm{C}$.

3) $\mathrm{Qtz}_{\mathrm{BL}}$ (blocky quartz): the quartz grains have blocky morphology and display syntaxial growth morphology that indicates advective flow of the parent fluid. This is further constrained by the small quartz filled microveins at some places. The crystals contain one phase aqueous inclusions, which is indicative of low temperature $\left(<50{ }^{\circ} \mathrm{C}\right)$ and possibly meteoric origin. 
4) $\mathrm{Cal}_{\mathrm{SF}}$ (space filling calcite): sealing of the remnant voids was completed with the precipitation of the massive space filling calcite. Two generations of subsequent fluids are entrapped in this calcite. The lack of primary inclusions precludes the interpretation of the parent fluid's origin. The orange cathodoluminescent metasomatic zones along the grain boundaries in the zone of $\mathrm{Cal}_{\mathrm{EB}} 1$ and $\mathrm{Dol}_{\mathrm{ZON}}$ crystals suggest fluid percolation along the boundaries of the pre-existing crystals. This flow event could produce space filling calcite.

5) $\mathrm{Cal}_{\text {MASS }}$ (massive calcite): deposition of the red massive calcite occurred after a forceful fracture event, as indicated by features like dragged off fragments of the pre-existing vein minerals. The red colour is given by a vast of small, submicroscopic hematite inclusions. The deposit was interpreted to be related to the Cretaceous volcanic activity, without the definition of the genetic process. The disintegration and macroscopic discolouration of the pre-existing vein minerals (including $\mathrm{Cal}_{\mathrm{SF}}$ ) at some places are also assigned to the fluids associated with the formation of this phase.

6) $\mathrm{Cal}_{\mathrm{MC}}, \mathrm{Cal}_{\mathrm{AT}}$ (microcrack calcite, ataxial calcite): microcrack systems of different extension and connectivity are prevalent in rocks of the Mecsekalja zone, a phenomenon very similar to that described in the Mórágy Granite to the south. Stable isotope compositions of the microcrack calcite define a trend that points from the compositions of dyke ocelli toward marine carbonate compositions, what constrain the fluid's volcanic origin. The trend can be interpreted as being formed during isotope exchange with the $\mathrm{Cal}_{\mathrm{EB}} 1$ calcite, or as being formed due to mixing of the volcanic fluid and seawater. The former interpretation also demands $\mathrm{CO}_{2}$ outgassing, while the latter assume the intrusion of seawater or formation water into the crystalline rock mass. Both explanations are inherent in seismic activity, what suggest that the microcracks are formed as a result of seismic damage around the Ófalu tectonic line during its active period. The parent fluid of the calcite can be identified with those contained as secondary inclusions in the space filling calcite, which indicate that the fluid flow event associated to the formation of the microcracks followed the precipitation of $\mathrm{Cal}_{\mathrm{SF}}$. Assuming that the seismic activity was a recurrent phenomenon, the ataxial vein $\left(\mathrm{Cal}_{\mathrm{AT}}\right)$ displaying crack-seal texture in the amphibolite can be identified with the microcrack calcite. However this possibility needs further examination.

7) $\mathrm{Cal}_{\mathrm{ANT}}, \mathrm{Cal}_{\mathrm{EB}} 2, \mathrm{Cal}_{\mathrm{BL}}$ (antitaxial calcite, elongate blocky calcite, blocky calcite): based on cross-cutting relations, the partially limonite stained syntaxial calcite was precipitated from the youngest fluid generation, the crystals of which have blocky and elongate blocky textures. The veins filled with the limonite stained calcite still preserve remnant voids, what also 
suggest that it is the youngest vein generation. The syntaxial texture indicates fracture channelized flow of the parent fluid. However the gneissic mass is generally cross cut by the antitaxial counterparts of these syntaxial veins. These latter display crack-seal patterns, which are indicative of intermittency during formation. The parent fluids entrapped in the primary inclusions of the antitaxial veins have densities in a very wide range, which is interpreted to be representative of the fluid pressure's fluctuation during the crack-seal process. The very narrow range of fluid salinities in samples from different sites indicates that the fluid efficiently flushed the system, while the clustering of the isotope compositions indicates local fluid-rock systems. These features are satisfactorily explained by a model of seismically governed vein development. The isotope compositions of the antitaxial and syntaxial veins indicate different types of fluid-rock interactions and possibly represent flow along stress induced microcrack systems and fracture channelized flow, respectively.

The involvement of seismic activity in the formation of the antitaxial veins of the study area call the attention to the relationship between stress and the efficiency of pervasion in a crystalline rock, possibly through the formation of stress induced microcracks. These relationships can be revealed in more detail by the application of the methods of rock mechanics, e.g. by measuring the stress conditions of crack initiation and crack closure in case of the Ófalu gneissic rocks, or the orientation of the foliation planes with respect to the stress axes that favours microcrack growth. Rock mechanic parameters of the rock types at the Ófalu study area, e.g. the tension strength of different gneissic rocks can aid the application of rock mechanic models, e.g. that of Sibson (1998).

Radiometric methods can possibly shed light on the depth and temperature of dyke emplacement, and these types of data could be applied together with rock mechanic models, to resolve the boundary conditions of the fluid flow events, and a more proper recognition of the system's hydraulic behaviour can be built up.

The more proper knowledge of the hydraulic behaviour in turn opens the way for further geochemical studies, e.g. trace element investigations to understand the mobilization of elements in a pervasive fluid flow. The relevance of the trace element system is accentuated by the studies of Nédli and Szabó (2007), who found that no primary relation of the vein carbonates to the volcanic dykes in the Mórágy Granite can be set forth. This is in conflict with our stable isotope data, which suggest the volcanic origin of the most prevalent carbonate phases. This inconsistency indicates that the fluid-rock interaction was very intricate with 
respect to the trace element system during the studied flow events, and that the vein minerals possibly provide valuable clues to the understanding of this process.

In summary the Ófalu study area is a very beneficial fluid-rock laboratory where the veins are the very spectacular products of the experiments. Several steps of resolving the experiments are successfully taken. The recognition of the experiment parameters is still an intriguing task, every step of which expectedly provides valuable information on fluid flow and water-rock interaction in a crystalline medium. 


\section{Összegzés}

Az Ófalui Metamorf komplexum paleohidrogeológiai rekonstrukciója során 75 darab, több ütemben begyüjtött minta makroszkópos vizsgálatát végeztem el. Ezekből a mintákból 77 darab csiszolat készült, ezek katódlumineszcens mikroszkópi felvételekkel kiegészített szöveti leírása szolgáltatott további információkat a kiválássorrend értelmezéséhez. Az így elkülönített kitöltés-típusokból hat tartalmazott szövetileg jól értelmezhető, mérésre alkalmas fluidumzárvány-együtteseket. A vizsgált érkitöltő karbonát-generációkból 40 darab stabilizotóp-összetétel mérés történt, továbbá 4 darab hidrogénizotóp-mérés a vizsgált fluidumzárványokban csapdázott folyadékokból. A mintákat, illetve a belőlük készült csiszolatokat és méréseket az S1 táblázat foglalja össze.

A vizsgálatok a Goldgrund-völgyi amfibolit testet átmetsző többgenerációs érrendszer vizsgálatával kezdődtek, ahol nyolc egymást követő érkitöltő ásványgeneráció kiválássorrendjét lehetett meghatározni. A kutatás következő fázisában a mintagyüjtés kiterjedt a metamorf képződményeket feltáró teljes területre. A begyüjtött minták mikroszkópos vizsgálata során egyértelmüvé vált, hogy a gneiszeket átmetsző ereket kitöltő ásványok megfeleltethetőek az amfibolitból leírt egyes érkitöltő ásványgenerációknak, ám a gneiszben azoktól eltérő szövettel jelennek meg. A stabilizotóp-összetétel mérések úgy lettek megtervezve, hogy a szöveti vizsgálatok alapján elkülönített áványgenerációkat az adatok külön-külön jól jellemezzék. A kimért stabilizotóp-összetételi csoportok jól kirajzolják a szövetileg is elkülönülő csoportokat. A mikrotermometriai mérések a megfelelő frakcionációs-egyenletek alkalmazásával lehetővé tették a különböző szövetű kiválások szülőoldatainak eredetének lehatárolását, egyes esetekben bizonyságot is szolgáltattak a rokonságra nézvést. Az izotóp-összetételek trendjei és alcsoportjai bizonyos esetekben a szülőoldat áramlási mechanizmusába is betekintést engedtek, a kőzet-víz rendszer hidraulikai viselkedés-modelljének megértését téve lehetővé. A kialakított hidraulikai viselkedésmodellek magukban foglalják az érkitöltő generációk szövete alapján a kőzet-víz rendszer müködésére vonatkozóan levonható következtetéseket is. Az eredmények illetve azok értelmezése a nemzetközi szakirodalom adott szövetet tárgyaló fejezeteivel összevetve lettek kialakítva. Az így megismert paleofluidum-evolúció szakaszait a kutatási terület tágabb környezetében végzett paleofluidum-vizsgálatok eredményeivel is összevetettem. A kitekintés egyrést segítette egyes fluidumáramlási események regionális jelentőségének megértését, másrészt a hidaulikai viselkedés-modellek alakulását is befolyásolta. 
Már a korai szöveti vizsgálatok rámutattak, hogy a területen előforduló érszövetek némelyik típusát, kialakulásának egyes mozzanatait a nemzetközi szakirodalom részletesen diszkutálja, ilyenek például a szintaxiális és az antitaxiális növekedési morfológiájú erek. Más estekben a szakirodalomban nem találtunk analógiát, vagy értelmezést. Utóbbiakra példa a térkitöltő kalcit $\left(\mathrm{Cal}_{\mathrm{SF}}\right)$, vagy a kőzeteket átjáró kalcittal kitöltött mikro-repedések rendszere. A következő szakaszban a leírt érkitöltő ásvány-generációk rövid áttekintő bemutatására kerül sor, az egyes fluidumáramlási eseményekkel kapcsolatos legfontosabb megállapításokat is beleértve. Az összefoglalás áttekinthetőségét az S2 táblázat segíti.

1) $\mathrm{Cal}_{\mathrm{EB}} 1$ - megnyúlt tömbös (elongate blocky) kalcit: a legkorábban kivált érkitöltő ásványgeneráció, megnyúlt tömbös szövetü, szintaxiális növekedési morfológiát mutató kalcit kristályokból épül fel (S2 tábla). A szülőoldat advektíven áramolt a helyenként $2 \mathrm{~cm}$-es átmérőt is elérő repedésrendszerben. Az érrendszer bezáródott a teljes kitöltődés előtt, így maradék pórusterek alakultak ki ar érrendszerben. A kalcit stabilizotóp-összetétele alapján tengeri karbonátokkal mutat rokonságot. Figyelembe véve, hogy a tágabb környezetben a karbonátos üledékképződés kezdetete a triász időszak, így a vizsgált érrendszer fejlődése sem indulhatott korábban.

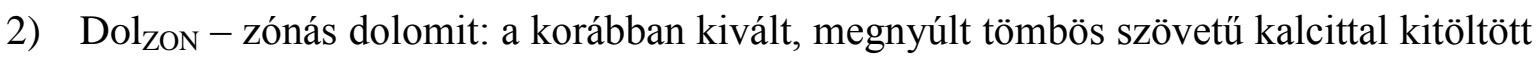
érrendszer maradvány-tereiben vált $\mathrm{ki}$, ahol a $\mathrm{Cal}_{\mathrm{EB}} 1$ kristályainak szintaxiális továbbnövekedéseként jelenik meg. Az ásványgeneráció szülőoldata nagy valószínűséggel a kőzettesten keresztül szivárgó oldat lehetett. A szivárgás lokális jelentőségére utalnak a katódlumineszcens felvételeken a $\mathrm{Cal}_{\mathrm{EB}} 1$ kristályokon belül megjelenő metaszomatizált zónák. A katódlumineszcens felvételek a zónás dolomiton belüli oszcilláló alzónára is felhívják a figyelmet, ami zárt renszerben történő bepárlódásként is értelmezhető. A dolomitban csapdázott elsődleges zárványok homogenizációs hőmérsékletei alapján a kiválás hőmérsékletének minimuma $95^{\circ} \mathrm{C}$.

3) Qtz $_{\mathrm{BL}}$ - tömbös (blocky) kvarc: a szemcsék tömbös szövetüek, növekedési morfológiájuk szintaxiális, ami szintén advektív, repedések menti oldatáramlást jelez. A kvarc szemcsék egyfázisú vizes oldatokat tartalmaznak, ami alacsony, $50{ }^{\circ} \mathrm{C}$ alatti kiválást jelez, és a szülőoldat meteorikus eredetét is felveti.

4) $\mathrm{Cal}_{\mathrm{SF}}$ - térkitöltő (space filling) kalcit. Az érrendszer maradványtereinek kitöltődése a tömeges térkitöltő kalcit kiválásával vált teljessé. Ebben a kalcitban a kőzetben két később megjelenő fluidum is csapdázódott másodlagos zárványsorok formájában, ám elsődleges 
zárványokat nem tartalmaz, így a szülőoldat hőmérsékletére, összetételére vonatkozóan nem állnak rendelkezésre információk. Felmerül, hogy a szülőoldat a $\mathrm{Cal}_{\mathrm{EB}} 1$ és a Dol ${ }_{\mathrm{ZON}}$ kristályok szemcsehatárain szivárgó, a kristályokat a szemcsehatárok mentén metaszomatizáló oldat lehetett, ami a katódlumineszcens felvételeken válik láthatóvá.

5) $\mathrm{Cal}_{\text {MASS }}$ - tömeges (massive) kalcit. A tömeges jelző az érkitöltő fázis makroszkópos megjelenését írja le, a vörös színü kiválás szubmikroszkópikus méretü hematit rostok gömbszerü halmazait tartalmazza nagy tömegben. A vörös kalcit a $\mathrm{Cal}_{\mathrm{EB}} 1$ kalcit leszakított szemcsesorait tartalmazza, ami alapján a korábbi érrendszer erőteljes újranyílását feltételezhetjük. Analógiák alapján, a pontos genetika meghatározása nélkül a kiválás a mecseki kréta vulkanizmussal hozható kapcsolatba. Az amfibolt átmetsző korábbi érrendszer helyenként megfigyelhető elszineződése és szétesése az esemény során megjelenő fluidum hatásával magyarázható.

6) $\mathrm{Cal}_{\mathrm{MC}}, \mathrm{Cal}_{\mathrm{AT}}-$ mikrorepedést kitöltő (microcrack) kalcit és ataxiális kalcit. A mikroszkópi (különösen a katódlumineszcens mikroszkópi) vizsgálatok a Mecsekalja Zóna kőzeteit átmetsző kalcittal kitöltött mikroér-rendszerek létére hívták fel a figyelmet. Hasonló jelenséget írtak le a Mórágyi Gránit Formáció kőzeteiben. A mikrorepedéseket kitöltő kalcitok stabilizotóp-összetételei egy lineáris trendet rajzolnak ki, ami a kelet-mecseki szubvulkáni képződmények ocellumainak összetételi tartományából indul ki, így a fluidum magmás eredetét bizonyítja. A trend ugyanakkor a tengeri karbonátok összetételi tartományába mutat, ami értelmezhető izotópcsere folyamatok eredményeként vagy tengervízzel történt keveredésként. Az előbbi magyarázat jelentős mértékű szén-dioxid eltávozást is feltételez, míg az utóbbi a tengervíz beszivárgását a kőzet mikrorepedéseibe. Mindkét lehetőség jól magyarázható a fluidumáramlással egyidejü földrengéses tevékenységgel és a kőzetek szeizmikus igénybevételével az Ófalu vonal mentén annak müködése során. A mikrorepedéseket kitöltő kalcit szülőoldata azonosítható a térkitöltő kalcitban $\left(\mathrm{Cal}_{\mathrm{SF}}\right)$ megjelenő másodlagos fluidumokkal, ami alapján a fluidumáramlás a térkitöltő kalcit kiválását követte. Az amfibolit testet átmetsző crack-seal szövetü, ataxiális növekedési morfológiát mutató ér szintén szakaszos müködést jelez, ami a szeizmikus ciklusok szerepét jelezheti a fluidumáramlásban. Az ataxiális és a mikrorepedést kitöltő kalcit azonosságát további vizsgálatokkal kell igazolni.

7) $\mathrm{Cal}_{\mathrm{ANT}}, \mathrm{Cal}_{\mathrm{EB}} 2, \mathrm{Cal}_{\mathrm{BL}}$ - antitaxiális, megnyúlt tömbös és tömbös kalcit. Mind a szintaxiális szövetü megnyúlt tömbös kalcit, mind az antitaxiális kalcit részben limonitfoltos. Átmetsző szöveti helyzetek alapján egyértelműen a legfiatalabb kiválás, amit az is alátámaszt, 
hogy helyenként kitöltetlen maradványtereket tartalmaz. A szintaxiális szövet repedések menti advektív áramlást jelez. Ugyanakkor a kalcitgeneráció a gneiszben antitaxiális szövettel jelenik meg, crack-seal (többször ismétlődő felnyílást és bezáródást jelző) szövettel. Az antitaxiális erekben csapdázott fluidumok nagyon széles sürüség-tartományt képviselnek, ami a fluidumnyomás érképződés során fennálló fluktuációjaként értelmezhető. Az eltérő mintavételi helyekről származó mintákra egységesen jellemző nagyon szük szalinitási tartomány azt jelzi, hogy a fluidum hatékonyan „mosta át” a kőzetvázat, míg a stabilizotópösszetételek csoportokat alkotnak a mintavétel helye szerint, azaz lokális kőzet-víz rendszereket jeleznek. Ezek a tulajdonságok jól magyarázhatóak, ha az érképződést szeizmikus ciklusok által irányított folyamatként értelmezzük. Az antitaxiális és a szintaxiális erek stabilizotóp-összetételei szintén eltérőek, ami eltérő mértékü kőzet-víz kölcsönhatást tükröz és részben repedések mentén történő advektív áramlást, részben a szeizmicitást kiváltó feszültségtér által felnyitott mikrorepedésekben zajló szivárgást jelez.

A szeizmikus tevékenység és az érképződés között feltételezett kapcsolat összecseng a feszültségterek kristályos kőzetekben kialakuló hatékony fluidumáramlásokban betöltött aktív szerepével. A modell szerint a feszültségterek által indukált mikrorepedések hatékonyan segítették a fluidumok szivárgását, így a kőzetmechanika eszköztárával a folyamat jobban megérthető. Ilyen lehetőség a mikrorepedések terjedését kiváltó, az ófalui gneiszekre jellemző feszültségek kimérése (crack initiation stress), vagy ennek alakulása a feszültségtengelyek és a foliáció által bezárt szögek függvényében. Egyéb kőzetmechanikai paraméterek - mint például a különböző kőzetekre jellemző húzószilárdság - segítségével a fluidumnyomás kőzetrepesztésben játszott szerepét vizsgáló modellek (pl. Sibson, 1998) is alkalmazhatóvá válnak a folyamat vizsgálatában.

Fontos, az érképződés részletesebb megértéséhez vezető továbblépési lehetőség a kőzetek radiometrikus korolása, ami a telérbenyomulás korára, szerencsés esetben pedig a kőzetek kéregbeli mélységére, vagy a telérek felfütési hatótávolságára vonatkozóan is értékes adatokkal gyarapíthatná az ismereteinket. Az így kapott paraméterek további hasznos információkat szolgálhatnak a hidraulikai folyamatok modellezéséhez.

További lehetséges kutatási irány a nyomelem-geokémiai paraméterek alakulásának vizsgálata az érképződési folyamat során az antitaxiális erek alapján. Ennek jelentőségét hangsúlyozza, hogy Nédli és Szabó (2007) nyomelem-geokémiai vizsgálaik eredményeképpen arra a következtetésre jutottak, miszerint a karbonátos kitöltések 
közvetlenül nem vezethetőek le a vulkáni folyamatokból. Ez a megállapítás ellentmond a disszertációban bemutatott stabilizotóp-geokémiai eredményeknek, és bonyolult nyomelemgeokémiai folyamatokat sejtet a kőzet-víz kölcsönhatás során.

Mindent összevetve az Ófalui Komplexum egy nagyon értékes kőzet-víz kölcsönhatás laboratórium, amiben az elkülönülő érkitöltő ásványgenerációk az egyes kísérletek termékei. A disszertációban bemutatot eredmények a kísérletek megértésének első sikeres lépései. A kísérleti paraméterek feltárására irányuló minden további lépés értékes adalékokkal gyarapíthatja a kristályos kőzetekben zajló fluidumáramlásokkal kapcsolatos ismereteinket. 


\section{Acknowledgements}

First of all I have to say thank for my parents for their support in every way. I have to say thank for my supervisors, Tivadar M. Tóth and Félix Schubert for being at service when I was in need of discussion and for their support in every way. I have to say thank for my colleagues at the Institute for Geological and Geochemical Research, Research Centre for Astronomy and Earth Sciences, who helped me in different ways: Bernadett Bajnóczi for making the cathodoluminescence images and for stable isotope measurements, Zoltán Siklósy and György Czuppon for the stable isotope measurements. My sister and the Széll family are also acknowledged. And finally I have to say thank for all my colleagues at the Department of Mineralogy, Geochemistry and Petrology. 


\section{References}

Árkai, P., Nagy, G., 1994. Tectonic and magmatic effects on amphibole chemistry in mylonitized amphibolites and amphibole bearing enclaves associated with granitoid rocks. Acta Geologica Hungarica 37/3-4, 235-268.

Bakker, R.J., 2003. Package FLUIDS 1. Computer programs for analysis of fluid inclusion data and for modeling bulk fluid properties. Chemical Geology 194, 3-23.

Balla, Z., Császár, G., Gulácsi, Z., Gyalog L., Kaiser M., Király E., Koloszár L., Koroknai B, Magyari Á., Maros, Gy., Marsi, I., Molár, P., Rotárné Szalkai, Á., Tóth, G., 2009. Geology of the Northeastern Part of the Mórágy Block. Regional Map-series of Hungary, pp. 73-81. Geological Institute of Hungary, Budapest.

Barker, S.L.L., Cox, S.F., Eggins. S.M., Gagan, M.K., 2006. Microchemical evidence for episodic growth of antitaxial veins during fracture-controlled fluid flow. Earth and Planetary Science Letters $250,331-44$.

Barker S.L.L., Bennett, V.C., Cox, S.F., Norman, M.D., Gagan, M.K., 2009. Sm-Nd, Sr, C and O isotope systematics in hydrothermal calcite-fluorite veins: implications for fluid-rock reaction and geochronology. Chemical Geology 268, 58-66.

Best, M.G., 2003. Igneous and Metamorphic Petrology, 2nd edn. Blackwell Publishing.

Blyth, A., Frape, S., Blomqvist, R., Nissinen, P., 2000. Assessing the past thermal and chemical history of fluids in crystalline rock by combining fluid inclusion and isotopic investigations of fracture calcite. Applied Geochemistry 15, 1417-1437.

Blyth, A., Frape, S., Ruskeeniemi, T., Blomquist, R., 2004. Origins, closed system formation and preservation of calcites in glaciated crystalline bedrock: evidence from the Palmottu natural analogue site, Finland. Applied Geochemistry 19, 675-686.

Bodnar, R.J., 1992. Revised equation and table for freezing point depressions of $\mathrm{H}_{2} \mathrm{O}$-salt fluid inclusions. PACROFI IV, Fourth Biennial Pan-American Conference on Research on Fluid Inclusions, Lake Arrowhead, Abstract, pp. 108-111.

Bons, P.D., 2000. The formation of veins and their micostructures. In: Jessel, M.W., Urai, J.L. (Eds.), Stress, Strain and Structure: a volume in honour of Win D. Means. Journal of Virtual Explorer 2. 
Bons, P.D., 2001. Developement of crystal morphology during unitaxial growth in a progressively widening vein: I. The numerical model. Journal of Structural Geology 23, 865-872.

Bons, P.D., Montenari, M., 2005. The formation of antitaxial calcite veins with well developed fibres, Oppaminda Creek, South Australia. Journal of Structural Geology 27, 231-248.

Bottomley. J.D., Veizer, J., 1992. The nature of groundwater flow in fractured rock: evidence from the chemical and isotopic evolution of recrystallized fracture calcites from the Canadian Precambrian Shield. Geochimica et Cosmochimica Acta 56, 369-388.

Cai, M., 2009. Practical estimates of tensile strength and Hoek-Brown strength parameter mi of brittle rock. Rock Mechanics and Rock Engineering 43 (2), 167-184.

Cox, S.F., 2007. Structural and isotopic constraints on fluid flow regimes and fluid pathways during upper crustal deformation: an example from the Taemas area of the Lachlan Orogen, SE Australia. Journal of Geophysical Research 112, B08208, doi: 10.1029/2006JB004734.

Császár, G., 2003. Alpine burial history of the Mórágy Block and its environs. In: Balla, Z. (Ed.), Annual report of the Geological Institute of Hungary, 2003, pp. 395-406.

Császár, G., Görög. Á., Gyuricza, Gy., Sieglné Farkas, Á., Szente, I., Szinger, B., 2007. The geological, paleontological and sedimentological pattern of the Vasas Marl Formation between Zsibrik and Ófalu, South Transdanubia. Bulletin of the Hungarian Geological Society 137, 193 227.

Dabi, G., M. Tóth, T., Schubert, F., 2006. Analysis of oscillatory zoning in syntectonic calcite crystals evaluating UV-spectra. X. Congress of Hungarian Geomathematics, Mórahalom.

Dabi, G., M. Tóth, T., Schubert, F., 2009a. Carbonate veins of different texture and their role in reconstructing fracture cementation (Ófalu, Goldgrund valley). Bulletin of the Hungarian Geological Society 139, 3-20.

Dabi, G., Schubert, F., M. Tóth, T., 2009b. Application of fluid inclusions in antitaxial veins as a gauge of fluid pressure fluctuation during vein growth. ECROFI XX. Abstract series, pp. 59-60.

Dabi, G., Siklósy, Z., Schubert, F., Bajnóczi, B., M. Tóth, T., 2011. The relevance of vein texture in understanding the past hydraulic behaviour of a crystalline rock mass: reconstruction of the palaeohydrology of the Mecsekalja Zone, South Hungary. Geofluids 11, 309-327. 
Demény, A., Harangi, Sz., 1996. Stable isotope studies and processes of carbonate formation in Hungarian alkali basalts and lamprophyres: evolution of magmatic fluids and magma-sediment interactions. Lithos 37, 335-349.

Demény, A., Siklósy, Z., 2008. Combination of off-line preparation and continuous flow mass spectrometry: D/H analyses of inclusion waters. Rapid Communications in Mass Spectrometry 22, $1329-1334$

Diamond, L.W., 2001. Review of the systematics of $\mathrm{CO}_{2}-\mathrm{H}_{2} \mathrm{O}$ fluid inclusions. Lithos 55, 69-99.

Etheridge, M.A., Wall, V.J., Cox, S.F., Vernon, R.H., 1984. High fluid pressures during regional metamorphism and deformation: implications for mass transport and deformation mechanisms. Journal of Geophysical Research 89, 4344-4358.

Fisher, D.M., Brantley, S.M., 1992. Models of quartz overgrowth and vein formation: deformation in an ancient subduction zone. Journal of Geophysical Research, 97. 20043-20061.

Fourcade, S., Michelot, J.L., Buschaert, S., Cathelineau, M., Freiberger, R., Coulibaly, Y., Aranyossy, J.F., 2002. Fluid transfers at the basement / cover interface: Part I. Subsurface recycling of trace carbonate from granitoid basement rocks (France). Chemical Geology 192, 99-119.

Friedman, I., O'Neil, J.R., 1977. Compilation of stable isotope fractionation factors of geochemical interest. In: Data of Geochemistry, 6th edn. (Ed. Fleischer M), Chapter KK. USGS Professional Papers 440-KK.

Fülöp, J., 1994. Geology of Hungary, Paleozoic II (in Hungarian), pp. 297-306. Akadémiai Kiadó, Budapest. pp. 297-305.

Gatter, I., Török, K., 2004. Mineralogical notes and fluid inclusion studies on quartz-feldspar granite pegmatites and quartz veins from Mórágy and Erdősmecske granitoid, S-Hungary. Acta Mineralogica Petrographica Szeged 45, 39-48.

Ghoneim, M.F., Szederkényi, T., 1977. Preliminary petrological and geochemical studies of the area Ófalu, Mecsek Mountains, Hungary. Acta Mineralogica Petrographica Szeged 23, 15-28.

Goldstein, R.H., Reynolds, T.,J., 1994. Systematics of Fluid Inclusions in Diagenetic Minerals. SEPM Short Course, vol. 31. Society of Economic Paleontologists and Mineralogists, Tulsa. 
Gottschalk, R.R., Kronenberg, A.K., Russel, J.E., Handin, J., 1990. Mechanical anisotropy of gneiss: failure criterion and textural sources of directional behaviour. Journal of Geophysical Research 95, $21613-21634$.

Haas, J., Péró, Cs., 2004. Mesozoic evolution of the Tisza Mega-unit. International Journal of Earth Sciences (Geologische Rundschau) 93, 297-313.

Haas, J., Budai, T., Csontos, L., Fodor, L., Konrád, Gy., 2010. Pre-Cenozoic geological map of Hungary, 1:500 000. Geological Institute of Hungary.

Harangi, Sz., 1994. Geochemistry and petrogenesis of the Early Cretaceous continental rift-type volcanic rocks of the Mecsek Mountains, South Hungary. Lithos 33, 303-321.

Harangi, Sz., Árváné Sós, E., 1993. Early Cretaceous volcanic rocks of the Mecsek Mountains (South Hungary) I. Mineralogy and petrology. Bulletin of the Hungarian Geological Society 123, 129 165.

Hedenquist, J.W., Henley, R.W., 1985. The importance of $\mathrm{CO}_{2}$ on freezing point measurements of fluid inclusions: evidence from active geothermal systems and implications for epithermal ore deposition. Economic Geology 80, 1379-1406.

Hiramatsu, Y., Honma, H., Saiga, A., Furumoto, M., Ooida, T., 2005. Seismological evidence on characteristic time of crack healing in the shallow crust. Geophysical Research Letters 32 (9), 4.

Hilgers, C., Sindern, S., 2005. Textural and isotopic evidence on the fluid source and transport mechanism of antitaxial fibrous microstructures from the Alps and the Appalachians. Geofluids 5, $239-250$.

Hilgers, C., Urai, J.L., 2002a. Microstructural observations on natural syntectonic fibrous veins: implications for the growth process. Tectonophysics 352, 257-274.

Hilgers, C., Urai, J.L., 2002b. Experimental study of syntaxial vein growth during lateral fluid flow in transmitted light: first results. Journal of Structural Geology 24, 1029-1043.

Hilgers, C., Dilg-Gruschinski, K., Urai, J.L., 2003. Microstructures grown experimentally from advective supersaturated solution and their implication for natural vein systems. Journal of Geochemical Exploration 78-79, 221-225. 
Hilgers, C., Urai, J.L., 2005. On the arrangement of solid inclusions in fibrous veins and the role of the crack-seal mechanism. Journal of Structural Geology 27, 481-494.

Hilgers, C., Koehn, D., Bons, P.D., Urai, J.L., 2001. Development of crystal morphology during unitaxial growth in a progressively widening vein: II. Numerical simulations of the evolution of antitaxial fibrous veins. Journal of Structural Geology 23, 873-885.

Jáger, V., Molnár, F., Buchs, D., Koděra, P., 2012. The connection between iron ore formations and „mud-shrimp" colonizations around sunken wood debris and hydrothermal sediments in a Lower Cretaceous continental rift basin, Mecsek Mts. Hungary. Earth-Science Reviews 114, 250-278.

Jantsky, B. 1979. A mecseki gránitosodott alaphegység földtana. Földtani Intézet Évkönyve, 60, 385 p. (In Hungarian).

Johnson, J.P, Hutnak, R.P., Dziak, C.G., Fox, I., Urcuyo, J.P., Cowen, J.P., Nabelek, J., Fisher, C., 2000. Earthquake induced changes in a hydrothermal system on the Juan de Fuca mid-ocean ridge. Nature 407, 174-177.

Juhász, A., M. Tóth, T., Ramseyer, K., Matter, A., 2002. Connected fluid evolution in fractured crystalline basement and overlying sediments, Pannonian Basin, SE Hungary. Chemical Geology $182,91-120$.

Kandori, K., Sakai, J., Ishikawa, T., 2000. Definitive effects of chloride ions on the formation of spherical hematite particles in a forced hydrolysis reaction. Physical Chemistry Chemical Physics 2, 3293-3299.

Kandori, K., Yamamoto, N., Yasukawa, A., Ishikawa, T., 2002. Preparation and characterization of disk-shaped hematite particles by a forced hydrolysis reaction in the presence of polyvinyl alcohol. Physical Chemistry Chemical Physics 4, 6116-6122.

Király, E., Koroknai, B., 2003. The magmatic and metamorphic evolution of the north-eastern part of the Mórágy Block. In: Balla, Z. (Ed.), Annual report of the Geological Institute of Hungary, 2003, pp. 299-318.

Király, E., Török, K., 2003. Magmatic garnet in deformed applite dykes from the Mórágy granitoid, SE-Transdanubia, Hungary. Acta Geologica Hungarica 46/3, 239-254.

Kovács, S., Szederkényi, T., Haas, J., Buda, Gy., Császár. G., Nagymarosy, A., 2000. Tectonostratigraphic terranes in the Hungarian part of the Pannonian area. Acta Geologica Hungarica 43, 225-328 
Kovács-Pálffy, P., Földváry, M., Baráth Istvánné, 2003. Hydrothermal minerals and phenomena in the Mórágy Granite Formation. In: Balla, Z. (Ed.), Annual Report of the Geological Institute of Hungary, 2003, pp. 319-326.

Lajtai, E.Z., 1998. Microscopic failure processes in granite. Rock Mechanics and Rock Engineering 31 (4), 237-250.

Lassey, K.R., Blattner, P., 1988. Kinetically controlled oxygen isotope exchange between fluid and rock in one-dimensional advective flow. Geochimica et Cosmochimica Acta 52, 2169-2175.

Laubach, S.E., Reed, R.M., Olson, J.E., Landera, R.H., Bonella, L.M., 2004. Coevolution of crackseal texture and fracture porosity in sedimentary rocks: cathodoluminescence observations of regional fractures. Journal of Structural Geology 26, 967-982.

Lee Y-J., Morse J.W., 1999. Calcite precipitation in synthetic veins: implications for the time and fluid volume necessary for vein filling. Chemical Geology 156, 151-170.

Lee Y-J., Morse J.W., Wiltsko, D.V., 1996. An experimentally verified model for calcite precipitation in veins. Chemical Geology 130, 203-215.

Lelkes-Felvári, Gy., Árkai, P., Frank, W., Nagy, G., 2000. Late Variscan ultramylonite from the Mórágy Hills, SE Mecsek Mts., Hungary. Acta Geologica Hungarica 43, 65-84.

Lespinasse, M., 1999. Are fluid inclusion planes useful in structural geology? Journal of Structural Geology 21, 1237-1243.

Li, Y.-g., Chen, P., Cochran, E.S., Vidale, J.E., Burdette, T., 2006. Seismic evidence of rock damage and healing on the San Andreas Fault associated with the 2004 M 6.0 Parkfield earthquake. Bulletin of the Seismological Society of America 96, 349-363.

Lilley, M.D., Butterfield, D.A., Lupton, J.E., Olson, E.J., 2003. Magmatic events can produce rapid changes in hydrothermal vent chemistry. Nature 422, 878-881.

Lin, A., Tanaka, N., Uda, S., Satish-Kumar, M., 2003. Repeated coseismic infiltration of meteoric and seawater into deep fault zones: a case study of the Nojima fault zone, Japan. Chemical Geology 202, 139-153. 
Lockner, D.A., 1995. Rock failure. In: Ahrens, T.J. (Ed.), Rock Physics and phase relations: a handbook of physical constants, AGU reference shelf 3, pp. 127-147.

Maros, Gy., Koroknai, B., Palotás, K., Fodor, L., Dudko, A., Forián-Szabó, M., Zilahi-Sebess, L., Bán-Györi, E., Tectonic analysis and structural evolution of the north-eastern Mórágy-Block. In: Balla, Z. (Ed.), Annual report of the Geological Institute of Hungary, 2003, pp. 371-394.

Machel, H.G., Mason, R.A., Mariano, A.N., Mucci, A.N., 1991. Causes and emission of luminescence in calcite and dolomite. In: Barker, C.E., Kopp, O.C. (Eds.), Luminescence Microscopy and Spectroscopy - Qualitative and quantitative applications. SEPM (Society for Sedimentary Geology) Short Course 25, 9-29.

Machel, H.G., Burton, E., 1991. Factors governing cathodoluminescence in calcite and dolomite, and their implications for studies of carbonate diagenesis. In: Barker, C.E., Kopp, O.C. (Eds.), Luminescence Microscopy and Spectroscopy. Qualitative and quantitative applications. SEPM (Society for Sedimentary Geology) Short Course 25, 37-57.

Machel, H.G., 2000. Application of Cathodluminescence to Carbonate Diagenesis. In: Pagel, M., Barmin, V., Blanc, P., Ohnestetter, ?. (Ed.), Cathodoluminescence in Geosciences, SpringerVerlag, New York 225-243.

Milliken, K.L., Laubach, S.E., 2000. Brittle deformation in sandstone diagenesis as revealed by scanned cathodoluminescence imaging with application to characterization of fractured reservoirs. In: Pagel, M., Barmin, V., Blanc, P., Ohnestetter, ?. (Ed.), Cathodoluminescence in Geosciences, Springer-Verlag, New York 225-243.

Morris, R.V., Ming, D.W., Graff, T.G., Arvidson, R.E., Bell, J.F. III, Squyres, S.W., Mertzman, S.A., Gruener, J.E., Golden, D.C., Le L., Robinson, G.A., 2005. Hematite spherules in basaltic tephra altered under aqueous, acid-sulfate conditions on Mauna Kea volcano, Hawaii: possible clues for the occurrence of hematite rich spherules in the Burns formation at Meridiani Planum, Mars. Earth and Planetary Science Letters 240, 168-178.

Morse, J.W., Mackenzie, F.T., 1993. Geochemical constraints on CaCO3 transport in subsurface sedimentary environments. Chemical Geology 105, 181-196.

M. Tóth, T., Szücs, É., Schubert, F., Hollós, Cs., 2004. Conceptual fracture network model of the crystalline basement of the Szeghalom Dome (Pannonian Basin, SE Hungary). Acta Geologica Hungarica 47/1, 19-34. 
M. Tóth, T., Kovács, G., Schubert, F., Dályai, V., 2005. Origin and deformation history of the Ófalu migmatite. Bulletin of the Hungarian Geological Society 135, 331-352.

Nédli, Zs., Szabó, Cs., 2007. Study of possible geochemical relationships between various minerals of the fissure fillings at Üveghuta. Study of magmatic relationships between samples of volcanic rocks. Manuscript, Geological Institute of Hungary, Budapest, Tekt. 1375, in Hungarian.

Nédli, Zs., M. Tóth, T., Downes, H., Császár, G., Beard, A., Szabó, Cs., 2010. Petrology and geochemical interpretation of mantle xenoliths from Late Cretaceous lamprophyres, Villány Mts (S Hungary). Tectonophysics 489, 43-54.

Némedi Varga, Z., 1998. Stratigraphy of the Jurassic formations of the Mecsek and the Villány units. In: Bérczy, I. (Ed.), Stratigraphy of the Hungarian geological formations, Geological Institute of Hungary, MOL Hungarian Oil and Gas Company, Budapest, pp. 319-336. In Hungarian.

Nollet, S., Urai, J.L., Bons, P.D., Hilgers, C., 2005. Numerical simulation of polycrystal growth in veins. Journal of Structural Geology 27, 217-230.

Northrop, D.A., Clayton, R.N., 1966. Oxygen-isotope fractionations in systems containing dolomite. The Journal of Geology 74, 174-196.

Oliver, N.H.S., Bons, P.D., 2001. Mechanisms of fluid flow and fluid-rock interaction in fossil metamorphic hydrotermal systems inferred from vein-wallrock patterns, geometry and microstucture. Geofluids 1, 137-162.

O'Neil J.R., Clayton, N.R., Mayeda, T.K., 1969. Oxygen isotopic fractionation in divalent metal carbonates. The Journal of Chemical Physics 51, 5547-58.

Passchier, C.W., Trouw, R.A.J., 2005. Microtectonics. Springer, Berlin.

Parry, W.T., 1998. Fault-fluid compositions from fluid-inclusion observations and solubilities of fracture-sealing minerals. Tectonophysics 290, 1-26.

Paterson, M.S., Wong, T.-f., 2005. Experimental rock deformation - the brittle field. Springer-Verlag, Berlin Heidelberg, pp. 155-161.

Poros, Zs., Molnár, F., Koroknai, B., Lespinasse, M., Maros, Gy., Benkó, Zs., 2008. Application of studies on fluid inclusion planes and fracture systems in the reconstruction of the fracturing history 
of granitoid rocks III: results of studies in drillcores from the radioactive waste depository site at Bátaapáti (Üveghuta). Bulletin of the Hungarian Geological Society 138/4, 361-382.

Poros, Zs., 2007. The palaeofluid reconstruction of the Mórágy Granite, and analysis of its fracture systems in boreholes. MSc thesis, Eötvös Loránd University, Budapest (in Hungarian).

Prokoph, A., Shields, G.A., Veizer, J., 2008. Compilation and timeseries analysis of a marine carbonate $\delta^{18} \mathrm{O}, \delta^{13} \mathrm{C},{ }^{87} \mathrm{Sr}^{86} \mathrm{Sr}$ and $\delta^{34} \mathrm{~S}$ database through Earth history. Earth-Science Reviews 87, $113-133$.

Ramsay, J.G., 1980. The crack-seal mechanism of rock deformation. Nature 284, 135-139.

Raucsik, B., 1997. Stable isotopic composition of the Komló Calcareous Marl Formation ("'Spotted Marl' s. str.), Mecsek Mountains, S Hungary. Acta Mineralogica-Petrographica Szeged, 38, 95109.

Rawling, G.C., Baud, P., Wong, T.-f., 2002. Dilatancy, brittle strength, and anisotropy of foliated rocks: Experimental deformation and micromechanical modeling. Journal of Geophysical Research 107, NO. B10, 2234, doi:10.1029/2001JB000422.

Rye, D.M., Bradbury, H.J., 1988. Fluid flow in the crust: an example from a Pyrenean thrust ramp. American Journal of Science 288, 197-235.

Scholz, C.H., Sykes, L.R., Aggarwal, Y.P., 1973. Earthquake prediction: a physical basis. Science 181, 803-811.

Schubert, F., Diamond, L.W., M. Tóth, T., 2007. Fluid-inclusion evidence of petroleum migration through a buried metamorphic dome in the Pannonian Basin, Hungary. Chemical Geology 244, $357-381$.

Schubert, F., Kóthay, K., Dégi, J., M. Tóth, T., Bali, E., Szabó, Cs., Benkó, Zs., Zajacz, Z., 2007. Terms and symbols used in English and Hungarian fluid and melt inclusion literature. Bulletin of the Hungarian Geological Society 137, 83-102.

Shea, W.T., Kronenberg, A.K., 1993. Strength and anisotropy of foliated rocks with varied mica content. Journal Structural Geology 15, 1097-1121. 
Sheppard, S. 1986. Characterization and isotopic variations in natural waters. In: Valley, J.W., Taylor, Jr.P.H., O'Neil, J.R. (Eds.), Reviews in Mineralogy, Stable isotopes in high temperature geological processes, Mineralogy Society of America, pp. 165-184.

Sibson, R.H., 1998. Brittle failure mode plots for compressional and extensional tectonic regimes. Journal of Structural Geology 20, 655-660.

Sibson, R.H., Moore, J.McM., Rankin, A.H., 1975. Seismic pumping - a hydrothermal fluid transport mechanism. Journal of the Geological Society London 131, 653-659.

Seewald, J., Cruse, A., Saccocia, P., 2003. Aqueous volatiles in hydrothermal fluids from the main Endeavour Field, northern Juan de Fuca Ridge: temporal variability following earthquake activity. Earth and Planetary Science Letters 216, 575-590.

Špičák, A., Horálek, J., 2001. Possible role of fluids in the process of earthquake swarm generation in the West Bohemia/Vogtland seismoactive region. Tectonophysics 336, 151-161.

Sverjensky, D., 1981. Isotopic alteration of carbonate host rock as a function of water to rock ratio an example from the Upper Mississippi Valley zinc-lead deposit. Economic Geology 76, 154-157.

Szabó, B., Benkó, Zs., Molnár, F., 2008. The application of studies on fluid inclusion planes and fracture systems in the reconstruction of fracturing history of granitoid rocks II. Fracture systems of the Mórágy Granite. Bulletin of the Hungarian Geological Society 138, 193-227.

Szabó, Cs., Gálné Sólymos, K., Fall, A., 2003. Karbonátos repedéskitöltés vizsgálatok Üveghuta környékén mélyített fúrások granitoid kőzetein. Kutatási Jelentés. In Hungarian.

Szádeczky-Kardoss., E. 1959. A kárpáti közbenső tömeg magmás mechanizmusáról. Nemzetközi Geokémiai Konferencia, Budapest. In Hungarian.

Szederkényi, T., 1977. Geological evolution of South Transdanubia (Hungary) in Paleozoic time. Acta Mineralogica Petrographica Szeged 23/1, 3-14.

Szederkényi, T., 1983. Origin of amphibolites and metavolcanics of crystalline complexes of South Transdanubia, Hungary. Acta Geologica Hungarica 26/1-2, 103-136.

Taylor, B.E., 1987. Stable isotope geochemistry of ore forming fluids. In: Kyser, T.K. (Ed.), Short Course in Stable Isotope Geochemistry of Low Temperature Fluids, Vol. 13., Chap. 8, pp. 337418. Mineralogical Association of Canada, Saskatoon. 
Taylor, H.P., 1978. Oxygen and hydrogen isotope studies of plutonic granitic rocks. Earth and Planetary Science Letters 38, 177-210.

Templeton, A.S., Chamberlain, C.P., Koons, P.O., Craw, D., 1998. Stable isotopic evidence for mixing between metamorphic fluids and surface-derived waters during recent uplift of the Southern Alps, New Zealand. Earth and Planetary Science Letters 154, 73-92.

Townend, J., Zoback, M.D., 2000. How faulting keeps the crust strong. Geology 28, 399-402.

Tóth, F., 2012. Remnants of past percolation flow events entrapped in lateral secretion quartz lenses of the Ófalu Complex. MSc thesis, University of Szeged, Szeged (in Hungarian).

Török, Á., 1998. Stratigraphy of the Triassic formations of the Mecsek and the Villány units. In: Bérczy, I. (Ed.), Stratigraphy of the Hungarian Geological Formations, Geological Institute of Hungary, MOL Hungarian Oil and Gas Company, Budapest, pp. 253-279. In Hungarian.

Tsunogai, U., Wakita, H., 1995. Precursory chemical changes in ground water: Kobe earthquake, Japan. Science 269, 61-63.

Twiss, R.J., Moores, E.M., 1992. Structural Geology. Freeman, New York, pp. 165-185.

Uysal, I.T., Feng, Y.-x., Zhao, J.-x., Bolhar, R., Işik, V., Baublys, K.A., Yago, A., Golding, S.D., 2011. Seismic cycles recorded in late quaternary calcite veins: Geochronological, geochemical and microstructural evidence. Earth and Planetary Science Letters 303, 84-96.

Varga, A., Raucsik, B., Hámorné Vidó, M., Rostási, Á., 2007. Isotope geochemistry and characterization of hydrocarbon potential of black shale from Óbánya Siltstone Formation. Bulletin of the Hungarian Geological Society 137, 449-472.

Varga, A., Mikes, T., Raucsik, B., 2009. The petrography and heavy minerals of the Toarcian black shale of the Réka Valley section of the Mecsek Hills: a pilot study. Bulletin of the Hungarian Geological Society 139, 33-54.

Wallin, B., Peterman, Z., 1999. Calcite fracture fillings as indicators of palaeohydrology at Laxemar at the Äspö Hard Rock Laboratory, southern Sweden. Applied Geochemistry 14. 953-962.

Wang, Y., Merino, E., 1992. Dynamic model of oscillatory zoning of trace elements in calcite: double layer, inhibition, and self-organization. Geochimica Cosmochimica Acta 56, 587-596. 
Watson, B.E., 1996. Surface enrichment and trace element uptake during crystal growth. Geochimica et Cosmochimica Acta 60, 5013-5020.

Watson, B.E., 2004. A conceptual model for near-surface kinetic controls on the trace element and stable isotope composition of abiogenic calcite crystals. Geochimica et Cosmochimica Acta 68, 1473-1488.

Weise, S.M., Bräuer, K., Kämpf, H., Strauch, G., Koch, U., 2001. Transport of mantle volatiles through the crust traced by seismically released fluids: a natural experiment in the earthquake swarm area Vogtland/NW Bohemia, central Europe. Tectonophysics 336, 137-150.

Zoback, M.D., Byerlee, J.D., 1975a. The effect of microcrack dilatancy on the permeability of Westerly Granite. Journal of Geophysical Research 80, 752-755.

Zoback, M.D., Byerlee, J.D., 1975b. The effect of cyclic differential stress on dilatancy in Westerly Granite under uniaxial and triaxial conditions. Journal of Geophysical Research 80, 1526-1530.

Zoback, M.D., Townend, J., 2001. Implications of hydrostatic pore pressures and high crustal strength for the deformation of intraplate litosphere. Tectonophysics 336, 19-30.

Zoback, M.D., Harjes, H.-P., Injection-induced earthquakes and crustal stress at $9 \mathrm{~km}$ depth at the KTB deep drilling site, Germany. Journal of Geophysical Research 102, 18477-18491. 